NUREG/CR-6087

BNL-NUREG-52390

\title{
The Effects of Aging on BWR Core Isolation Cooling Systems
}

Manuscript Completed: July 1994

Date Published: October 1994

Prepared by

B. S. Lee

Contributors

A. Fresco, A. DiBiasio, R. Travis, E. Grove

S. K. Aggarwal, NRC Program Manager

Brookhaven National Laboratory

Upton, NY 11973

Prepared for

Division of Engineering

Office of Nuclear Regulatory Research

U.S. Nuclear Regulatory Commission

Washington, DC 20555-0001

NRC FIN A3270 



\section{DISCLAIMER}

This report was prepared as an account of work sponsored by an agency of the United States Government. Neither the United States Government nor any agency thereof, nor any of their employees, make any warranty, express or implied, or assumes any legal liability or responsibility for the accuracy, completeness, or usefulness of any information, apparatus, product, or process disclosed, or represents that its use would not infringe privately owned rights. Reference herein to any specific commercial product, process, or service by trade name, trademark, manufacturer, or otherwise does not necessarily constitute or imply its endorsement, recommendation, or favoring by the United States Government or any agency thereof. The views and opinions of authors expressed herein do not necessarily state or reflect those of the United States Government or any agency thereof. 


\section{DISCLAIMER}

Portions of this document may be illegible in electronic image products. Images are produced from the best available original document. 


\begin{abstract}
A study was performed to assess the effects of aging on the Reactor Core Isolation Cooling (RCIC) system in commercial Boiling Water Reactors (BWRs). This study is part of the Nuclear Plant Aging Research (NPAR) program sponsored by the U.S. Nuclear Regulatory Commission. The objectives of this program are to provide an understanding of the aging process and how it affects plant safety so that it can be properly managed. This is one of a number of studies performed under the NPAR program which provide a technical basis for the identification and evaluation of degradation caused by age.

The failure data from national databases, as well as plant specific data were reviewed and analyzed to understand the effects of aging on the RCIC system. This analysis identified important components that should receive the highest priority in terms of aging management. The aging characterization provided information on the effects of aging on component failure frequency, failure modes, and failures causes. Current inspection, surveillance, and monitoring practices were also reviewed.
\end{abstract}





\section{CONTENTS}

Page

ABSTRACT $\ldots \ldots \ldots \ldots \ldots \ldots \ldots \ldots \ldots \ldots \ldots \ldots \ldots \ldots \ldots \ldots \ldots \ldots \ldots$

EXECUTIVE SUMMARY $\ldots \ldots \ldots \ldots \ldots \ldots \ldots \ldots \ldots \ldots \ldots \ldots \ldots \ldots$

ACKNOWLEDGMENTS $\ldots \ldots \ldots \ldots \ldots \ldots \ldots \ldots \ldots \ldots \ldots \ldots \ldots \ldots \ldots \ldots \ldots$

ACRONYMS $\quad \ldots \ldots \ldots \ldots \ldots \ldots \ldots \ldots \ldots \ldots \ldots \ldots \ldots \ldots \ldots \ldots \ldots$

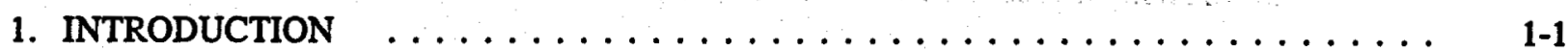

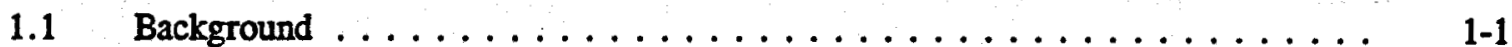

$1.2 \quad$ Objectives and Scope of this Study ...................... 1-1

1.3 System Definition ........................ 1-2

1.3.1 Description of RCIC System ................... 1-2

1.3.2 System Interfaces and Boundaries $\ldots \ldots \ldots \ldots \ldots \ldots \ldots \ldots \ldots . \ldots \ldots$

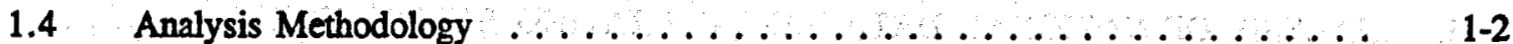

$1.5 \quad$ Report Organization . . . . . . . . . . . . . . . . . . . 1-4

2. RCIC SYSTEM DESIGN REVIEW $\ldots \ldots \ldots \ldots \ldots \ldots \ldots \ldots \ldots \ldots \ldots \ldots \ldots \ldots$

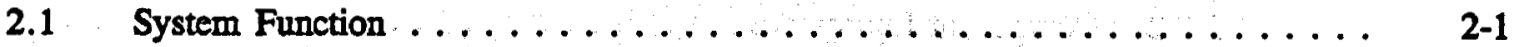

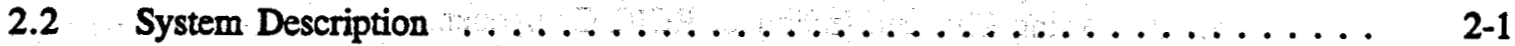

2.2.1 Main Train $\ldots \ldots \ldots \ldots \ldots \ldots \ldots \ldots \ldots \ldots \ldots \ldots \ldots \ldots \ldots . \ldots \ldots \ldots$

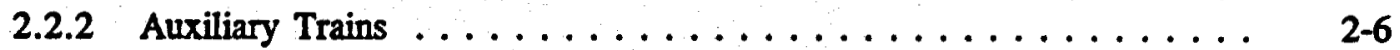

2.3 RCIC System Instrumentation, Control, and

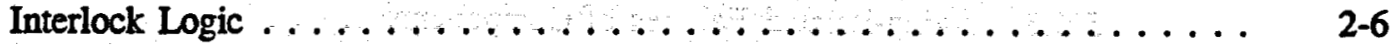

2.3.1 System Automatic Initiation $\ldots \ldots \ldots \ldots \ldots \ldots \ldots \ldots \ldots \ldots . \ldots \ldots$

2.3.2 RCIC System Isolation $\ldots \ldots \ldots \ldots \ldots \ldots \ldots \ldots \ldots \ldots \ldots . \ldots \ldots$

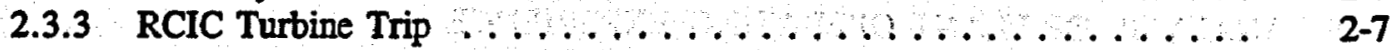

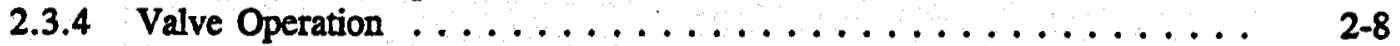

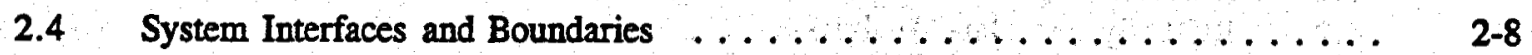

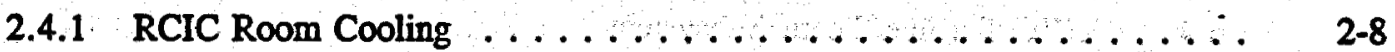

2.4.2 Main Steam System . . . . . . . . . . . . . . . . . 2-8

2.4.3 Condensate and Feedwater System . . . . . . . . . . . .

2.4.4 Primary Containment System ................ 2-8

2.4.5 Residual Heat Removal System . . . . . . .......... 2-8

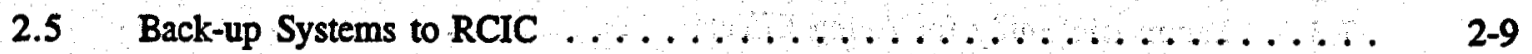




\section{CONTENTS (Cont'd)}

3. SAFETY SIGNIFICANCE OF THE RCIC SYSTEM $\ldots \ldots \ldots \ldots \ldots \ldots \ldots \ldots$

3.1 Review of Probabilistic Risk Assessment Information . . . . . . . . . 3-1

3.2 Review of Bulletins, Generic Letters, and

Information Notices . . . . . . . . . . . . . . . . 3-1

4. OPERATIONAL AND ENVIRONMENTAL STRESSES $\ldots \ldots \ldots \ldots \ldots \ldots$ 4-1

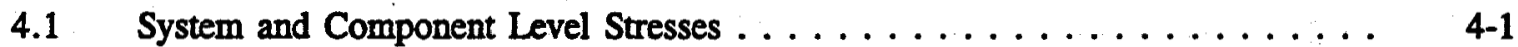

$4.2 \quad$ Stresses Induced by Testing . . . . . . . . . . . . . . . . . 4-2

4.3 Stresses Induced by Human Performance . . . . . . . . . . . . . . 4-3

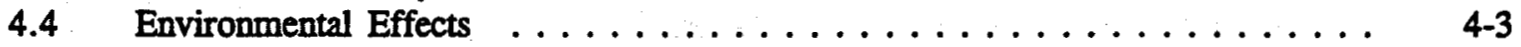

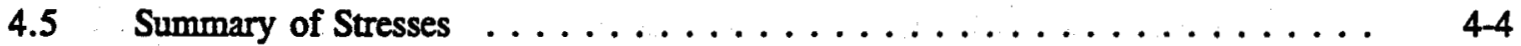

5. ANALYSIS OF NATIONAL DATA BASE OPERATING EXPERIENCE $\ldots \ldots \ldots \ldots$

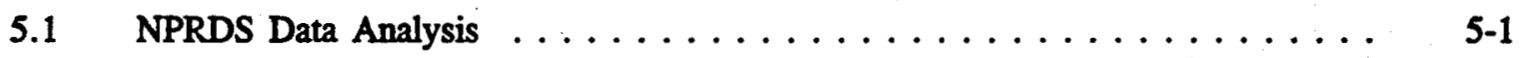

5.1.1 Effects of RCIC Component Aging on Plant Operation . . . . . . . 5-2

5.1 .2 Component Importance $\ldots \ldots \ldots \ldots \ldots \ldots \ldots \ldots$ 5-3

5.1.3 Aging Characterization of RCIC Components ........... $5-4$

$5.2 \quad$ Licensee Event Reports Analysis . . . . . . . . . . . . . . . . . . 5-29

5.2.1 Effects of Aging on Licensee Events . . . . . . . . . . . . . . 5-29

5.2 .2 Importance Ranking . . . . . . . . . . . . . . . . . . 5-31

5.2.3 Aging-Related Failures of Components $\ldots \ldots \ldots \ldots \ldots \ldots$ 5-31

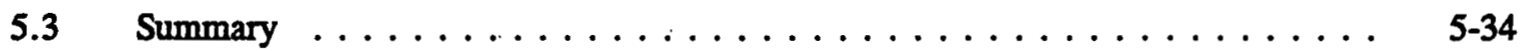

6. ANALYSIS OF PLANT OPERATING EXPERIENCE $\ldots \ldots \ldots \ldots \ldots$. $\ldots \ldots \ldots$

$6.1 \quad$ Database ............................... $6-1$

$6.2 \quad$ RCIC System Data Analysis . . . . . . . . . . . . . . . . . 6-1

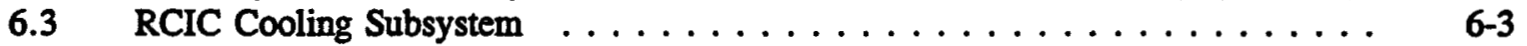

6.4 $\quad$ RCIC Turbine/Steam Subsystem $\ldots \ldots \ldots \ldots \ldots \ldots \ldots \ldots \ldots \ldots$

7. PROBABILISTIC UNAVAILABILITY ANALYSIS $\ldots \ldots \ldots \ldots \ldots \ldots \ldots \ldots$

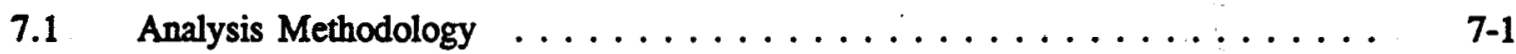

7.2 Base Case Analysis . . . . . . . . . . . . . . . . . 7-2

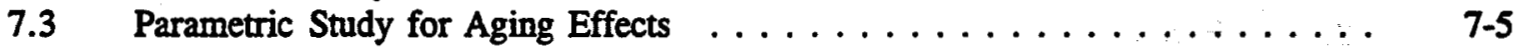

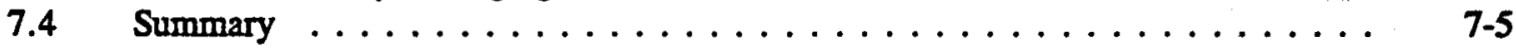


8. INSPECTION, SURVEILLANCE, AND MONTORING

(IS\&M) PRACTICES $\ldots \ldots \ldots \ldots \ldots \ldots \ldots \ldots \ldots \ldots \ldots \ldots \ldots \ldots . \ldots \ldots$

8.1 Failure Detection Methods $\ldots \ldots \ldots \ldots \ldots \ldots \ldots \ldots \ldots \ldots \ldots$ 8-1

8.2 System Testing $\ldots \ldots \ldots \ldots \ldots \ldots \ldots \ldots \ldots \ldots \ldots \ldots \ldots, 8,1$

8.3 Component Testing $\ldots \ldots \ldots \ldots \ldots \ldots \ldots \ldots \ldots \ldots \ldots \ldots, 8,1$

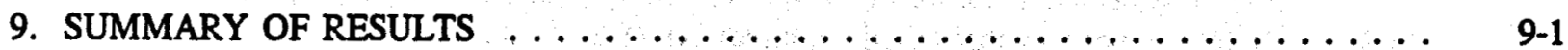

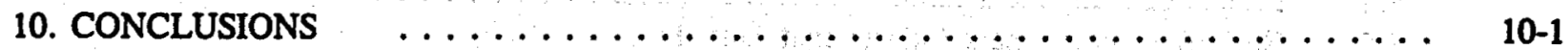

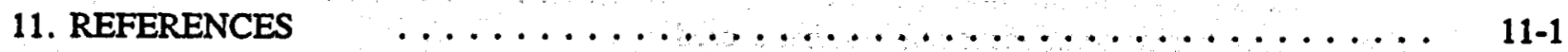

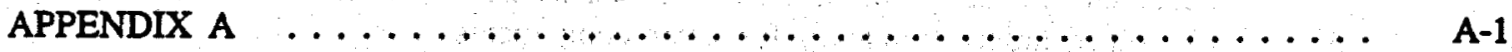

APPENDIX B $\ldots, \ldots \ldots \ldots \ldots \ldots \ldots \ldots \ldots \ldots \ldots \ldots \ldots \ldots \ldots \ldots \ldots \ldots$, B-1 


\section{FIGURES}

Figure No.

2.1 Functional diagram of $\mathrm{RCIC}$ system $\ldots \ldots \ldots \ldots \ldots \ldots \ldots$

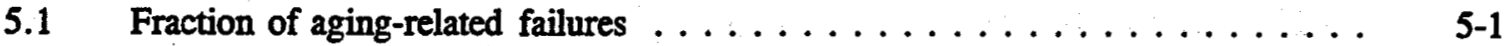

5.2 Fraction of RCIC component failures that caused

loss of system function or degraded system operation . . . . . . . . . . 5-3

5.3 RCIC components that failed. Source: NPRDS $\ldots \ldots \ldots \ldots \ldots \ldots \ldots$

5.4 Effects of component failures on RCIC system . . . . . . . . . . 5-5

5.5 Number of component failures that caused $\ldots \ldots \ldots \ldots \ldots \ldots \ldots \ldots \ldots$

5.6 Number of component failures that caused $\ldots \ldots \ldots \ldots \ldots \ldots \ldots \ldots \ldots \ldots$

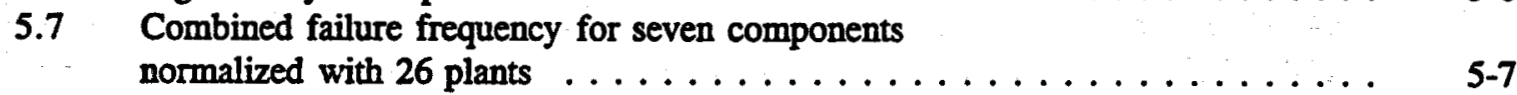

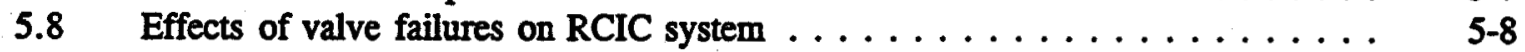

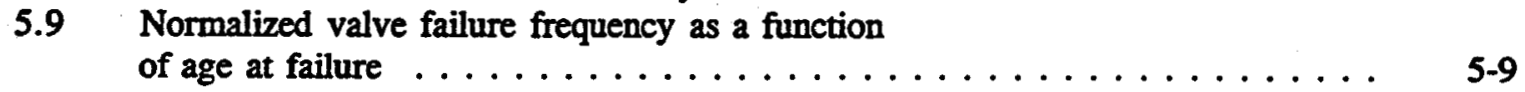

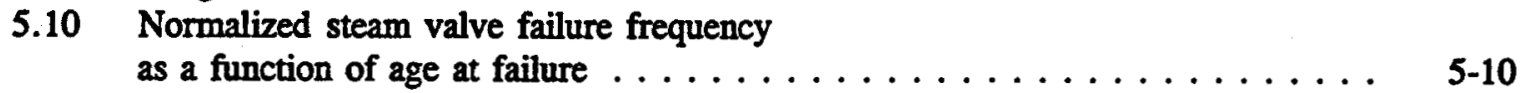

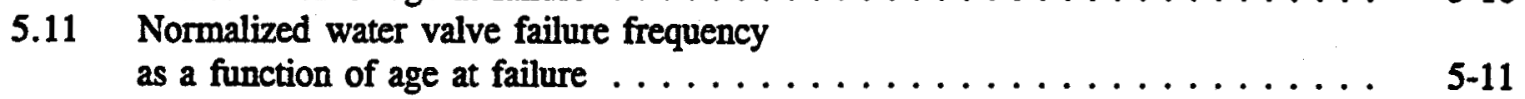

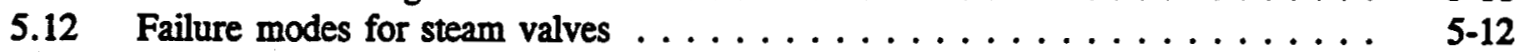

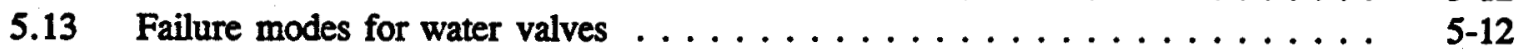

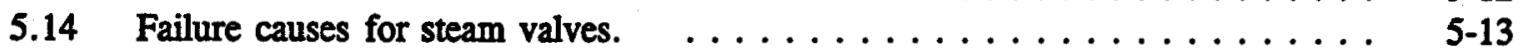

5.15 Proximate causes for steam valve failures $\ldots \ldots \ldots \ldots \ldots \ldots \ldots \ldots \ldots \ldots . \ldots \ldots$

5.16 Proximate causes for water valve failures $\ldots \ldots \ldots \ldots \ldots \ldots \ldots \ldots \ldots$ 5-15

5.17 Normalized failure frequency for valve

5.18 Effects of valve operator failures on the $\mathrm{RCIC}$ system $\ldots \ldots \ldots \ldots \ldots \ldots \ldots$

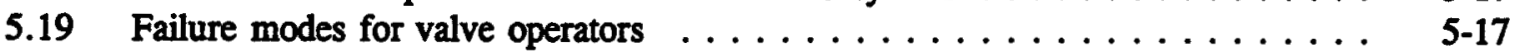

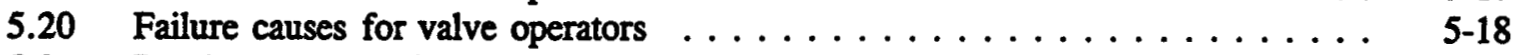

5.21 Proximate causes for valve operator failures . . . . . . . . . . . . 5 5-19

5.22 Effects of switch failures on RCIC system . . . . . . . . . . . $5-20$

5.23 Normalized failure frequency for switches

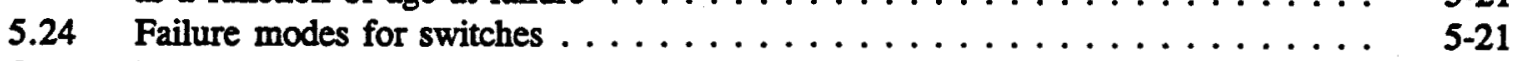

5.25 Normalized failure frequency for circuit breakers

5.26 Effects of circuit breaker failures on RCIC system $\ldots \ldots \ldots \ldots \ldots \ldots \ldots \ldots \ldots$

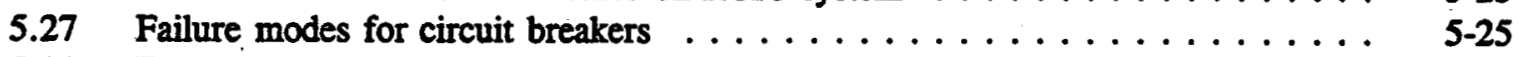

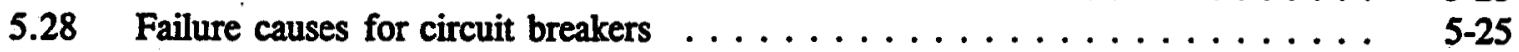

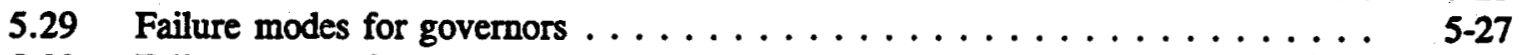

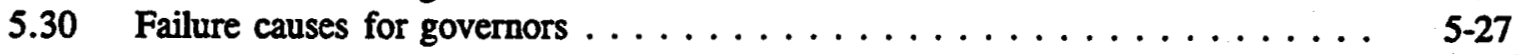




\section{FIGURES (Cont'd)}

Page

Figure No.

5.31 Fraction of aging-related component

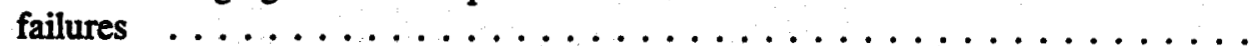

5.32 Fraction of LERs caused by aging-related

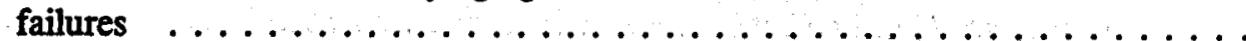

Number of aging-related component failures reported to LERs

$5-32$

5.34

Proximate causes for valve operator failures

5.35 Proximate causes for instrumentation and

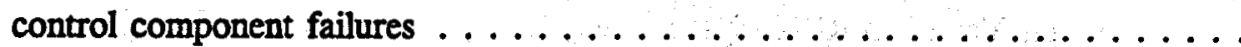

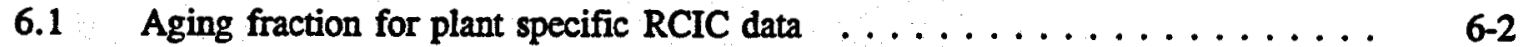

$6.2 \quad$ RCIC system components that failed .................... $6-2$

6.3 RCIC cooling subsystem components that failed ............... $6-4$

$6.4 \quad$ RCIC steam subsystem components that failed .................. $6-4$

6.5 Failures of motor operators and motor-operated

valves in RCIC cooling and steam subsystems .............. 6-5

8.1 Failure detection for valve operators $\ldots \ldots \ldots \ldots \ldots \ldots \ldots \ldots \ldots \ldots$

$8.2 \quad$ Failure detection for valves $\ldots \ldots \ldots \ldots \ldots \ldots \ldots \ldots \ldots \ldots \ldots$

8.3 Failure detection for bistables/switches $\ldots \ldots \ldots \ldots \ldots \ldots \ldots \ldots \ldots$ 8-3

8.4 Failure detection for circuit breakers . . . . . . . . . . . . . . 8-4

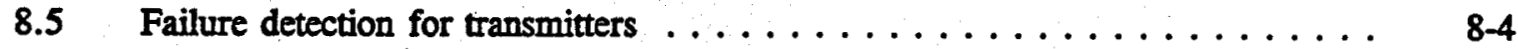

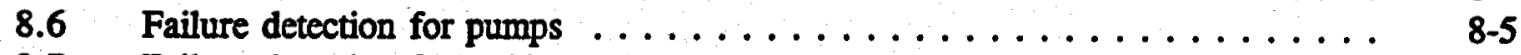

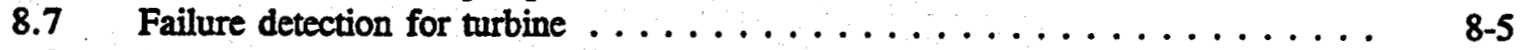

8.8 The fraction of the failures detected by

operational abnormality ..................... 8-6 


\section{TABLES}

Page

Table No.

2.1 Boiling Water Reactors in U.S. . . . . . . . . . . . . . $2-2$

4.1 Typical Environmental Stresses on RCIC Components in Primary Containment $\ldots \ldots \ldots \ldots \ldots \ldots \ldots \ldots \ldots$ 4. . . . . . . . .

4.2 Aging Effects on RCIC System Components $\ldots \ldots \ldots \ldots \ldots \ldots \ldots \ldots$

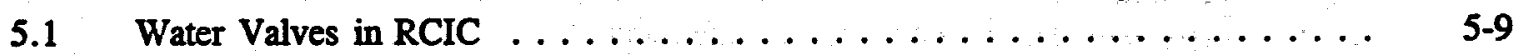

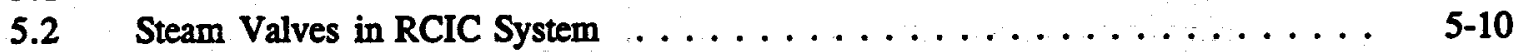

5.3 Importance Ranking for RCIC Components . . . . . . . . . . . . 5 5-35

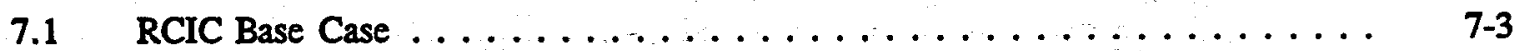

7.2 A List of the Component Groups Selected for the RCIC System Parametric Study . . . . . . . . . . . . . . . . . . 7-4

7.3 Results of the Parametric Study . . . . . . . . . . . . . . . 7-6

8.1 Summary of RCIC Component Tests and Inspections . . . . . . . . . 8-7

9.1 Importance Ranking for RCIC Components . . . . . . . . . . . . . 9 9-2

9.2 Aging Characteristics for RCIC Components . . . . . . . . . . . . . 9-4 


\section{EXECUTIVE SUMMARY}

An aging assessment of Reactor Core Isolation Cooling (RCIC) systems in commercial boiling water reactors (BWRs) has been performed as part of the Nuclear Plant Aging Research (NPAR) program. The NPAR program is sponsored by the U.S. Nuclear Regulatory Commission, Office of Research, Division of Engineering. Its goal is to provide a technical basis for understanding and managing the effects of aging in nuclear plants. As a safety-related system, the RClC system plays a vital role in the safe operation of the plant providing makeup water to the reactor vessel of a BWR for core cooling when the reactor is isolated from the main condenser with the feedwater system unavailable.

Loss of the RCIC system contributes to four of the eight representative accident sequences developed in NUREG/CR-5692, Generic Risk Insights for General Electric Boiling Water Reactors. For Station Blackout (SBO) scenarios, the RCIC system was found to be one of the most important systems for preventing core melt in BWRs. RCIC is especially important to the BWR 5 and 6 plants in the SBO sequences because it is the only system that is independent of $A C$ power. BWR 5 and 6 plants have a motor-driven, high pressure core spray system instead of the turbine-driven high pressure coolant injection system found in earlier plants.

In accordance with the NPAR Program Plan, the primary goals of this Phase I RCIC system study are to identify and characterize aging effects which, if unchecked, could cause the RCIC components and system to degrade, and thereby impair plant safety. This study includes an aging characterization of the system and its important components. In addition, a preliminary review of current inspection, surveillance, and monitoring practices identified areas where improvements can be made to more effectively detect and mitigate aging degradation.

Because RCIC is a standby system, it experiences less aging degradation due to wear, erosion and vibration compared to continuously operating systems. However, the aging degradation caused by corrosion and dirt accumulation may be more prevalent due to the stagnant conditions during standby periods. Also, this study found that testing is an important source of stress for some standby components (e.g., turbines, pumps, valve operators) that may contribute to premature failures. Since this system is categorized as a safety-related system, components are more frequently tested to assure their operability.

From January 1986 to December 1991,920 RCIC component failures were reported to the Nuclear Plant Reliability Data System (NPRDS), of which $87 \%$ were aging-related. Between January 1985 and April 1992, 132 Licensee Event Reports (LER) were identified as caused by failures of RCIC components, of which $80 \%$ were aging-related. This contribution of aging-related failures to the LER events increased as the plants got older. Plant specific data from an operating BWR showed the plant conducted 144 corrective maintenance actions on the RCIC system over a five year period, and $83 \%$ of these were due to aging-related failures. These results clearly show that aging is a significant contributor to failures in the RCIC system.

Analysis of the NPRDS data showed that the effects of component failures on RCIC system function become increasingly more serious as the components age. During the period of $1986-87$, about $22 \%$ of the component failures resulted in loss of system function or degraded system operation, which increased to $30 \%$ and $36 \%$ for the periods of $1988-89$ and $1990-91$, respectively. Throughout this period, about the same number of BWR plants were in operation, therefore the populations of components were relatively constant. This finding agrees with that from LER analysis which showed increased aging 
failures in the LER events as the plants got older. LERs contain events that are more safety significant than those reported to NPRDS. Thus, the increased fractions of LERs caused by aging-related failures mean they resulted in more safety significant events as the components got older.

The RCIC system does not have a redundancy in itself except a limited one in its instrumentation and control (I\&C) subsystem; the High Pressure Coolant Injection (HPCI) system or the High Pressure Core Spray (HPCS) system is the main back-up to the RCIC system. Therefore, many more losses of system function due to component failures occur compared to other safety systems.

For effective aging management, it is valuable to rank the importance of the RCIC components, i.e., prioritization. Table E.1 shows the rankings obtained using four different criteria: number of agingrelated failures reported to NPRDS, number of loss of system function failures reported to NPRDS, number of aging-related failures as LERs, and contribution to system unavailability. The information for the last criterion was obtained by conducting a probabilistic analysis. Valves fail most often mainly because they are more numerous than other components, but they are ranked 5th when the criterion of number of loss of system function failures is used. The reason is because the main failure mode for valves is leakage, which generally degrades the system operation, but does not necessarily cause a loss of system function. On the other hand, the failure frequency of the governors is low, but most of their failures cause a loss of system function, putting them in a higher rank when the criterion of number of loss of system function failures is used.

The fault-tree analysis identified pump failure to start/run, valve failures to open, instrumentation failures, and maintenance as the main causes of RCIC system unavailability. Further analysis using the IRRAS code found that the base-case system unavailability is $5.0 \times 10^{-2}$, and that the contribution to system unavailability due to these four groups is roughly equal, at about $20 \%$ each. The components whose failures are responsible for the system unavailability are switches/bistables, pumps, and valve operators. The unavailability analysis is, in fact, based on the product of importance of the component and the failure rate, which is equivalent to combining the other three criteria. Thus, the resulting ranking agrees with the rankings obtained from the other criteria, except for the pump. This analysis showed that RCIC pumps are very important due to their significant role in the accident scenario, despite a generally low failure rate.

This study shows that if only one criterion is used for prioritization, some important components may be overlooked. For example, if number of failures is the criterion used, governors and pumps would not be identified as important. Based on the four criteria examined in this study to prioritize components, it is concluded that aging management of valve operators, switches/bistables, governors, valves, circuit breakers, and pumps is important to reduce and mitigate the aging effects on the RCIC system. These components should receive the highest priority in terms of aging management.

A parametric unavailability study, which simulated uncontrolled aging degradation showed that when the failure rate of one of the three important components (i.e., switches/bistables, pumps, and MOVs and PCVs) doubles, the total system unavailability increases by a factor of 1.2. When the rates increase by factors of 5 and 10, total system unavailability increases by a factor of 1.8 and 2.8, respectively. The potential importance of independent aging related effects on system unavailability is underscored by increasing the failure rates of all components subject to aging by factors of 2,5 , and 10 . Although the potential impact of aging is generally more pronounced on multiple train systems, it is also significant for RCIC. When the failure rates of all the components are increased, due to uncontrolled 
Table E.1 Importance Rankings for RCIC Components

\begin{tabular}{|c|l|l|l|l|}
\hline \multirow{2}{*}{ Ranking } & \multicolumn{4}{|c|}{ Criteria } \\
\cline { 2 - 5 } & $\begin{array}{c}\text { Number of NPRDS } \\
\text { Aging-related } \\
\text { failures }\end{array}$ & $\begin{array}{c}\text { Number of NPRDS } \\
\text { Loss of System } \\
\text { Function Failures }\end{array}$ & $\begin{array}{c}\text { Number of } \\
\text { LERs }\end{array}$ & Unavailability \\
\hline 1 & Valves & Valves Operators & $\begin{array}{l}\text { Valve } \\
\text { operators }\end{array}$ & $\begin{array}{l}\text { Switches/ } \\
\text { Bistables }\end{array}$ \\
\hline 2 & Switches/Bistables & Switches/Bistables & $\begin{array}{l}\text { Switches/ } \\
\text { Bistables }\end{array}$ & Pumps \\
\hline 3 & Valve Operators & Circuit Breakers & Governors & Valve Operators \\
\hline 4 & Circuit Breakers & Governors & Valves & \\
\hline 5 & Transmitters & Valves & Turbines & \\
\hline 6 & Governors & Turbines & Flow & \\
\hline 7 & Turbines & Transmitters & Pumps & \\
\hline 8 & Pumps & Pumps & Transmitters & \\
\hline
\end{tabular}

aging, by factors of 2,5 , and 10 , the system unavailability increases by a factor of 1.9, 4.2, and 7.6, respectively. These results show that if the aging degradation of these components is not properly controlled, and the failure rates increase over time, the aging-related failures will lead to an increased RCIC system unavailability.

Out of the 31 BWR units that have RCIC systems, 26 were selected for a failure frequency analysis based on the number of failures reported by each. The failure frequency curve for the RCIC system shows a peak at $3-4$ years of age, followed by another peak at $11-13$ years. Since this RCIC component failure frequency is the combined value for several major components, it is important to know which components contributed to these peaks. It was found that failures of valves and switches/bistables were the primary cause of the peak at $3-4$ years; failures of valve operators also contributed to this peak. The second failure frequency peak at $11-13$ years is due to increased failures of valves, switches/bistables, circuit breakers, and valve operators.

There are two major groups of valves in a RCIC system, steam valves and water valves, and it is important to know which is more susceptible to aging. The analysis of NPRDS data shows that the failure frequencies for steam valves are much higher than those for water valves. This is believed to be due to the fact that steam valves operate under harsher environmental stresses than water valves, therefore, more attention should be paid to their maintenance. The analysis of the plant-specific data also gave the same results. The aging characteristics for the major components, obtained from the analysis of the operational data, are summarized in Table E.2. 
Table E.2 Aging Characteristics for RCIC Components

\begin{tabular}{|c|c|c|c|}
\hline Components & Failure Mode & Failure Cause/Mechanism & Proximate Cause \\
\hline Valves & $\begin{array}{l}\text { - External leak } \\
\text {-Internal leak } \\
\text { - Fail to close } \\
\text { - Fail to open }\end{array}$ & $\begin{array}{l}\text { - Normal/abnormal wear } \\
\text { - Dirt accumulation } \\
\text { - Out of adjustment } \\
\text { - Fatigue } \\
\text { - Corrosion }\end{array}$ & $\begin{array}{l}\text {-Worn } \\
\text { Seat/Disc } \\
\text { - Worn packing } \\
\text { - Worn gasket } \\
\text { - Corrosion } \\
\text { product } \\
\text { accumulation }\end{array}$ \\
\hline Valve Operators & $\begin{array}{l}\text {-Fail to operate } \\
\text { as required } \\
\text { - Fail to open } \\
\text { - Fail to close } \\
\text { - Found during } \\
\text { IS\&M }\end{array}$ & $\begin{array}{l}\text { - Normal/abnormal wear } \\
\text { - Out of mechanical } \\
\text { adjustment } \\
\text { - Mechanical damage } \\
\text { - Burned/burned out } \\
\text { - Defective connection }\end{array}$ & $\begin{array}{l}\text { - Failed Torque } \\
\text { switch } \\
\text { - Failed Motor } \\
\text { - Failed Limit } \\
\text { switch } \\
\text {-Tripper finger }\end{array}$ \\
\hline Switches & $\begin{array}{l}\text { - Fail to change } \\
\text { state } \\
\text { - High actuation } \\
\text { - Low actuation } \\
\text { - Fail to actuate } \\
\text { properly }\end{array}$ & $\begin{array}{l}\text { - Normal/abnormal wear } \\
\text { - Set point drift } \\
\text { - Out of calibration } \\
\text { - Defective circuits }\end{array}$ & - Sticking float \\
\hline Bistables & $\begin{array}{l}\text { - Fail to change } \\
\text { state } \\
\text { - Spurious } \\
\text { actuation }\end{array}$ & $\begin{array}{l}\text { - Defective circuits } \\
\text { - Burned/burned out }\end{array}$ & $\begin{array}{l}\text { - Failed Transistor } \\
\text { - Dirty Contacts } \\
\text { - Failed Relay }\end{array}$ \\
\hline Circuit Breakers & $\begin{array}{l}\text {-Fail to change } \\
\text { state } \\
\text {-Fail to operate } \\
\text { as required } \\
\text {-Spurious } \\
\text { actuation }\end{array}$ & $\begin{array}{l}\text { - Normal/abnormal } \\
\text { - Mechanical damage } \\
\text {-Fatigue } \\
\text { - Burned/burned out }\end{array}$ & $\begin{array}{l}\text {-Failed } \\
\text { Contactor } \\
\text {-Failed } \\
\text { Contactor coil } \\
\text { - Failed Thermal } \\
\text { overload relay }\end{array}$ \\
\hline Governors & $\begin{array}{l}\text { - Fail to control } \\
\text { - Fail to start }\end{array}$ & $\begin{array}{l}\text { - Circuit defect } \\
\text { - Out of calibration } \\
\text { - Wear } \\
\text { - Mechanical damage } \\
\text { - Out of adjustment }\end{array}$ & $\begin{array}{l}\text {-Worn-out } \\
\text { Overspeed tappet } \\
\text { - Failed Ramp } \\
\text { generator } \\
\text { - Failed Magnetic } \\
\text { pickup }\end{array}$ \\
\hline
\end{tabular}


Table E.2 (Cont'd)

\begin{tabular}{|c|c|c|c|}
\hline Components & Failure Mode & Failure Cause/Mechanism & Proximate Cause \\
\hline Transmitters & $\begin{array}{l}\text { - Low output } \\
\text { - Failure output } \\
\text { - High output }\end{array}$ & $\begin{array}{l}\text { - Out of calibration } \\
\text { - Defective circuit }\end{array}$ & $\begin{array}{l}\text {-Electronic drift } \\
\text { - Sensing line } \\
\text { problems } \\
\text { - Failed sensor } \\
\text { - Burned-out } \\
\text { amplifier }\end{array}$ \\
\hline Turbine & - Fail to run & - Normal/abnormal wear & $\begin{array}{l}\text { Worn/loose } \\
\text { mechanical parts }\end{array}$ \\
\hline Pump & - Fail to run & - Normal/abnormal wear & $\begin{array}{l}\text {-Worn seal } \\
\text {-Worn gasket } \\
\text {-Worn bearing }\end{array}$ \\
\hline
\end{tabular}

A review of operational data shows that most RCIC failures are detected by surveillance tests. However, for valve operators, pumps, and transmitters, about $18 \%$ of the failures were demand faults; for circuit breakers, an even higher portion of the failures (27\%) were demand faults. Thus, current inspection, surveillance, and monitoring (IS\&M) procedures for valve operators, pumps, transmitters, and circuit breakers should be reviewed to determine if improvements can be made to better detect failures before they affect the system function.

As a result of this Phase I study, aging processes in the RCIC system are better understood through aging characterization of the system and components. The components most frequently affected by aging degradation and those that need priority aging management are identified. The information obtained from this study provides a technical basis upon which future work can be performed. 


\section{ACKNOWLEDGEMENTS}

The authors wish to thank the NRC Program Manager, Satish K. Aggarwal for his technical direction. We also are grateful to personnel at the utility for supplying information to support this work.

We would like to express our gratitude to various members of the Engineering Technology Division of BNL, including Robert E. Hall, Robert Lofaro, John Taylor, and Jim Higgins. Especially, we would like to extend our gratitude to Jeffrey Badger for his help during his stay at BNL.

We also wish to thank Patricia Ennis for her help in preparing this report. 


\begin{tabular}{ll} 
ADS & Automatic Depressurization System \\
AOV & Air-Operated Valve \\
ATWS & Anticipated Transients without Scram \\
BWR & Boiling Water Reactor \\
CRDH & Control Rod Drive Hydraulic \\
CST & Condensate Storage Tank \\
ECCS & Emergency Core Cooling System \\
EPRI & Electric Power Research Institute \\
ESF & Engineered Safety Feature \\
HPCI & High Pressure Coolant Injection \\
HPCS & High Pressure Core Spray \\
LCO & Limiting Condition of Operation \\
LER & Licensee Event Reports \\
LPCI & Low Pressure Coolant Injection \\
MOV & Motor-Operated Valve \\
MSIVs & Main Steam Isolation Valves \\
NPAR & Nuclear Plant Aging Research \\
NPRDS & Nuclear Plant Reliability Data System \\
PCV & Pressure Control Valve \\
RCIC & Reactor Core Isolation Cooling \\
RHR & Residual Heat Removal \\
RPV & Reactor Pressure Vessel \\
RTD & Resistance Temperature Detectors \\
SBO & Station Blackout \\
SSCs & Systems, Structures and Components \\
\hline
\end{tabular}





\section{INTRODUCTION}

\subsection{Background}

By the year 2014, 48 nuclear power plants in the United States are projected to reach 40 years of operation (Ref. 1). As the population of old commercial nuclear power plants increases, aging degradation of the systems and components in these plants becomes an important consideration to the nuclear community.

The NRC Office of Nuclear Regulatory Research, Division of Engineering has a continuing research program for assessing aging effects on equipment and systems in nuclear power plants. The program, entitled "Nuclear Plant Aging Research" (NPAR), seeks to improve the operational readiness of plant systems and components that are vital to the safe operation of nuclear power plants by understanding and managing aging degradation. Work under the program began by evaluating the aging effects on selected plant components (Ref. 2 -9). Current NPAR studies focus on the effects of aging on entire plant systems.

The main goals of the NPAR program are to understand aging and to identify ways to manage aging of safety-related systems, structures, and components (SSCs). The following are the technical objectives of the program (Ref. 10):

- identify and characterize aging effects which, if unmitigated, could cause degradation of SSCs and thereby impair plant safety,

- develop supporting data and information to facilitate management of age-related degradation;

- identify methods of inspection, surveillance, and monitoring, or of evaluating residuallife of SSCs, which will ensure timely detection of significant aging effects before safety function is lost,
- evaluate the effectiveness of storage, maintenance, repair, and replacement in mitigating the effects of aging and diminishing the rate and extent of degradation it causes,

- provide a technical basis and support for the License Renewal Rule and the license renewal process, and develop a regulatory guide on the format and technical information content for license renewal applications.

\subsection{Objectives and Scope of This Study}

This study addresses the impact of aging degradation on Reactor Core Isolation Cooling (RCIC) . systems in boiling water reactors (BWRs). The RCIC system was chosen because, as a safety-related system, it plays a vital role in the safe operation of the plant. For Station Blackout scenarios, the RCIC system is an important system for preventing core melt in BWRs (Ref. 11 - 12).

NPAR studies typically have two phases. The current study is a Phase I study, and its scope is the following, as described in the NPAR program plan (Ref. 10):

After the components and systems are selected, the first step is to establish a boundary to define what is included in the component or system under consideration, and also to identify important interfaces between the component or system to be investigated and other adjacent components or systems. The phase I study is based on information from public and private databases, vendor information, open literatare, utility sources, operating experience, and expert opinion. The information includes the identification of failure modes, preliminary identification of failures caused by age-related degradation, and reviews of inspection, surveillance, and monitoring methods (IS\&M), including manufacturer-recommended surveillance and maintenance practices. Performance parameters or condition indicators potentially useful in 
detecting degradation are identified, and preliminary recommendations are made about improving IS \& $M$ and maintenance practices. Recommendations also are developed to identify the detailed engineering tests and analyses conducted in Phase II. A key outcome of the phase I investigation is a decision about the need for a phase II assessment on specific SSCs. Reference 10 contains more detailed discussions on the activities that comprise the Phase I and II investigations.

\subsection{System Definition}

\subsubsection{Description of RCIC System}

The RCIC system is that group of components which includes a steam turbinedriven pump, and associated valves, interconnecting piping, pipe supports/restraints, electrical power supply components and instrumentation/controls, which function together to:

1. Assure that there is adequate core cooling to prevent the reactor fuel from over-heating in the event that the reactor vessel is isolated when flow from the reactor feedwater system also has been lost.

2. Allow complete plant shutdown when normal feedwater is lost by maintaining sufficient water inventory until the reactor is depressurized to a level where the Residual Heat Removal (RHR) System can be placed in operation in the Shutdown Cooling mode.

3. Assure that there is adequate core cooling to prevent the reactor fuel from over-heating when the reactor is isolated and maintained in the Hot Standby condition.

4. Operate automatically in time to maintain sufficient coolant in the reactor vessel so that the integrity of the radioactive material barrier is not compromised during (1), (2), or (3).

5. Withstand the effects of the Safe Shutdown Earthquake (SSE) without a failure that could lead to a significant release of radioactivity.

Section 2 gives a more detailed description of the design and operation of the RCIC system.

\subsubsection{System Interfaces and Boundaries}

The RCIC system interfaces with the following plant systems:

- RCIC Room Cooling System

- Main Steam System

- Condensate and Feedwater System*

- Primary Containment System

- High Pressure Coolant Injection/High Pressure Core Spray Systems

- Residual Heat Removal System

The degradation and unavailability of the RCIC system affect the performance and availability of these systems, and vice versa. The interfaces between the RCIC system and these systems are discussed in more detail in Section 2.4 .

The RCIC system has a clearly defined boundary, and the major components within this boundary are described in Section 2.2. Failures which occur outside the RCIC boundaries are not included in this study.

\subsection{Analysis Methodology}

A detailed analysis was made of the various failure data bases summarizing the actual operating experience of RCIC systems. These data bases include:

* Except BWR 5 or 6, which has a separate injection point into the head as spray or inside the shroud. 
- Nuclear Plant Reliability Data System (NPRDS),

- Licensee Event Reports (LER),

- Plant Specific Failure Data from a Selected Plant.

In reviewing these data, decisions were made as to whether or not the failures were aging-related. It is noted that different reviewers using the same information may arrive at different conclusions, based upon their personal knowledge and experience. To obtain consistency, a set of guidelines was used to define what constitutes an "aging-related failure." These guidelines represent a minimum set of criteria which must be satisfied to classify the failure as aging-related.

The first criterion is that the failure satisfies the NPAR definition of aging (Ref. 10); aging is defined as being the cumulative changes with passage of time that may occur within a component, structure, or system which, if unchecked, may result in loss of function and impairment of safety. Factors causing aging include:

a. natural internal chemical or physical processes during operation,

b. external stressors (e.g., radiation, humidity) caused by storage or the operational environment,

c. service wear, including changes in dimension and/or relative positions of individual parts or subassemblies caused by operational cycling,

d. excessive testing,

e. lack of maintenance.

In addition, the circumstances of the failure must meet the following criteria:
1. The component must have been in service for at least 6 months before the failure; this eliminates infant mortality failures.

2. The failure must be the result of operation or service over some period and not be due to a temporary, instantaneous event.

Three categories of aging were used; "due to aging", "possibly due to aging", and "nonaging." When the failure met all the criteria above, and the description of the failure clearly indicated the cause as aging, it was classified as "due to aging." In many of these cases, terms such as aging, old, obsolete, or age of the component are used in the description. When the description does not provide enough information, but the failure mode, the failure cause, and the component age indicate that the failure was probably due to aging, it was categorized as "possibly aging." When human factors, including human errors, procedural problems, and design problems are the clear causes, the failure was categorized as "nonaging."

The data classified as "aging" and "possibly aging" were combined and termed "aging-related failures." Only these aging-related failures were analyzed to characterize aging degradation, and the following information was obtained:

- Effects of aging on system failure frequency,

- Effects of aging-related system failures on plant operation,

- Aging fraction of component failures,

- Effects of aging-related component failures on system operation,

- Effects of aging on component failure frequency,

- Component failure modes, and

- Component failure causes and mechanisms. 
Plant specific data for the system were obtained to supplement and check on the generic databases. The data included maintenance records from an operating BWR covering five years. An analysis was made, similar to that used for the data base records, to identify aging characteristics, including a determination of aging fraction, failure modes, and causes, as well as an identification of the components failing most frequently.

One piece of information needed for aging management is which components are most important, i.e., an importance ranking. The number of failures is one possible criterion in determining their importance; another is the significance of the component's failure to the system function and the safety of the plant. Information on the significance of the failures to the system function is obtained from the data on the effects of aging-related component failures on system operation, while information on the significance of the component failures to the safety of the plant was obtained by the LER data analysis. LERs contain events that are more safety significant than those reported to NPRDS. The last criterion used is the plant safety significance based on an unavailability analysis using a probabilistic approach.

A plant with a completed PRA was chosen for the unavailability analysis, and the PRA model of the RCIC system for that plant was used to represent the common essential features of the RCIC system design and to accommodate age-related failure rates. This analysis identified the components which have the dominant effect on system availability. By including a parametric study in this analysis, the effects of uncontrolled aging degradation on system availability also were evaluated.
From these deterministic and probabilistic analyses, several important components were selected, which should receive the highest priorities in the aging management programs.

\subsection{Report Organization}

In Section 2, the system and its major components are described, and interfaces with other systems and the system boundaries are also discussed. Section 3 of this report describes the significance of the RCIC system in ensuring safe operation of a BWR plant by reviewing the probabilistic risk assessment information and the bulletins, generic letters, and information notices.

Section 4 discusses operational and environmental stresses which cause aging degradation. Operational stresses include those induced by normal operation, stresses induced by testing, and stresses induced by human performance.

Section 5 gives the results of all data base analyses and identifies the predominant RCIC system failures from the operating experience at nuclear plants. The analysis of operating data from one BWR plant is presented in Section 6. Section 7 presents an unavailability analysis for a typical RCIC system.

Section 8 reviews current utility practices on testing and maintenance of RCIC systems. The summary of results are given in Section 9, and conclusions are made in Section 10. The appendices give detailed information on specific areas. 


\section{RCIC SYSTEM DESIGN REVIEW}

\subsection{System Function}

The function of the RCIC System is to provide adequate core cooling, without requiring actuation of the Emergency Core Cooling System (ECCS), during reactor shutdown or isolation from the main condenser when feedwater is not available. The RCIC System is functionally classified as a safety-related system, but it is not a part of Engineered Safety Feature (ESF) Systems, which include the following (Ref. 13):

1. Emergency Core Cooling System (ECCS)

a. High Pressure Coolant Injection (HPCI) System

b. Automatic Depressurization System (ADS)

c. Core Spray System

d. Low Pressure Coolant Injection (LPCI) mode of the Residual Heat Removal (RHR) System.

2. Primary Containment and Reactor Vessel Isolation Systems

3. Containment Heat Removal and Depressurization System

4. Containment Air Purification and Cleanup Systems

5. Containment Combustible Gas Control Systems

However, RCIC is one of the systems required for safe shutdown, which are:

1. Reactor Core Isolation Cooling (RCIC) System

2. Standby Liquid Control System
3. Residual Heat Removal-reactor shutdown
cooling mode

4. Remote Shutdown System

5. Essential Auxiliary Supporting Systems necessary to support safe shutdown system operation

a. Station Service Water System

b. Safety Auxiliary Cooling System

c. Class 1E power systems

d. Safe Shutdown Equipment Area Ventilation Systems

The RCIC system may provide the ability to mitigate the consequences of an accident (small pipe break), but this is not its primary function. The ECCS provides redundant protection for the entire spectrum of pipe breaks.

The early BWRs, specifically Big Rock Point, Oyster Creek, Nine Mile Point 1, Dresden 2 and 3, and Millstone 1 do not have RCIC systems. Instead, isolation condensers are used for emergency decay heat removal. Millstone 1 and Dresden 2 and 3 are BWR 3 designs. Monticello, Quad Cities 1 and 2, and Pilgrim are also BWR 3 designs, however, they have RCIC systems. All BWR 4 and later designs have RCIC systems (Table 2.1).

The RCIC System is in service as a standby system during normal plant operation with the condensate storage tank aligned as the primary water source. The suppression pool provides a backup water source and is normally isolated.

\subsection{System Description}

The RCIC system consists of a steam turbine-driven pump, with piping and valves that can deliver water to the reactor vessel at operating conditions (Ref. 14). The turbine is driven by steam produced in the reactor, which exhausts to the suppression pool. The turbinedriven pump unit supplies makeup water from the Condensate Storage Tank (CST), with an 
Table 2.1 Boiling Water Reactors in United States

\begin{tabular}{|c|c|c|}
\hline BWR Type & Units & \\
\hline BWR 1 & Big Rock Point & NO RCIC \\
\hline BWR 2 & $\begin{array}{l}\text { Oyster Creek } \\
\text { Nine Mile Point } 1\end{array}$ & $\begin{array}{l}\text { NO RCIC } \\
\text { NO RCIC }\end{array}$ \\
\hline BWR 3 & $\begin{array}{l}\text { Dresden } 2 \text { and } 3 \\
\text { Millstone } 1 \\
\text { Quad Cities } 1 \text { and } 2 \\
\text { Pilgrim } \\
\text { Monticello }\end{array}$ & $\begin{array}{l}\text { NO RCIC } \\
\text { NO RCIC } \\
\text { RCIC } \\
\text { RCIC } \\
\text { RCIC }\end{array}$ \\
\hline BWR 4 & $\begin{array}{l}\text { Brunswick } 1 \text { and } 2 \\
\text { Fermi } 2 \\
\text { Cooper } \\
\text { Limerick } 1 \text { and } 2 \\
\text { Hope Creek } \\
\text { Edwin Hatch } 1 \text { and } 2 \\
\text { Vermont Yankee } \\
\text { James A. Fitzpatrick } \\
\text { Duane Arnold } \\
\text { Susquehanna } 1 \text { and } 2 \\
\text { Peach Bottom } 2 \text { and } 3 \\
\text { Brown's Ferry } 1,2 \text { and } 3 \\
\end{array}$ & $\begin{array}{l}\mathrm{RCIC} \\
\mathrm{RCIC} \\
\mathrm{RCIC} \\
\mathrm{RCIC} \\
\mathrm{RCIC} \\
\mathrm{RCIC} \\
\mathrm{RCIC} \\
\mathrm{RCIC} \\
\mathrm{RCIC} \\
\mathrm{RCIC} \\
\mathrm{RCIC} \\
\mathrm{RCIC}\end{array}$ \\
\hline BWR 5 & $\begin{array}{l}\text { LaSalle } 1 \text { and } 2 \\
\text { Nine Mile Point } 2 \\
\text { WNP } 2\end{array}$ & $\begin{array}{l}\mathrm{RCIC} \\
\mathrm{RCIC} \\
\mathrm{RCIC}\end{array}$ \\
\hline BWR 6 & $\begin{array}{l}\text { Perry } 1 \\
\text { River Bend } \\
\text { Grand Gulf } 1 \\
\text { Clinton }\end{array}$ & $\begin{array}{l}\mathrm{RCIC} \\
\mathrm{RCIC} \\
\mathrm{RCIC} \\
\mathrm{RCIC}\end{array}$ \\
\hline \multicolumn{3}{|c|}{$\begin{array}{l}\text { Summary: } \\
37 \text { operating BWR plants in U.S. } \\
31 \text { plants with RCIC }\end{array}$} \\
\hline
\end{tabular}


alternate supply from the suppression pool, to the reactor vessel via the feedwater line (BWR 3 and 4 designs), or to the reactor vessel head spray line (BWR 5 and 6 designs). Figure 2.1 shows the functional diagram of a typical RCIC system.

Additional discharge flow paths are provided to allow recirculation to the CST for system testing, and a pump-minimum flow line to the suppression pool for protecting the pump. There is sufficient capacity to prevent the level in the reactor vessel from falling below the top of the core. The system's flow rate is approximately equal to the boil-off rate of the water in the reactor 15 minutes after shutdown with designlevel decay heat being generated in the reactor. The system is initiated automatically on reactor vessel low-water level (Level 2) or manually by the operator. System operation is completely independent of AC power, plant service air, or external cooling water systems.

There is very little variation in the basic design features of the RCIC systems in the various BWR classes. The major difference is that in the most recent designs (BWR 5 and 6) RCIC injects into the RPV head spray line instead of the feedwater line, as in the earlier BWRs. Appendix A gives design information for several plants.

The RCIC system can be divided into a main train and auxiliary trains, which are the gland condensing train, the lube oil train, and the vacuum breaker train. These trains and their components are further described in this section. The instrumentation and control (I \& C) system for the RCIC system is described in the Section 2.3.

\subsubsection{Main Train}

Because there is no redundancy in the main train of the RCIC system, it is considered as a single train system. The following are the major components of the RCIC system main train:
- Steam Isolation Valves

- Trip Throttle Valve

- Governor Valve

- RCIC Turbine

- Pump Suction Valves

- RCIC Pump

- Pump Discharge Valve

- RCIC Flow Controller

- Turbine Exhaust

- Water Leg Pump

- Check Valves

\subsubsection{Steam isolation valves}

Steam is provided to the RCIC turbine from one of the main steam lines at a branch point upstream of the inboard main steam isolation valves. In the event of a leak, the line is isolated by two motor-operated valves, one inboard and one outboard of primary containment. The steam supply line is drained, warmed, and pressurized by a bypass valve around the inboard isolation valve. The turbine steam supply is normally isolated by a third motor-operated valve downstream near the RCIC turbine.

\subsubsection{Turbine trip throttle valve}

The RCIC turbine is rapidly isolated by the turbine trip throttle valve, located upstream of the turbine governor valve, which protects against potentially unsafe turbine conditions. The valve closes by spring force, and is reopened by an electric motor which is controlled from the control room. The turbine is automatically tripped and the throttle valve closed if any of the RCIC turbine trip conditions exist, which are described in Section 2.3.3.

\subsubsection{Governor valve}

The RCIC pump flow is proportional to the speed of the turbine, which, in turn, is controlled by throttling the steam supply to the turbine. The RCIC flow controller positions 


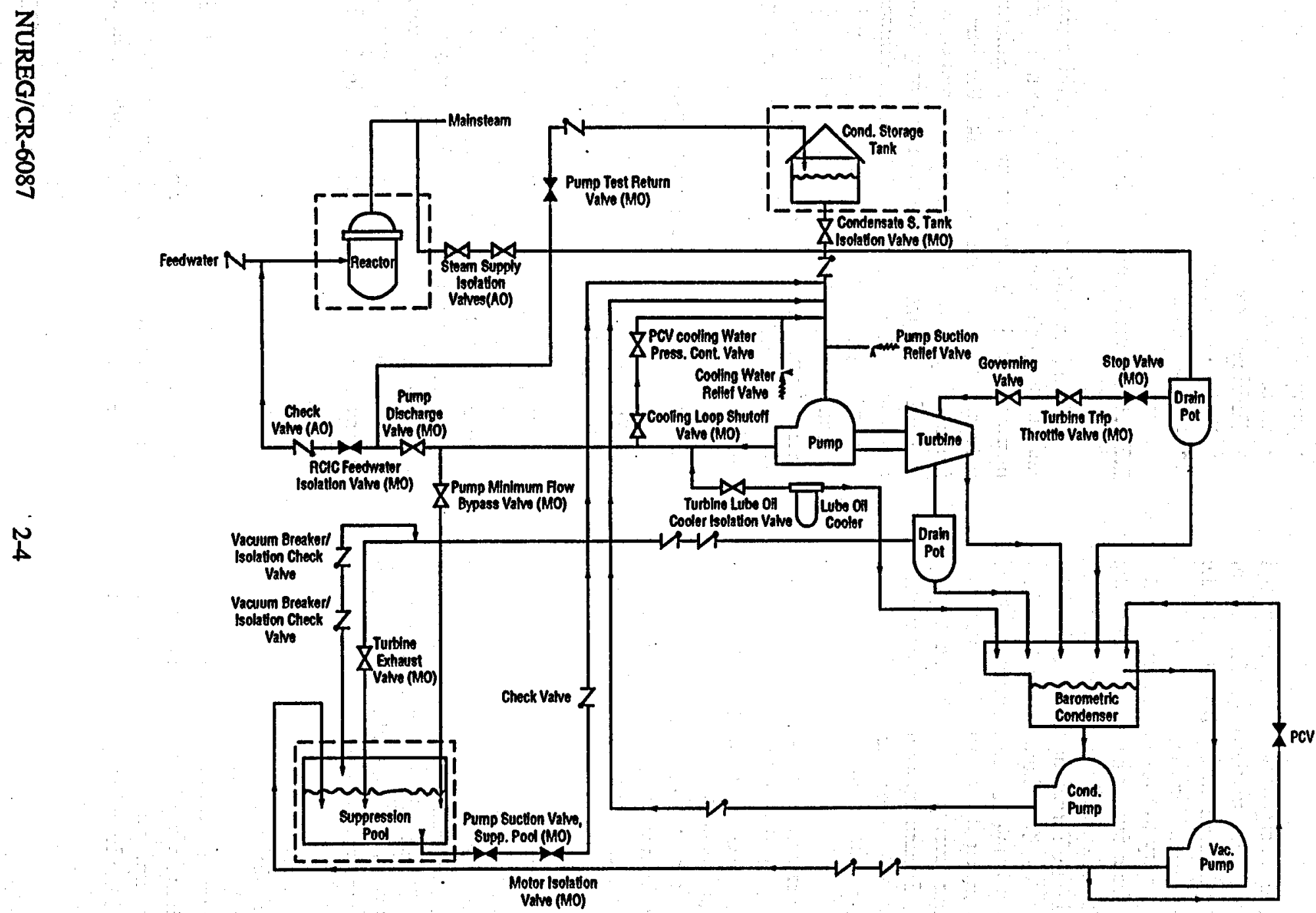

Note: The components inside the dotted boxes are outside the RCIC boundary.

Figure 2.1 Functional diagram of RCIC system 
the governor valve to produce the required pump discharge flow. The governor valve is opened by spring force and closed by oil pressure.

$$
\text { is: }
$$

\subsubsection{RCIC turbine}

The RCIC turbine is a horizontally mounted, noncondensing turbine designed to operate with a steam supply pressure ranging from 1177 down to 150 psig. The turbine operates with a 10 psig exhaust pressure, and exhausts to the suppression pool. The system is designed to deliver flow within 30 seconds after actuation. The turbine is a "Terry water wheel", a tangential-flow, single-wheel turbine with a low efficiency, that is selected primarily for reliability and can accommodate dry and saturated steam. The turbine-driven lube-oil pump lubricates the bearings and supplies oil to the governor valve control system. The lube oil is cooled in a small heat exchanger by water from the RCIC pump discharge.

\subsubsection{Pump suction valves}

The RCIC pump suction is aligned either to the condensate storage tank (CST) or to the suppression pool by motor-operated valves. When both suction valves are open, check valves prevent flow between the CST and the suppression pool. The suppression pool suction valve opens either when the level in the CST reaches a minimum, or when the level in the suppression pool reaches the maximum permissible. This change from manual to automatic switch over on low CST level was required by NUREG-0737, Item II.K.3.22. When the suppression pool suction valve is fully open, the CST suction valve automatically closes.

\subsubsection{RCIC pump}

The RCIC pump is a turbine-driven, horizontal, multistage, centrifugal pump with capacity ranging from 400 GPM to 800 GPM. The pump is designed for water temperatures between $4^{\circ} \mathrm{C}$ and $60^{\circ} \mathrm{C}$. The pump is located well below the suppression pool and CST level in the Reactor Building to ensure adequate net positive suction head (NPSH).

\subsubsection{RCIC feedwater isolation valve (RCIC Injection Valve)}

This valve isolates the reactor from the RCIC system. It is a normally closed, DC motor-operated gate valve, and opens 6 seconds after a receipt of an automatic or a manual initiation signal. This valve automatically closes when the RCIC turbine trip and throttle valves fully close or when the steam supply valve fully closes. This valve is located outside the primary containment.

\subsubsection{RCIC flow controller}

The RCIC system flow is automatically controlled upon initiation by a flow controller which also can be set for manual operation from the control room. When operating automatically, the RCIC system flow, measured by a flow element on the discharge of the pump, is compared to the flow setpoint, which is adjusted by the operator at the controller. The governor valve is driven by a hydraulic signal which balances any deviation between the actual and desired flows. For manual operation, the operator adjusts a manual potentiometer at the flow controller to create a desired flow signal that is independent of the automatic flow control setpoint. Any difference between the actual and desired flow is also balanced in the same way as for automatic operation.

\subsubsection{Turbine exhaust}

The RCIC turbine casing and exhaust piping are protected against overpressure by dual rupture disks. Downstream of the rupture disks are check valves, motor operated valves, and vacuum breaker valves. After RCIC operation, steam condenses in the turbine exhaust line to the suppression pool, creating a vacuum. To prevent water from siphoning and the potential of creating a water hammer, vacuum breaker 
check valves are installed to allow air from the suppression pool to refill the exhaust line. Because the line containing these check valves penetrates the containment, there are inboard and outboard containment isolation motoroperated valves in this line located upstream and downstream of the check valves, respectively.

\subsubsection{Water leg pump}

Some plants have an AC or DC powered water leg pump which keeps the RCIC piping up to the isolation valves filled with water to prevent water hammer; other plants rely on the static head of the condensate transfer system. This pump operates continuously, and it is also called a jockey pump.

\subsubsection{Check valves}

Several check valves are provided in the RCIC system to prevent undesired flow of coolant or steam. The CST suction valve is interlocked with the suppression pool suction valve so that both of them are not open at the same time. In addition, check valves are provided to prevent flow between the condensate storage tank and the suppression pool when both suction valves are open. The check valves in the RCIC turbine exhaust line were described earlier (see 2.2.1.9).

\subsubsection{Auxiliary Trains}

\subsubsection{Gland condensing train}

The gland condensing train prevents radioactive steam leakage to atmosphere, and consists of a barometric condenser, a vacuum tank condensate pump, and a vacuum pump.

The steam from the RCIC turbine seals and leakage from the turbine governor valve and trip throttle valve exhaust to the barometric condenser, which maintains a vacuum on the seals to prevent steam leaking into the RCIC room.
The steam entering the barometric condenser is condensed by a water spray from the RCIC pump discharge, which passes through a pressure reducing valve and then through the RCIC turbine lube oil cooler, and on to the condenser. The condensate is removed from the condenser by a small 125 or $250 \mathrm{~V} \mathrm{DC}$ motordriven pump. The condensate is returned to the RCIC pump suction or to radioactive waste systems. Noncondensible gases are removed from the condenser by a small 125 or $250 \mathrm{~V}$ DC motor-driven vacuum pump which exhausts to the suppression pool and which maintains a condenser vacuum of approximately 10 in. $\mathrm{Hg}$. A relief valve on the condenser is set at approximately 5 to $7 \mathrm{psig}$.

Because of the small exhaust flows on the RCIC turbine seal steam, the barometric condenser is not considered necessary for safe shutdown when using the RCIC system.

\subsubsection{Lube oil train}

The oil train supplies oil for turbine lubrication, valve operation, and control, and consists of an oil pump and a lube oil cooler, which is a small heat exchanger.

\subsubsection{Vacuum breaker train}

The function of this train is breaking the vacuum created in the steam exhaust line, when it cools down after RCIC turbine operation. This train consists of two in-series check valves and one or two, depending on plant vintage, motor-operated isolation valves.

\subsection{RCIC System Instrumentation, Control, and Interlock Logic}

Earlier generation BWRs used process switches extensively to monitor pressure, differential pressure, temperature, flow, and level. The signals from these switches are sent to controls, indicators and alarms. Newer plants that began operation after 1984 are equipped 
mainly with bistables and transmitters with much fewer process switches. In this section, the system initiation, isolation, and interlock logic are briefly reviewed.

\subsubsection{System Automatic Initiation}

The RCIC system is automatically initiated whenever the water level in the reactor vessel decreases to a low level condition (Level 2). This causes the following responses:

1. The turbine steam supply valves open to admit steam to the turbine.

2. The normal discharge path to the reactor is aligned.

3. The test return line is isolated.

4. The discharge valve to the feedwater piping opens.

5. The turbine flow control system throttles the turbine governor valve and the attached lube oil pump builds up oil pressure as the speed of the turbine increases until the automatic setpoint flow rate on the flow controller is reached.

NUREG-0737, Clarification of TMI Action Plan Requirements, Item II.K.3.13 requires the RCIC initiation logic be modified so that RCIC will restart on low water level. Previously, if the RCIC tripped on high water level, it would not automatically restart when the low water level was reached, unlike the HPCI system.

\subsubsection{RCIC System Isolation}

The RCIC system continues to operate unless one of the following conditions occurs:

1. The system is manually secured.

2. Automatic isolation occurs.

3. RCIC turbine trip occurs.
The steam supply to the RCIC turbine is automatically isolated upon the following conditions:

1. RCIC equipment area high temperature.

2. RCIC high steam flow after a time delay.

3. Low steam supply pressure.

4. Exhaust diaphragm high pressure.

The RCIC System also can be isolated from the control room by depressing the manual isolation pushbutton.

An isolation signal causes the following automatic actions:

1. The isolation signal seals in.

2. The inboard and outboard RCIC steam supply containment isolation valves shut.

3. The suppression pool suction valve shuts.

4. The RCIC turbine trip throttle valve trips.

5. The RCIC pump discharge valve shuts.

6. The RCIC pump minimum flow recirculation valve shuts.

\subsubsection{RCIC Turbine Trip}

The RCIC turbine automatically trips upon the following conditions (i.e., the turbine trip throttle valve closes):

1. Turbine overspeed

2. High turbine exhaust pressure

3. Low pump suction pressure

4. Automatic isolation signal

a. High area temperature

b. Steam line high differential pressure

c. Steam supply pressure low

d. Exhaust diaphragm high pressure. 
5. Reactor vessel high water level. If low water level (Level 2) is reached again, the steam isolation valve automatically reopens.

The RCIC turbine may be tripped by depressing the turbine trip pushbutton in the control room.

\subsubsection{Valve Operation}

All the motor-operated valves (MOVs) and air-operated valves (AOVs) are controlled by hand switches located on the panel, which have either of three positions, AUTO/CLOSE/OPEN, or two positions, CLOSE/OPEN. In the AUTO position, the valve opens or closes upon receipt of a signal from transmitters, resistance temperature detectors (RTD), process switches or interlock systems.

Important MOVs are provided with valve motor protection devices for overload protection, which are classified as circuit breakers in this report following the NPRDS designation. Thus, it should be noted that most of the circuit breakers in this report are in fact valve motor protection devices. (See Section 5.1.3.5).

\subsection{System Interfaces and Boundaries}

\subsubsection{RCIC Room Cooling}

Long term operation of the RCIC system may require space cooling to maintain the pump room temperature within allowable limits. As discussed above, the turbine will isolate when the temperature in the area is high. Cooling the room requires service water and $\mathrm{AC}$ power for the fans and service water system. NUREG0737, Item II.K.3.24 required licensees to confirm that space cooling is adequate for at least 2 hours after a complete loss of off-site AC power.

\subsubsection{Main Steam System}

The RCIC system steam supply line is connected to one of the main steam lines upstream of the inboard main steam isolation valve. The boundary of the RCIC System is considered to be the connection of the steam supply branch line.

\subsubsection{Condensate and Feedwater System}

The normal suction source for the $\mathrm{RCIC}$ System is the Condensate Storage Tank (CST). The RCIC system starts at and includes the CST Isolation Valve.

\subsubsection{Primary Containment System}

The alternate suction source for the RCIC System is the suppression pool. Thus, the RCIC system starts at and includes the first isolation valve in the line from the suppression pool to the pump suction. Also, the RCIC pump minimum flow line and the RCIC turbine steam exhaust both are routed to the pool. The RCIC system ends at the turbine exhaust to suppression pool isolation valve, and the minimum flow to suppression pool valve.

\subsubsection{Residual Heat Removal System}

In some plants, the RCIC steam supply line can direct steam to the Residual Heat Removal (RHR) system heat exchangers for the steam condensing mode of RHR. Condensate may also be returned to the reactor vessel using the RCIC pump, providing a closed circuit cooling loop which conserves the reactor coolant and limits the increase in temperature and volume of the suppression pool. Decay heat can thereby be transferred to the service water system, instead of to the suppression pool. The RHR steam condensing mode has been deleted at many plants, either physically or procedurally. 
Additionally, the RHR system operates in the suppression pool cooling mode to maintain the temperature of the suppression pool after HPCI or RCIC turbine discharge to the pool, allowing extended operation of the RCIC system.

\subsection{Back-up Systems to RCIC}

The High Pressure Coolant Injection (HPCI) System, in most BWR 3 (except Millstone 1) and BWR 4 designs, and the High Pressure Core Spray (HPCS) System, in BWR 5 and 6 designs, have functional interfaces with the $\mathrm{RCIC}$ system because both back up the isolation cooling function of RCIC system. Each system is automatically started upon low water level (Level 2) in the reactor vessel. These systems are physically independent, however. 



\section{SAFETY SIGNIFICANCE OF THE RCIC SYSTEM}

As discussed previously, the RCIC System provides makeup water to the reactor vessel of a BWR for core cooling when the reactor is isolated from the main condenser with the feedwater system unavailable. The RCIC system is one of several systems available to provide coolant injection, as discussed in Section 2. Additionally, during accidents, other nonemergency core cooling systems can be lined up to inject into the reactor pressure vessel, such as the service water, fire water, control rod drive hydraulic (CRDH) system, and the condensate system. This section discusses the safety significance of the RCIC system.

\subsection{Review of Probabilistic Risk Assessment Information}

The high pressure injection function (i.e., HPCI/HPCS, RCIC and CRDH) contributes to five of the eight representative accident sequences developed in NUREG/CR-5692, Generic Risk Insights for General Electric Boiling Water Reactors (Ref. 15). These sequences include station blackout with shortand intermediate-term failure of high pressure injection, loss of high pressure injection and failure to depressurize, anticipated transients without scram (ATWS), and unisolated LOCA outside containment. The representative sequences developed were based on the accident sequence core damage frequency of seven PRAs.

RCIC contributes to four of the five sequences, as this system does not have adequate injection capacity to prevent core damage in ATWS sequences. Station blackout is a major contributor to core damage frequency, accounting for as much as $98 \%$ at Grand Gulf, and $49 \%$ at Peach Bottom (Ref.16). RCIC is very important to the BWR 5 and 6 plants in SBO sequences because it is the only system that is independent of AC power. The BWR 5 and 6 plants have a motor-driven, high pressure core spray system instead of the turbine-driven, high pressure coolant injection system found in earlier plants.

At Grand Gulf, the total core damage frequency may be reduced by $48 \%$ if the probability of the RCIC pump failing to run was reduced to zero (Ref.16). Although the RCIC system is independent of AC power, its operation depends on DC power and the selfcooled pumps depend on moderate temperatures in the suppression pool for continued operation. During a station blackout, RCIC and HPCI typically fail in approximately 10 hours due to depletion of the DC battery, loss of room cooling, or high turbine exhaust pressure. Short-term failure of the RCIC system is primarily due to failures of the pump hardware and unavailability due to testing and maintenance. RCIC contributes to the unisolated LOCA outside containment sequence because $33 \%$ of the piping failures are postulated to occur in high pressure injection systems.

The high pressure injection function is of high importance when considering its contribution to plant risk. Other systems with high risk significance include the emergency AC power and the Reactor Protection System. Although the high pressure injection function is of high importance, the RCIC system itself is of medium risk importance because of the multiple systems available that can provide vessel makeup at high pressure (e.g., HPCI/HPCS and CRD). Other systems with medium risk importance are the standby liquid control, automatic depressurization system (ADS), service water, and $D C$ power systems.

\subsection{Review of Bulletins, Generic Letters, and Information Notices}

Before beginning the aging analysis, NRC Bulletins, Generic Letters, and Information Notices were reviewed to identify any past or present regulatory concerns about aging degradation of the RCIC system. 
Among the NRC communications, IE Information Notice 82-26 (Ref. 17) clearly addresses aging of the RCIC system, describing numerous failures of the RCIC turbine exhaust check valves due to wear caused by improper operation and system design. The valves were designed for full flow, and testing the system at low flows damaged the discs; in some cases, the discs separated from the hinge and lodged in the exhaust line. The RCIC turbine trips on high exhaust pressure, making this failure mechanism particularly significant for system availability and reliability.

Additionally, Information Notices 86-14 (Ref. 18) and 90-45 (Ref. 19) describe problems with overspeed trips of turbine-driven auxiliary feedwater pumps at PWRs, which can cause overpressurization of the AFW system. The Terry Turbine auxiliary feedwater pumps are similar to the RCIC pumps, and subject to the same failure mechanism. Most of the overspeed failures reported were due to operational and design deficiencies; however, failure of the overspeed trip mechanism was also attributed to damage of the tappet balls.

There are numerous NRC communications on generic design deficiencies; RCIC is among the systems affected. Those communications, which are not actually aging-related but rather test and maintenance-related include IE Bulletin 85-03: "Motor-Operated Valve Common Mode
Failures During Plant Transients Due to Improper Switch Settings". (Ref.20) and Generic Letter 89-10: "Safety-Related Motor-Operated Valve Testing and Surveillance" (Ref.21). These communications relate to NRC requirements that licensees develop and implement a program to ensure that valve motoroperated switch settings of torque, torque bypass, position limit and overload for MOVs in all safety-related systems are selected, set, and maintained so that the valves will operate under design-basis conditions for the life of the plant. These requirements are based on information that industry sizing equations for safety-related MOVs may not be conservative for all conditions.

IE Information Notice 82-16: "HPCI/RCIC High Steam Flow Setpoints" pertained to discovery of non-conservative, high differential pressure settings for steam flow on the HPCI system. The high steam flow trip is provided to detect a break in the HPCI steam supply line, and initiate closure of the steam supply isolation valves. There is a similar feature in the RCIC system. This is a design-related problem because the setpoints are initially determined by calculation. They actually depend upon the exact configuration of the elbow tap holes and associated instrumentation, and are not always accurately predictable. They must be established by testing at high steam flow conditions. 


\section{OPERATIONAL AND ENVIRONMENTAL STRESSES}

Degradation from aging occurs in materials subjected to certain stresses over time. These processes are well understood when one type of material is exposed to one kind of stress. However, with complex composite materials, or a component made of many different materials (which is the case for most components), and the synergistic effects of several stresses, these processes are difficult to understand. Extensive laboratory testing and material analyses are necessary to characterize these complex phenomena. Also, because aging is timedependent, considerable time would be necessary to completely understand the characteristics of the aging processes in an operating plant.

Aging is a degradation process (or mechanism) which exists at every level in a plant's hierarchy. If unchecked, it can limit the life of a component, system, or structure, and increase the risk to plant safety; therefore, it is important to understand aging phenomena. The following are some typical aging mechanisms which cause deterioration in a material's mechanical strength or physical properties:

- fatigue stress cycles (thermal, mechanical, or electrical),

- wear,

- corrosion,

- erosion,

- vibration,

- radiation damage,

- embrittlement,

- cracking or fracture, and

- accumulation of dirt/foreign material.

Each mechanism can occur in various materials when they are exposed to particular operating and environmental conditions. Abnormal conditions such as mechanical and electrical transients, pipe breaks, exposure to harsh environments or accidents accelerate the aging process, thus weakening the material faster than normal.
This section discusses the operational, environmental, and accident parameters which can degrade the mechanical strength or electrical/chemical properties of components in the RCIC system. These parameters include system and component level stresses, such as those induced by testing, human factors, environmental parameters, and their synergistic effects. The correlation with accident conditions when RCIC system function becomes vital for plant safe shutdown also is discussed.

\subsection{System and Component Level Stresses}

The RCIC system can be used to maintain Hot Standby, or to achieve and maintain Hot Shutdown by operating together with the Suppression Pool Cooling mode of the Residual Heat Removal (RHR) system. The system also provides core cooling during normal reactor shutdown with the normal feedwater system out of service by maintaining sufficient reactor water inventory until the reactor is depressurized to a level where the condensate system can provide makeup to the reactor vessel, or in the event of reactor isolation accompanied by loss of feedwater flow.

During cooldown, the RCIC system can continue to function until the reactor steam pressure to the RCIC pump turbine is approximately 125 psig. However, the RHR system normally would be transferred to the shutdown cooling mode and aligned directly to the reactor vessel at a reactor pressure of $\mathbf{3 5 0}$ pisg, so the RCIC system operation would be terminated at that point.

Additionally, during normal plant operating conditions, the RCIC system is aligned for automatic initiation upon a predetermined low water level in the reactor vessel, and is maintained in a standby condition. Therefore, the effects of operating stresses on various RCIC components are less severe than in a continuously operating system. However, these components experience stresses during periodic operations, as well as during testing. Aging 
mechanisms, such as wear, erosion, physical and electrical property deterioration, and degradation of contact surface typically are attributed to these stresses. LER 296/85-003 reports a typical failure in which the motor operator of a RCIC turbine trip throttle valve would not reopen the valve after testing, which had been necessitated by the unavailability of the High Pressure Coolant Injection system during power operation. The valve operator failed due to a worn brass worm gear.

The standby mode requires the system to remain filled, so that it can be initiated when a reactor vessel low level signal is received. Operation in a standby condition allows various aging-related degradation processes to occur, including corrosion, hardening of polymeric materials and contamination of electrical contact surfaces with dusts and other chemically active agents. In one failure reported to NPRDS, a steam line high flow switch would not hold pressure during a functional testing due to a cracked diaphragm. The diaphragms are made of elastic materials, which harden and eventually crack as they age. Another example of a component failure is a valve that failed a local leak rate test due to corroded internals, which was also reported to NPRDS. Rust and hard scale were found between the seat and the disc, which resulted in an internal leak. LER 254/88011 reported that the meter of a RCIC pump flow controller indicated full pump flow while the system was off, so that the pump would not have increased to full flow if it was initiated. A thin oxidized layer had built up on the contacts of the flow controller's plug connection, resulting in an open circuit.

In summary, because $\mathrm{RCIC}$ is primarily a standby system, its exposure to aging mechanisms such as wear, erosion, and vibration is reduced as compared to continuously operating systems. However, the degradation caused by corrosion and dirt accumulation may be more prevalent due to the stagnant conditions during standby periods.

\subsection{Stresses Induced by Testing}

RCIC system has a test line (typically a minimum flow line) which recirculates flow back to the CST. The system is tested typically once every three months. The operating time in any mode depends on the plant operating schedules, technical specification commitments, and maintenance and surveillance testing. Hence, the total time any component within this system is exposed to operating stresses is far less than its age. Nevertheless, each time the system is used, the high stresses imposed by starting the system or components contribute to their aging-related degradation, for example, starting and stopping the pump. Typical tests on RCIC systems are the following:

- Pump operability test - once/3 months (or monthly if required by the Technical Specifications).

- MOV operability test - once/3 months

- Pump capacity test - once/3 months

- Simulated automatic actuation test once/operating cycle

- Logic system functional test - once/6 months

In addition, other components are tested periodically such as the turbine, valves, and auxiliary components (piping and snubbers) to monitor their performance. These tests encompass valve stroke, motor insulation, bearing vibration, snubber operability, and pipe/valve leaks. All these tests are performed at certain frequencies as predictive measures and at the time of corrective maintenance. Therefore, their frequency varies from plant to plant, depending on the utility's practices and operating experience.

Since the RCIC system is instrumented for monitoring operating conditions, as well as for automatic actuation, setpoint drift is expected to be a dominant failure mechanism for the instrumentation and control components. Vibration of the components and environmental conditions inside the reactor building where most of the system is located may contribute to setpoint drift. 
Some of the operability and functional tests require the associated part of the system or the component to operate (or function) for a period to arrive at a steady-state indication. These stresses, together with normal operating stresses (on demand), contribute to the aging-related degradation in the RCIC system and its components. Certain maintenance tests, such as high-potential electrical testing or hydrostatic tests on piping, could impart more stress than the component is designed to experience normally.

\subsection{Stresses Induced by Human Performance}

Successful operation of the RCIC system requires a great deal of human input that begins with the initial design, manufacture, and installation of the system and its components, and continues throughout the life of the plant. Even with rigorous training programs, humans make errors. Past operating experience verifies that errors in maintenance, installation, and procedures contribute to failure of RCIC system components.

The causes of, and components affected by maintenance errors are very diverse. Any component which requires maintenance at any time in its life is subject to human errors. This category includes virtually all components in the plant; therefore, the potential here is quite large. It is only through rigorous training and the experience of personnel that maintenance errors are kept low. Also, development of and adherence to maintenance procedures is an important contributor to reducing maintenance errors.

Typical maintenance errors include the use of wrong replacement parts, improper tightening of bolts or screws, and improper lubrication of moving components. LER 293/92-003 gave an example in which the inboard main steam supply isolation valve to the RCIC turbine indicated closed but was actually open. The valve could not be closed because the motor operator was detached from the yoke. The yoke attaching capscrews had been insufficiently torqued during maintenance. The maintenance procedure incorrectly specified mild steel for the capscrew material, and the drawing of the valve gave the wrong capscrew size.

Installation errors can occur when the plant is first built, or later, when components are replaced. Examples of installation errors include improper alignment of pumps, which can lead to wear and premature failure of seals and bearings, or incorrect adjustment and calibration of instrumentation, resulting in erroneous readings.

Human errors related to operating procedures also can lead to failures. Since most systems and many components have very complex designs, involving various interlocks and subsystem alignment checks, detailed procedures must be properly written and properly followed, otherwise, the system or component could fail to operate or be severely damaged. For example, LER 333/87-016 reported that, with the plant at $100 \%$ power and the HPCI system unavailable, an automatic isolation of the RCIC system occurred during testing. The operator had inadvertently omitted a step in opening the RCIC inboard main steam supply isolation valve. Realizing the valve was shut, the operator immediately opened the valve and the surge of steam past the high steam flow elbow taps isolated the RCIC system.

Some human errors accelerate the aging processes, and the resulting failures can be considered aging-related. However, because it is difficult to identify this type of aging failure, this study classified all the failures caused by human error as non-aging failures.

\subsection{Environmental Effects}

Most RCIC components, such as the pump and turbine, piping, valves, and instrumentation are located between the primary and secondary containment. The major RCIC component inside the primary containment is the inboard steam 
supply isolation valve, which is exposed to the most severe temperature, humidity, and radiation. Typical values are shown in Table 4.1.

Other RCIC components located in the secondary containment area are exposed to normal temperatures of $21-60^{\circ} \mathrm{C}$, and up to $100^{\circ} \mathrm{C}$ in accidents. The humidity is similar to that of the primary containment. There is no design-basis radiation level for this area.

\subsection{Summary of Stresses}

Unlike a continuously operating system (i.e., component cooling water or service water), the RCIC system mostly remains in standby during normal plant operation, so that wear and erosion are limited. However, the aging degradation caused by corrosion and dirt accumulation may be more prevalent due to the stagnant conditions during the standby periods. Table 4.2 summarizes some of the potential aging mechanisms that are significant to RCIC components. One important source of stress which contributes to RCIC failures is testing. Since RCIC is categorized as a safety-related system, components are more frequently tested to assure their operability, which may place high levels of stress on them, causing premature failures. These insights were used as a baseline for evaluating the results from data analysis discussed in the following sections.

Table 4.1 Typical Environmental Stresses on RCIC Components in Primary Containment

\begin{tabular}{|c|c|c|}
\hline Parameter & Normal & Accident \\
\hline Temperature & $57-66^{\circ} \mathrm{C}$ & $93-171^{\circ} \mathrm{C}$ \\
\hline Relative Humidity & $40-90 \%$ & $100 \%$ (all steam) \\
\hline \multicolumn{3}{|l|}{$\begin{array}{l}\text { Radiation Integrated } \\
\text { over } 40 \text { years: }\end{array}$} \\
\hline Gamma & $1.8 \times 10^{7} \mathrm{rads}$ & $\begin{array}{l}2.6 \times 10^{7} \mathrm{rads} \\
\text { During LOCA } 1.3 \times 10^{6} \mathrm{rads} / \mathrm{hr}\end{array}$ \\
\hline Neutron & $\begin{array}{l}1.8 \times 10^{14} \\
\text { neutrons } / \mathrm{cm}^{2}\end{array}$ & None \\
\hline
\end{tabular}


Table 4.2 Aging Effects on RCIC System Components

\begin{tabular}{|c|c|c|c|c|}
\hline Stress Condition & Aging Effects & Mechanical & Electrical & Inst. \& Control \\
\hline \multirow[t]{6}{*}{$\begin{array}{l}\text { Normal } \\
\text { Operating } \\
\text { Conditions }\end{array}$} & $\begin{array}{l}\text { erosion, wear, } \\
\text { corrosion, } \\
\text { leakage }\end{array}$ & $\mathbf{x}$ & & \\
\hline & $\begin{array}{l}\text { clogging, } \\
\text { blocking, } \\
\text { reduced flow }\end{array}$ & $\mathbf{x}$ & & \\
\hline & $\begin{array}{l}\text { vibrations, } \\
\text { misalignments, } \\
\text { crack growth, } \\
\text { loose or } \\
\text { dislodged pieces } \\
\end{array}$ & $x$ & $\mathrm{x}$ & $\mathrm{x}$ \\
\hline & $\begin{array}{l}\text { mechanical } \\
\text { binding, } \\
\text { distortion, } \\
\text { rupture }\end{array}$ & $\mathrm{x}$ & & \\
\hline & $\begin{array}{l}\text { set point drift, } \\
\text { out of } \\
\text { calibration, loose } \\
\text { connections } \\
\end{array}$ & & $\mathbf{x}$ & $\mathbf{x}$ \\
\hline & $\begin{array}{l}\text { electrical shorts, } \\
\text { grounds, } \\
\text { surface pitting, } \\
\text { erratic } \\
\text { signals/indicators } \\
\end{array}$ & & $\mathrm{x}$ & $\mathbf{x}$ \\
\hline \multirow[t]{3}{*}{$\begin{array}{l}\text { Normal Standby } \\
\text { Conditions }\end{array}$} & $\begin{array}{l}\text { corrosion, } \\
\text { cracks, surface } \\
\text { damage (e.g., } \\
\text { pitting) }\end{array}$ & $\mathrm{x}$ & $\mathbf{x}$ & $\mathrm{x}$ \\
\hline & $\begin{array}{l}\text { burning, shorts, } \\
\text { grounds }\end{array}$ & & $\mathbf{X}$ & $\mathrm{x}$ \\
\hline & $\begin{array}{l}\text { embrittlement, } \\
\text { hardening }\end{array}$ & $\mathrm{x}$ & $\mathbf{X}$ & \\
\hline
\end{tabular}





\section{ANALYSIS OF NATIONAL DATA BASE OPERATING EXPERIENCE}

To characterize the effects of aging on the RCIC system, three different sources of data were analyzed, including the Nuclear Plant Reliability Data System (NPRDS) and Licensee Event Reports (LER), which are national data bases. To supplement and validate these data, plant specific information was obtained and analyzed. Section 6 gives the results of the plant specific data analysis.

Failures reported to the NPRDS and the LERs normally include the cause of failure. Unfortunately, in many cases, the reported causes are the most immediate or apparent cause, and not the root cause. The root cause may often be at the bottom of a causal chain of intermediate failures, which can only be determined after a detailed and complex investigation. Therefore, not all the failures receive root cause analysis.

For this report, the NPRDS narratives and LER abstracts were reviewed by BNL for information which, using engineering judgement, allowed the assignment of a probable intermediate cause, here referred to as the "proximate cause", that was more precise than the reported cause. Although this was only possible for some failures, the additional precision obtained provided further insights into the failure mechanisms for important components.

\subsection{NPRDS Data Analysis}

Between January 1986 to December 1991, there were 920 reported failures in the RCIC systems. Seventy-eight percent of the failures are due to aging, $9 \%$ possibly due to aging, and 13\% due to non-aging causes (Figure 5.1). Therefore, the aging-related failures (aging and possibly aging combined) are almost $87 \%$ of all the failures in the RCIC systems, which clearly indicates that aging is an important issue for this system.

In this section, NPRDS data are analyzed to understand the effects of RCIC component failures on the system and the plant. To further understand the aging characteristics of the system, it is necessary to study the aging effects at the component level. Thus, important components in the system are identified, based on different possible criteria; such information is needed for more effective aging management programs.

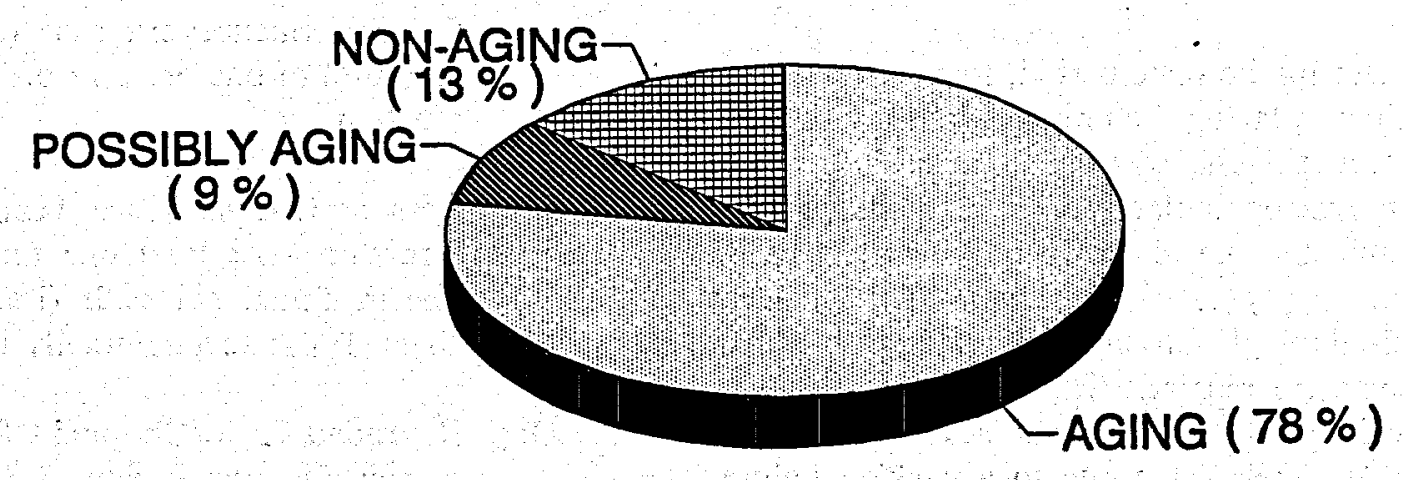

SOURCE : NPRDS (1986 - 91)

Figure 5.1 Fraction of aging-related failures 


\subsubsection{Effects of RCIC Component Aging on Plant Operation}

Aging-related failures of RCIC components affect the system and, in turn, plant operation; in this section, such effects are discussed.

\subsubsection{Effects of RCIC system aging on plant operation}

Most of the 920 reported failures in the RCIC systems did not affect the plant operation. However, in several cases, the plant had to reduce power or take the units off-line due to the aging-related RCIC failures. During the period studied, five aging-related RCIC failures forced the plants to reduce power. All five incidents were due to valve failures. Two of these were caused by the same feedwater inlet outboard testable check valve, which leaked steam due to worn out packing. The third failure occurred during a start-up; a major packing leak on RCIC inboard isolation valve forced the unit to reduce power. The fourth incident was caused by a leak from a pump suction piping pressure relief valve, of which the disc and guide were damaged. The last incident was caused by a RCIC discharge to feedwater check valve, which also had a packing leak. The power had to be reduced to perform corrective maintenance. It was found that steam cutting of the valve body and worn packing were the proximate causes.

During the same period, four valve failures resulted in taking the units off-line. In the first incident, the unit was operating at $60 \%$ power when reactor coolant leaked into the primary containment due to blown packing on a RCIC steam supply isolation valve. This incident required the plant to be placed in cold shutdown to complete repairs. The second incident was caused by a steam leak at a RCIC injection testable check valve due to a packing failure. This incident also resulted in a reactor shutdown. The third incident caused a delay of a plant start-up due to two failed check valves.
The internals of these valves, which are located in the turbine exhaust vacuum relief line, were stuck due to increased friction caused by dirt buildup. These valves are required to be open for increased power operation. The fourth incident was caused by a steam leak in a steam supply valve packing. The steam leak caused a high drywell temperature, and resulted in the unit being taken off-line. It was found that some pitting at the shaft and packing failure due to excessive wear were the proximate causes.

\subsubsection{Effects of component aging on RCIC system function}

NPRDS data contain information on the effect of component failures on the system. This is the effect the failure caused on the ability of the system to perform its intended function whether or not the system was called upon to function during the failure. The following 5 categories of system effects, A-E, in decreasing order of significance are used (Ref. 22):

A: Loss of One or More System Functions - At least one function of each train, channel, etc, of a system has become totally inoperable (e.g., zero flow, zero output, will not move).

B: Degraded System Operation - The system is operable but unable to satisfy the performance criterion (e.g., flow, pressure) of one or more of its intended functions.

C: Loss of One or More Train/Channel Function - At least one function of a system functional path (i.e., train or channel) has become totally inoperable.

D: Degraded Train/Channel - The affected system functional path (i.e., train or channel) is operable but unable to satisfy the performance criterion (e.g., flow, pressure, etc.) of one or more of the path's intended functions. 
E: System Function or Operation

Unaffected - Failure did not affect system function or operation.

Among the effects a component failure caused, the most significant effect should be reported. For instance, the failures of the components in the auxiliary trains may result in a loss of train function or in a degraded train function. In many cases, the loss of auxiliary train function in the RCIC system causes a degradation of the system function, and the failure is reported as a degraded system operation. However, degradation of the auxiliary train function does not usually cause the system degradation, and it is reported as a degraded train. The failures of the components in the main train almost always result in a loss of system function or a degraded system operation.

Since the loss of system function and degraded system operation are the more serious system effects, the combined portion of failures resulting in these effects are plotted for three different reporting periods (Figure 5.2). The percentages of the failures that resulted in these system effects are $22 \%$ for $1986-87,30 \%$ for $1988-89$, and $36 \%$ for $1990-91$. About the same number of plants reported component failures between January 1986 and December 1991 , so it is clear that the effects of the component failures become more and more serious as the components age.

\subsubsection{Component Importance}

For aging management, it is valuable to know which components are more important, i.e., an importance ranking. The number of failures is one possible criterion in determining the importance of components; others are the significance of the failure to the system's function, and also to the safety of the plant. In this section, the important components are selected based on the number of failures, and on their significance to system function.

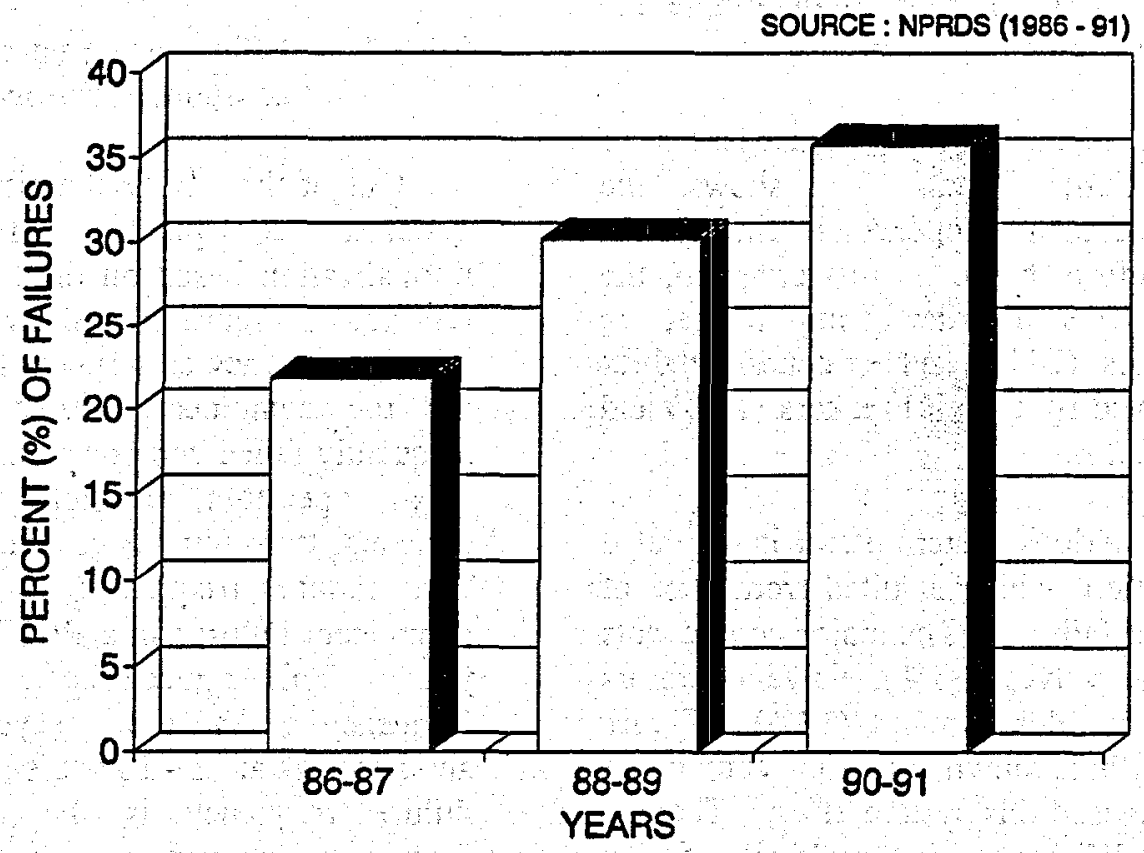

Figure 5.2. Fraction of RCIC component failures that caused loss of system function or degraded system operation 


\subsubsection{Number of component failures}

Of the aging-related failures, valves (30\%), switches/bistables $(20 \%)$, and valve operators (15\%) accounted for more than $65 \%$ of all the failures (Figure 5.3). The number of failures for circuit breakers (8\%) and transmitters $(5 \%)$ were also significant, but the number of failures for turbines (3\%), governors (3\%) and pumps (1\%) are low. The category, "others", includes flow controllers, flow meters, motors, relays, snubbers, and inverters. Thus, based on the number of aging-related failures, the above list shows the importance ranking for RCIC components.

\subsubsection{Effects of component failures on RCIC system}

Figure 5.4 shows the effects of aging-related component failures on RCIC function and operation; $9 \%$ of the component failures caused a loss of system function, the most serious effect. Thus, the number of component failures that resulted in a loss of RCIC system function can be used as a criterion to determine the importance of each component.

Seventy component failures caused a loss of system function; Figure 5.5 shows the contribution of each component to this system effect. Therefore, based on this criterion, the major components, in order of importance, are valve operators (28\%) and switches/bistables $(16 \%)$, followed by circuit breakers (13\%) and governors (10\%).

The next serious system effect is degraded system operation, which resulted from 19\% of the component failures. The major components involved were valves $(37 \%)$, valve operators (26\%), and bistables/switches (14\%). Figure 5.6 gives a breakdown of 153 component failures that caused this system effect. There is one major difference in ranking of the components from the previous one, which is the valves. These two rankings show that most of the valve failures can degrade system operation, but system function is not necessarily lost. The reasons for this will be given later when the failure modes and causes are discussed.

The system lost a train/channel function in $7 \%$ of the component failures, which was mainly due to the failures of switches/bistables (30\%) and circuit breakers (28\%). A degraded train/channel was the result in $29 \%$ of the component failures, due to valves (33\%), bistable/switches $(25 \%)$, and valve operators (14\%).

\subsubsection{Aging Characterization of RCIC Components}

In this section, NPRDS failure data for important RCIC components are analyzed for aging characterization, including the effects of aging on failure frequency, failure modes, and failure causes. It was shown earlier that the important components for RCIC system are valves, valve operators, switches/bistables, circuit breakers, transmitters, governors, turbines, and pumps.

\subsubsection{Effects of aging on RCIC component failure frequency}

Out of the 31 BWR units that have RCIC systems, 26 plants were selected for normalization based on the number of failures reported. Figure 5.7 shows the normalized failure frequency as a function of age at failure for the combined failures of seven most frequently failed components, which are valves, valve operators, bistables/switches, circuit breakers, transmitters, governors, and turbines. The failure frequency is the number of component failures in a RCIC system per unityear. This figure shows that the failure frequency peaks at $3-4$ years, followed by another peak at $11-13$ years. Since this system failure frequency is the combined failure frequency for seven components, it is important to know which components contributed to these peaks. 


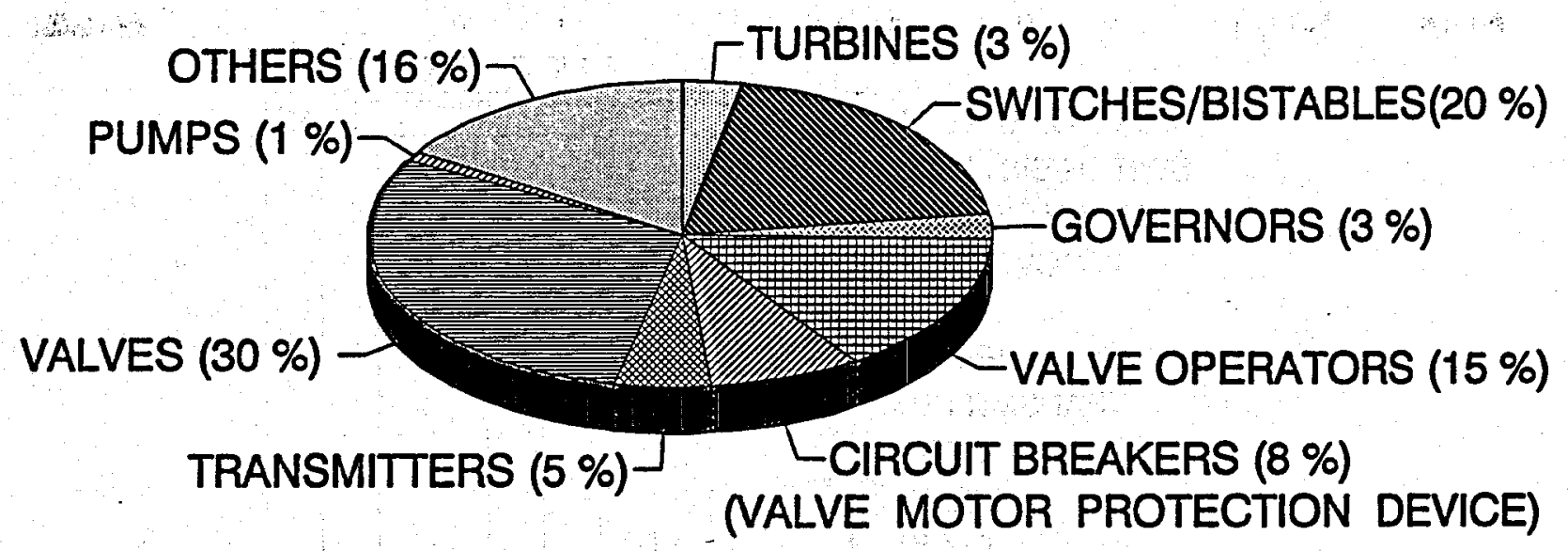

SOURCE : NPRDS (1986 - 91)

Figure 5.3. RCIC components that failed. Source: NPRDS

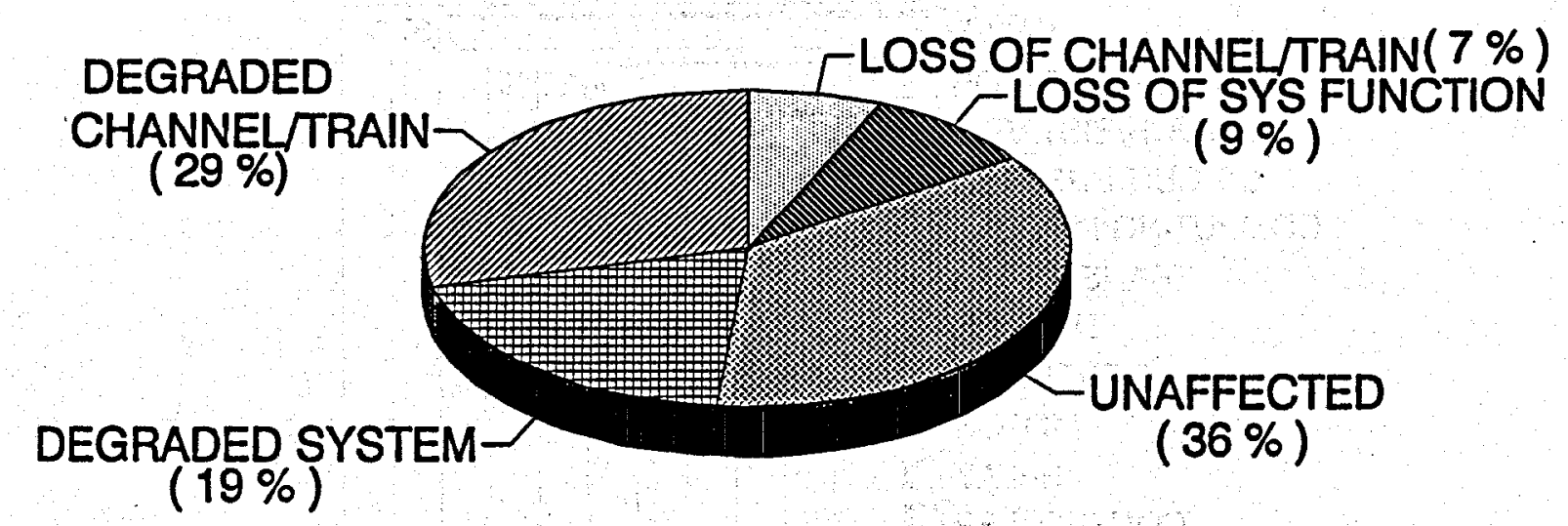

SOURCE : NPRDS (1986 - 91)

Figure 5.4. Effects of component failures on RCIC system 


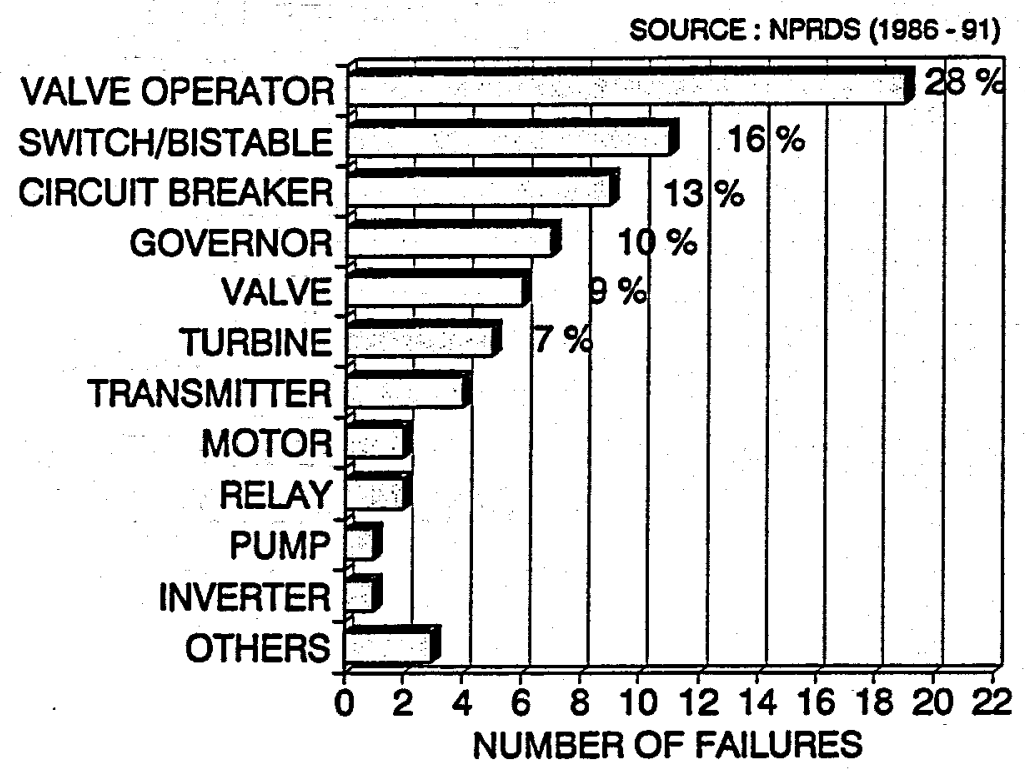

Figure 5.5 Number of component failures that caused loss of system fumction

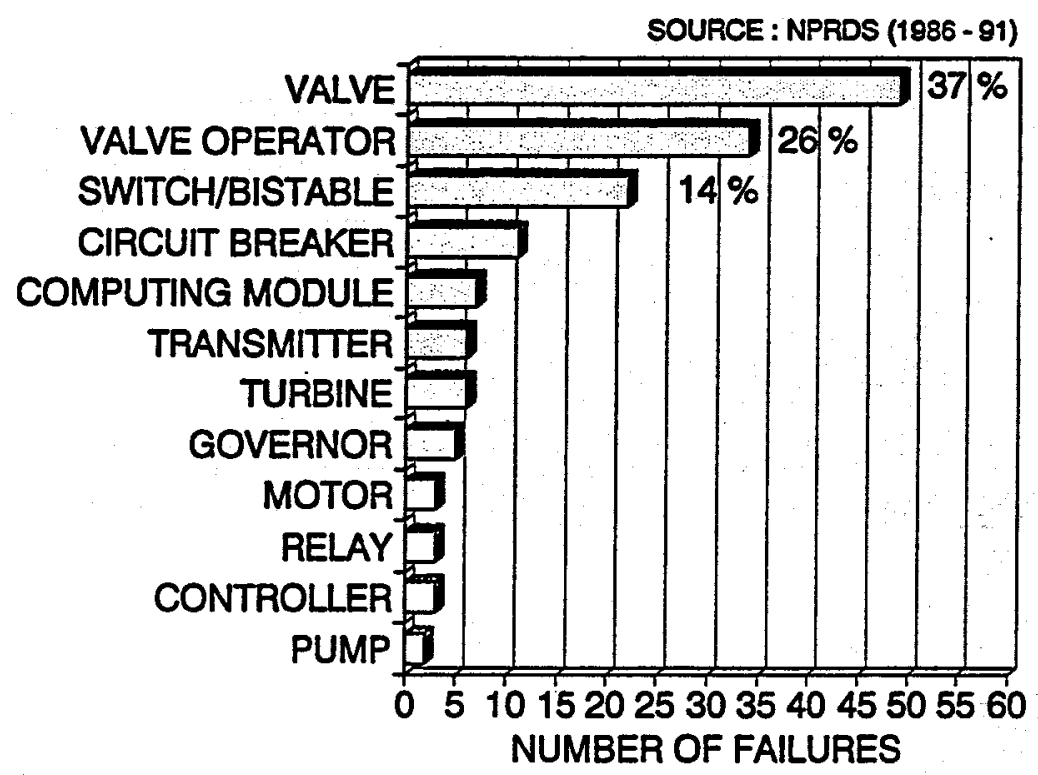

Figure 5.6. Number of component failures that caused degraded system operation 


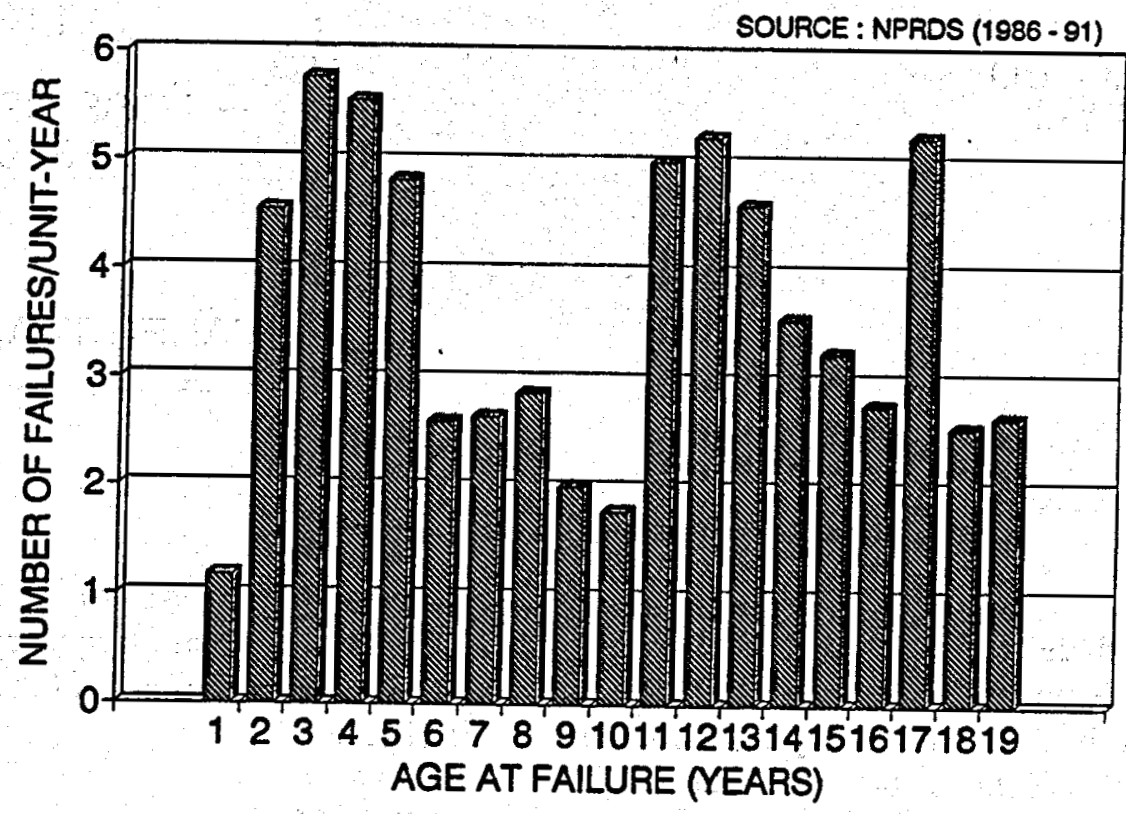

Figure 5.7. Combined failure frequency for seven components normalized with 26 plants

The values for the Age at Failure are from the NPRDS reports. The definition of the field "Age at Failure (in month)" in the NPRDS is the age of the component in month at failure, based on In-Service Date (component) and Failure Start Date.

It is noted that the shape of this failure frequency curve differs from the expected "bathtub curve". Since the system has numerous different components, the total component failure frequency curve is the superposition of that for each component, which, in turn, is the superposition of that for each subcomponent. Also, over the years, many subcomponents and components are repaired and replaced, which affects the shape of the failure frequency curves. In fact, it is believed that one of the possible reasons for the decrease after the peak may be due to the replacement and repair of parts and components. In the following sections, the components of which the failures are responsible for these peaks will be identified.

\subsubsection{Valves}

\section{Effects of Valve Failures on RCIC System}

There were 242 aging-related valve failures during the period studied. Of these, $2 \%$ caused a loss of system function, and $21 \%$ caused degraded system operations (Figure 5.8). The fraction of the valve failures that caused a loss of system function is much lower than that of other components, which will be discussed in more detail later.

Failure Frequency

When the valve failures from 26 plants are normalized to show the failure frequency per unit-year as a function of age at failure, the 


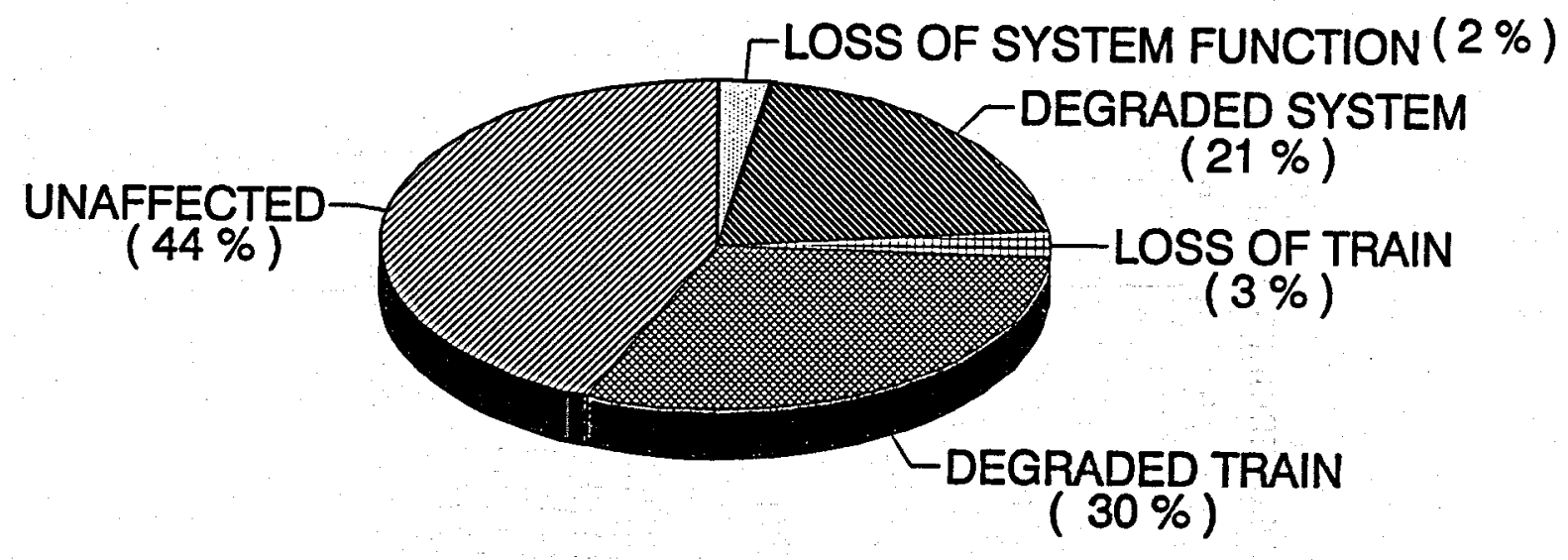

SOURCE : NPRDS (1986 - 91)

Figure 5.8. Effects of valve failures on RCIC system

curve shows three peaks at the ages of 3,11 , and 17 years (Figure 5.9). These peaks coincide with those for the failure frequency curve for the combined seven components in Figure 5.7, which indicates that valve failures are the main contributor to the three peaks in the system failure frequency curve.

There are between 50 and 100 valves in a typical RCIC system, depending on the BWR type. These fall into two major groups, steam valves and water valves, and it is important to know which group is more susceptible to aging degradation. Some of the major water and steam valves are listed in Tables 5.1 and 5.2.

These two groups of valves were analyzed separately; the results are shown in Figures 5.10 and 5.11. As expected, due to the harsher environment, the failure frequencies for the steam valves are much higher than those for the water valves. Since there are fewer steam valves, the actual difference is even higher than these figures show. The failure frequencies for the steam valves (Figure 5.10) stay almost constant until 11 years, when they peak. The failure frequency of water valives psal's at 5 years, after which it drops very low uittil 15 years, when the frequency again begins to increase. The possible reasons for the effects of aging on the failure frequency will be discussed later, using the results of failure mode and cause analysis.

\section{Failure Mode}

The failure modes for the steam valves were analyzed for three age periods, 1-9, 10-14, and 15-18 years, based on the shape of the frequency curve in Figure 5.10. The results show the relative proportion of each failure mode (Figure 5.12). The valve failure mode codes from the NPRDS are the following:

$$
\begin{aligned}
& \text { EL - External Leakage } \\
& \text { IL - Internal Leakage } \\
& \text { FC - Failure to Close } \\
& \text { OR - Failure to Operate as Required } \\
& \text { MO - Found during Testing, Surveillance, } \\
& \quad \text { Inspection, or Maintenance } \\
& \text { FO - Failure to Open }
\end{aligned}
$$

Over time, leakage remained the predominant failure mode. However, there was some increase in external leakage in place of internal leakage as the valves age.

A similar analysis on water valves shows more dramatic effects of aging on failure mode (Figure 5.13). During the early years (1 - 7 years), more than half of the failures were 


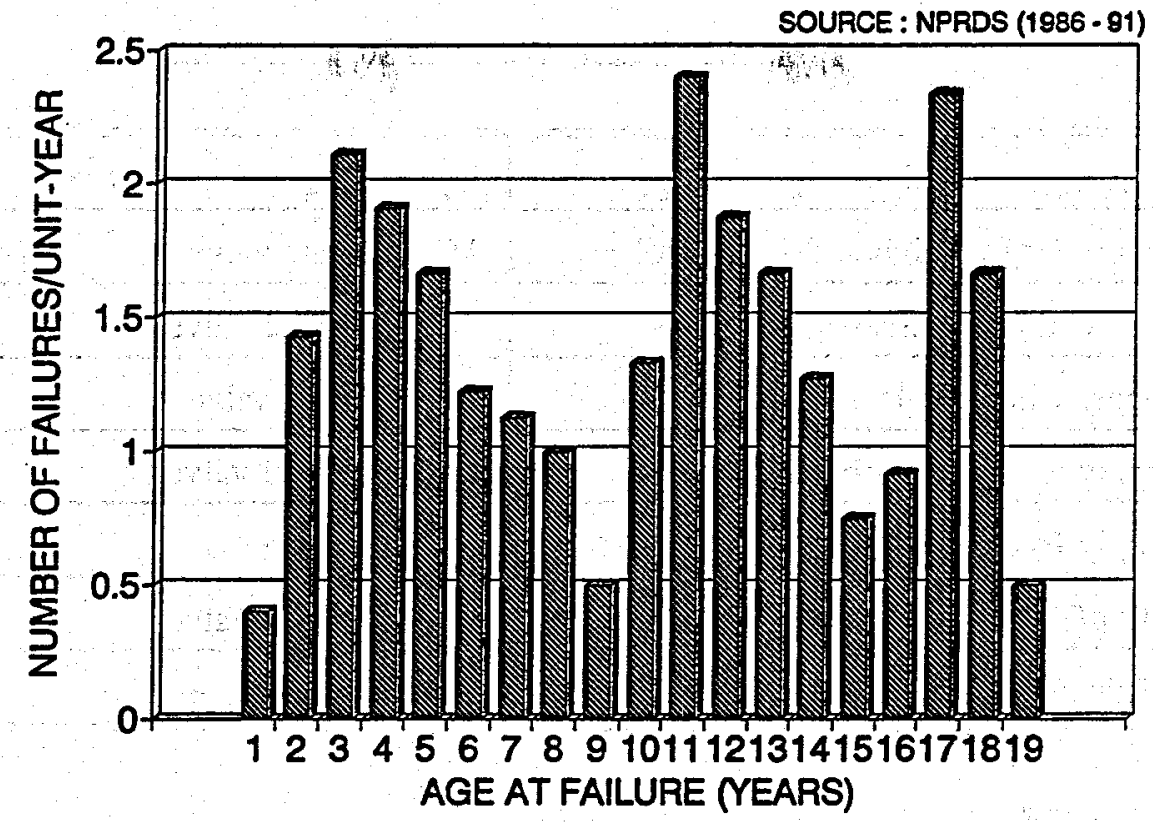

Figure 5.9. Normalized valve failure frequency as a function of age at failure

Table 5.1 Water Valves in RCIC

\begin{tabular}{||l|l|}
\hline \multicolumn{1}{|c|}{ Valve } & \multicolumn{1}{|c|}{ Type } \\
\hline Pump Suction from CST Valve & DC MO gate valve \\
\hline Pump Suction from Suppression Pool Valve & DC MO gate valve \\
\hline Injection Shutoff Valve & DC MO gate valve \\
\hline Minimum Flow to Suppression Pool Valve & DC MO globe valve \\
\hline Inboard Test Return to CST Valve & DC MO globe valve \\
\hline Outboard Test Return to CST Valve & DC MO globe valve \\
\hline Test Return FCV to CST & AO globe valve \\
\hline Water to Turbine Lube Oil Cooler Valve & DC MO globe valve \\
\hline Steam Supply Inboard Drain Valve & AO globe valve \\
\hline Steam Supply Outboard Drain Valve & AO globe valve \\
\hline Steam Supply Drain Trap Bypass Valve & AO globe valve \\
\hline Turbine Exhaust Inboard Drain Valve & AO globe valve \\
\hline Turbine Exhaust Outboard Drain Valve & AO globe valve \\
\hline CST = Condensate Storage Tank & FCV= Flow Control Valve \\
MO= Direct Current & AO \\
\hline
\end{tabular}


Table 5.2 Steam Valves in RCIC System

\begin{tabular}{||l|l||}
\hline \multicolumn{1}{|c|}{ Valve } & \multicolumn{1}{c|}{ Type } \\
\hline Steam Supply Drywell Inboard Isolation Valve & AC MO gate valve \\
\hline Steam Line Warmup Valve & AC MO globe valve \\
\hline Steam Supply Outboard Isolation Valve & DC MO gate valve \\
\hline Steam Supply to RCIC Turbine Valve & DC MO globe valve \\
\hline Steam Supply Bypass Valve & DC MO globe \\
\hline Turbine Trip/Throttle Valve & DC MO globe valve \\
\hline Turbine Exhaust to Suppression Pool valve & DC MO gate valve \\
\hline
\end{tabular}

AC $=$ Altemating Current

MO $=$ Motor Operated

$D C=$ Direct Current

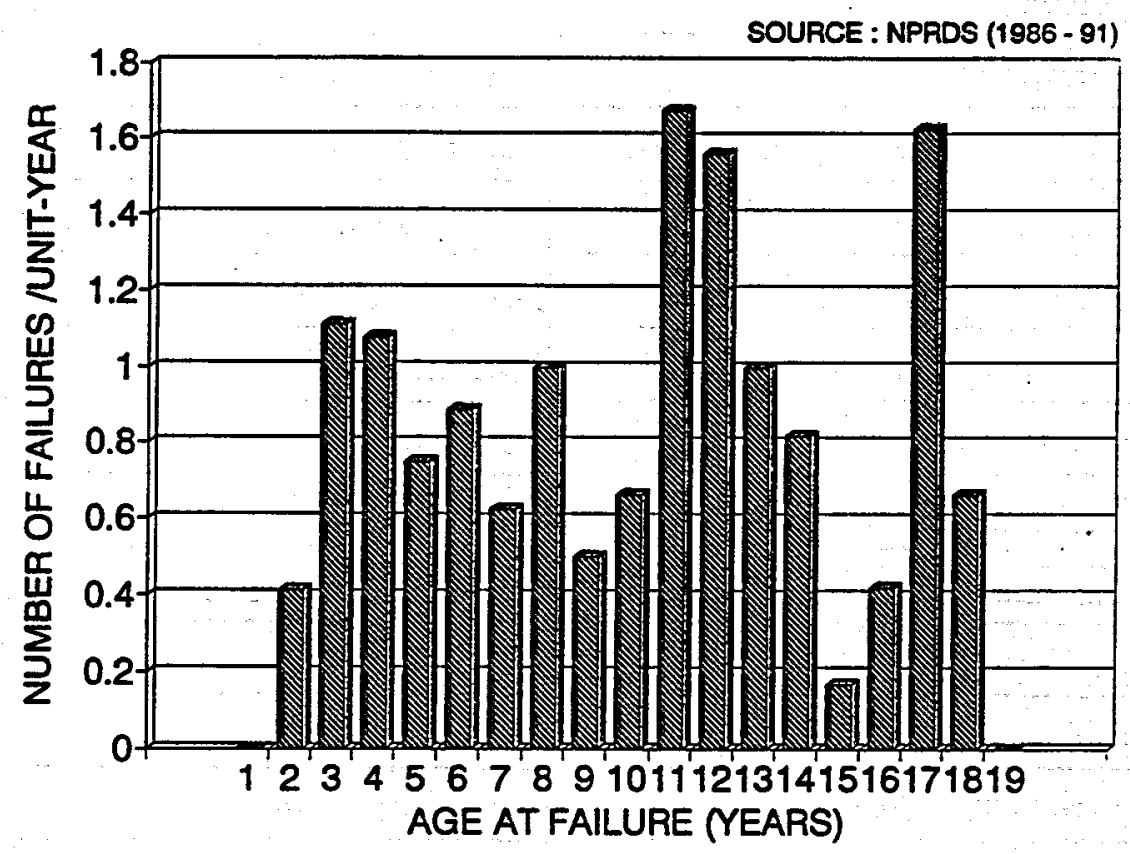

Figure 5.10. Normalized steam valve failure frequency as a function of age at failure 
internal leakage, but, for older valves (12 - 19 years), about $80 \%$ of the failures were external leakages. This indicates that the failure causes for these two periods are different, which will be discussed next.

\section{Failure Cause}

Figure 5.14 shows the failure causes for steam valves for the three different periods. The NPRDS cause codes are the following:

AD - Normal/Abnormal Wear

BE - Dirty Internals
BC - Out of Mechanical Adjustment

BB - Mechanical Damage/Binding

BD - Aging/Cyclic Fatigue

BG - Corrosion

As the valves get old, there are increased failures caused by dirty internals, out of mechanical adjustment, mechanical damage, and corrosion. However, between 50 and $70 \%$ of all the valve failures in the NPRDS data are categorized as normal/abnormal wear. This description indicates that the failure was due to aging, but it is not specific enough to provide more useful information.

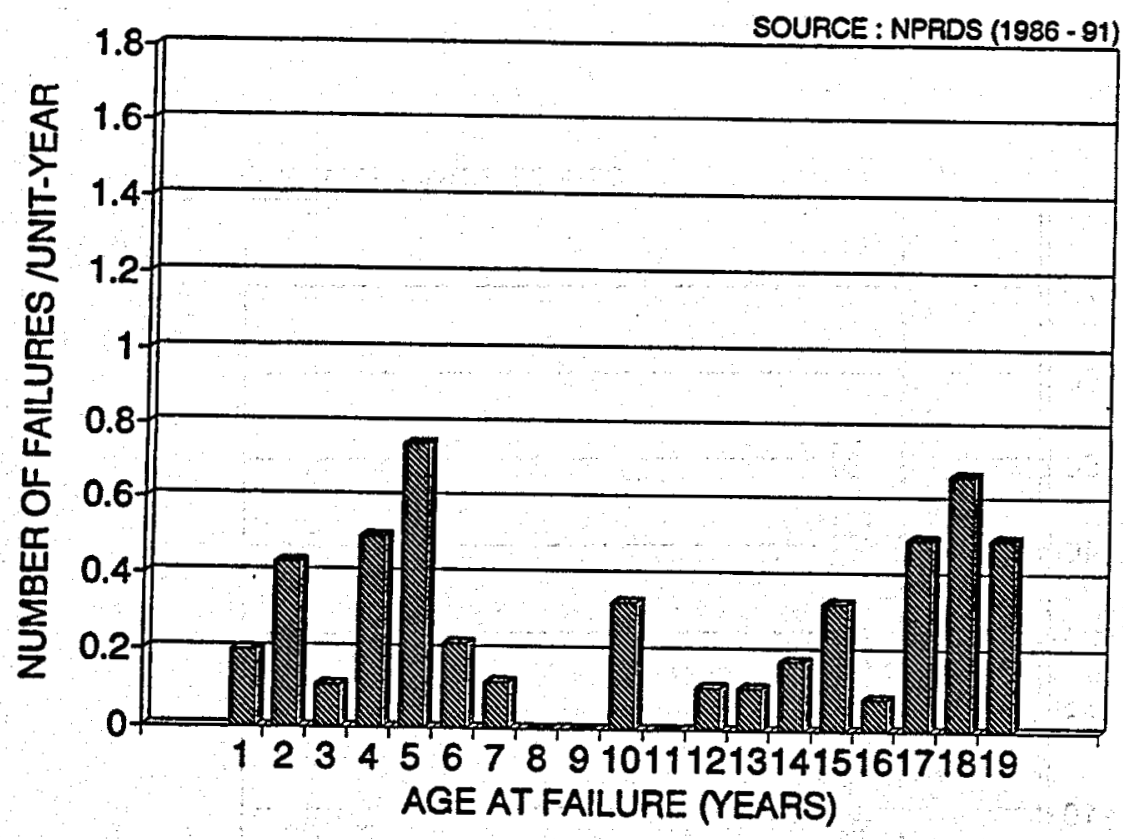

Figure 5.11. Normalized water valve failure frequency as a function of age at failure 


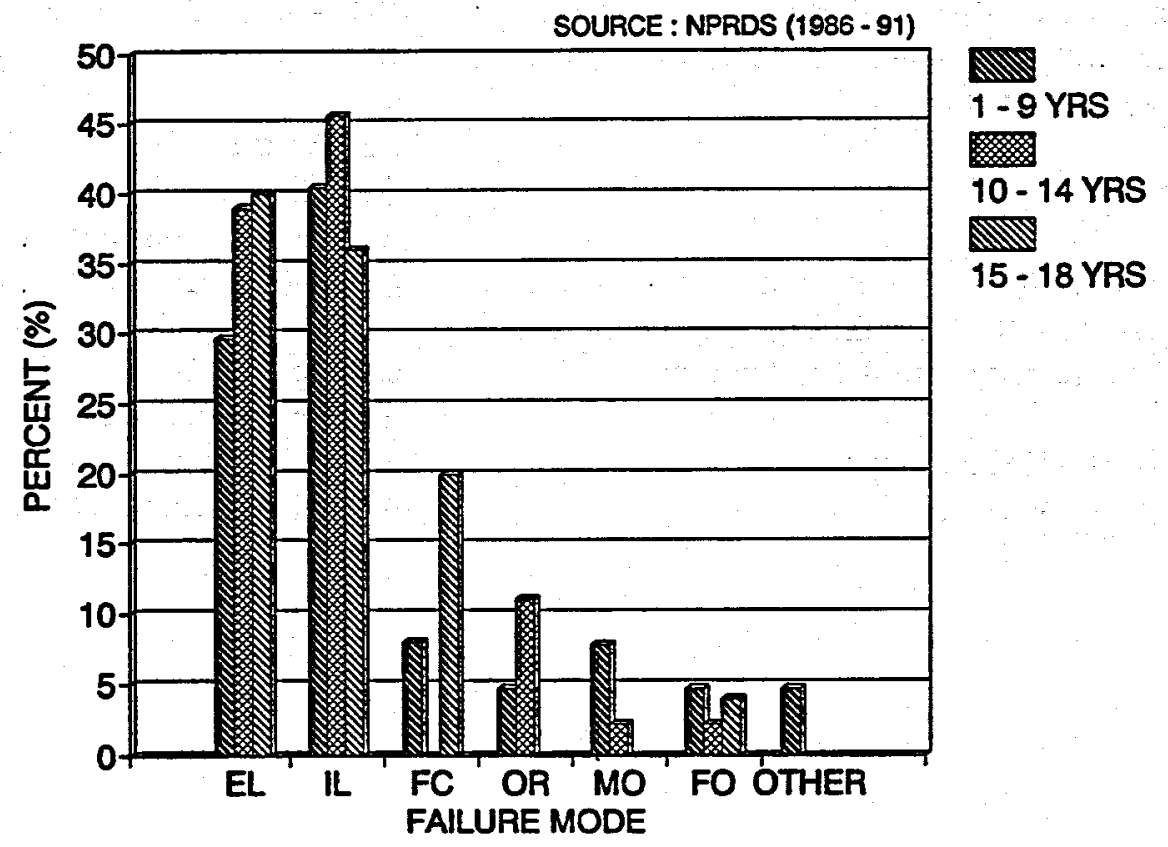

Figure 5.12. Failure modes for steam valves

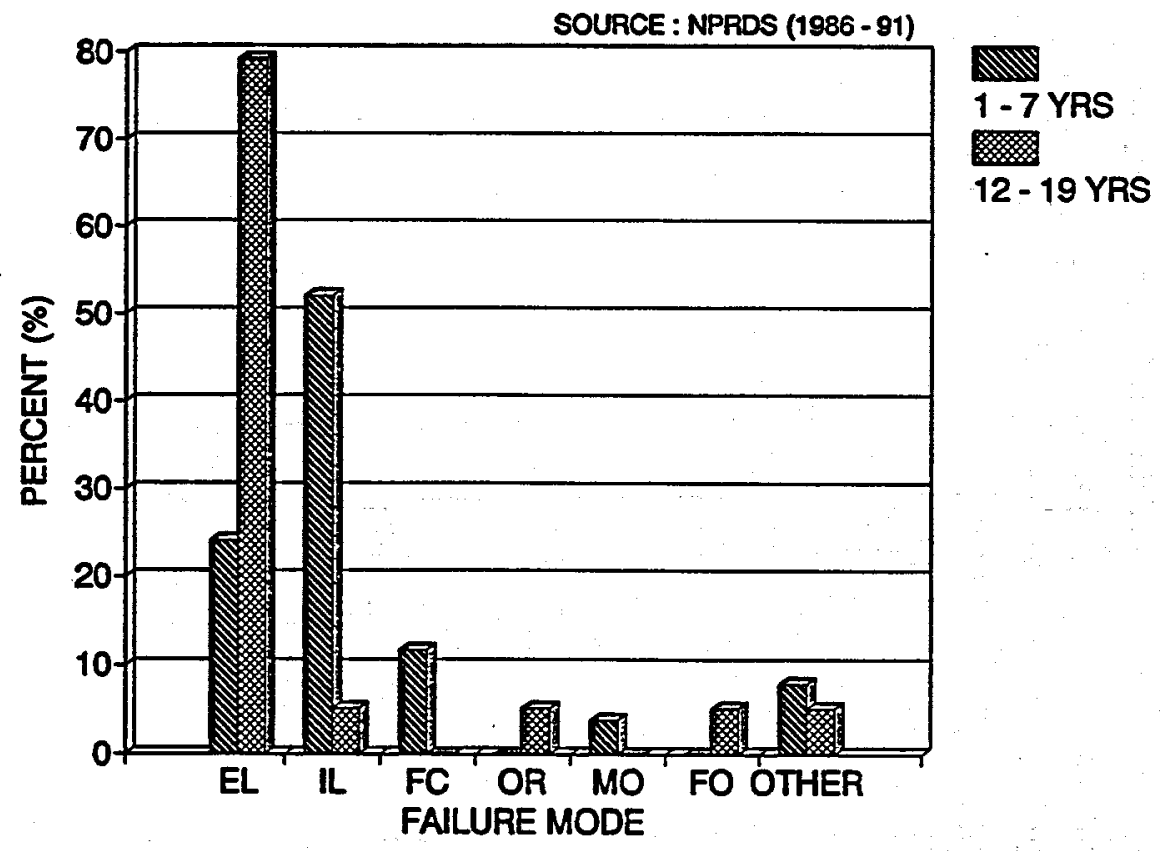

Figure 5.13. Failure modes for water valves 


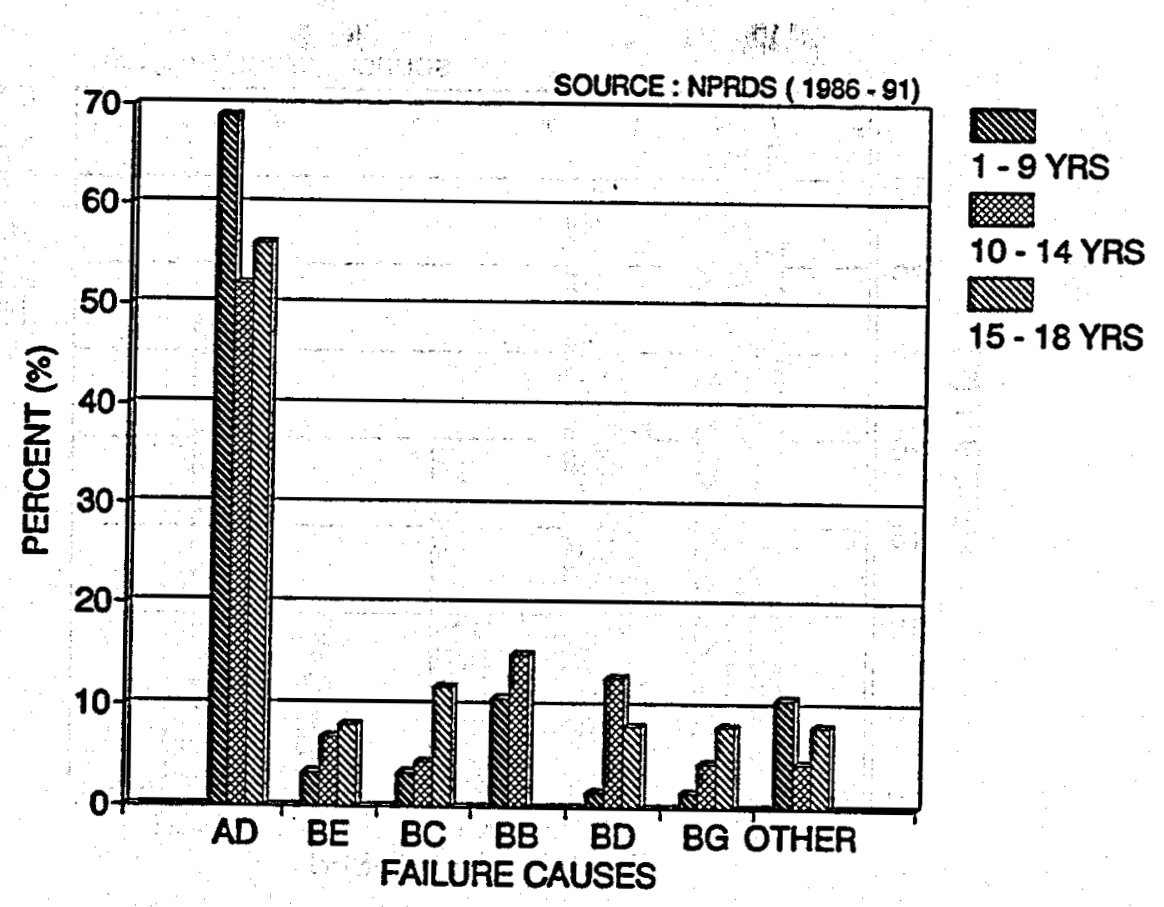

Figure 5.14. Failure causes for steam valves

The proximate causes developed by BNL provide more detailed information about the failures (Figure 5.15). The BNL codes for the proximate causes are the following:

WS - Worn Seat/Disc

WP - Worn Packing

CI - Corrosion Product or Dirt Buildup

WG - Worn Bonnet Gasket, Worn Gasket

Others in the figure include out of adjustment packing, worn wedge, worn seal ring, worn tappet nut, worn cylinder wall, broken or damaged stem, and worn hinge pin.

In the early ages ( 1 - 9 years), worn seat caused about $37 \%$ of the steam valve failures, worn packing about $22 \%$. For the older steam valves (15 - 18 years), worn packing caused about $35 \%$, and worn seat about $30 \%$. In addition to increased packing problems for the older valves, corrosion product buildup and worn gaskets become more important, causing $20 \%$ and $10 \%$ of the failures, respectively. These proximate causes may explain the increased failure frequency at 17 years shown in Figure 5.10.

These proximate causes also explain the failure modes shown in Figure 5.12. The increased external leaks are caused by more failures due to worn packing and worn gaskets, while a slight decrease in internal leaks in later years is due to fewer failures caused by worn seat.

Figure 5.15 also shows that worn gasket was the proximate cause for about $10 \%$ of the steam valve failures after 15 years, but was not identified earlier.

The effects of aging on the failure mode of water valves are quite dramatic. During the early years, external leaks and internal leaks account for about $23 \%$ and $52 \%$ of the failures, respectively (Figure 5:13). In later years, external leak is the failure mode for almost $80 \%$ of the failures. This significant effect of aging on 


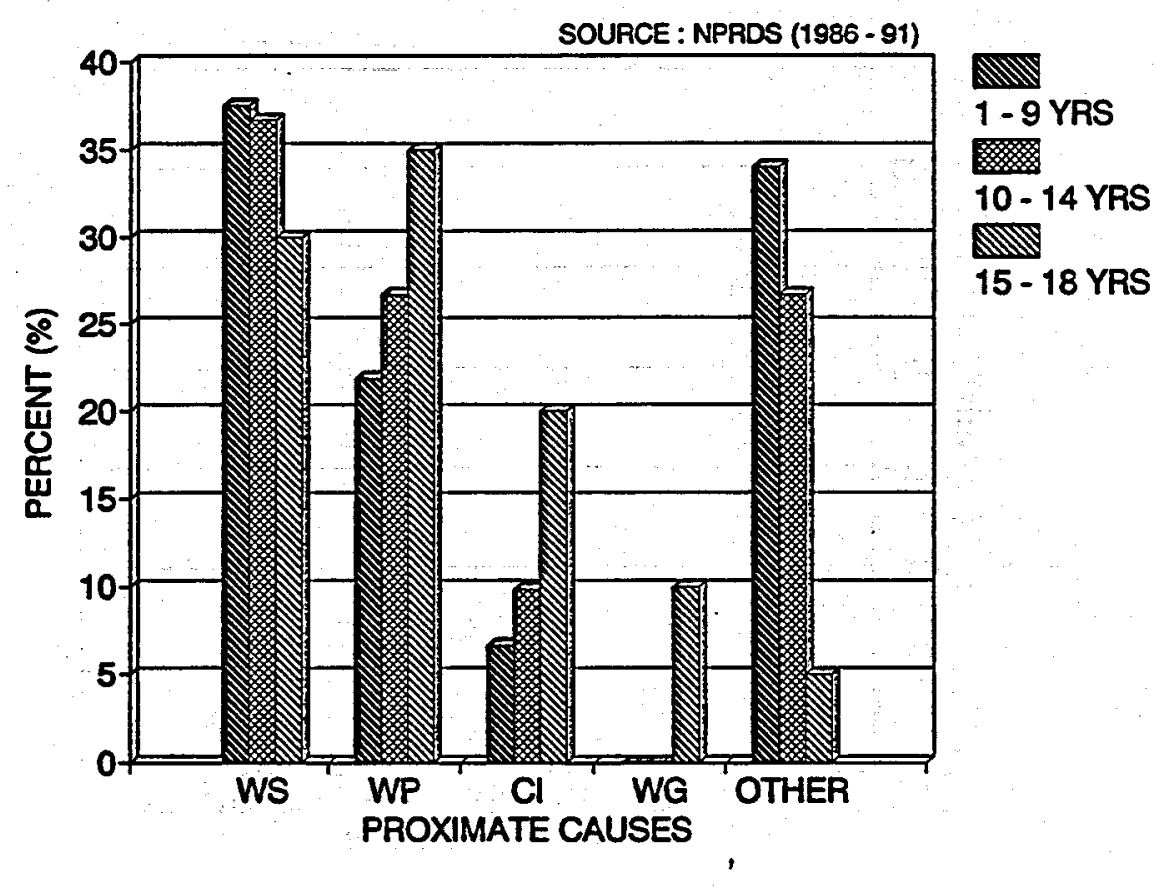

Figure 5.15. Proximate causes for steam valve failures

failure modes may be explained by their proximate causes. Figure 5.16 shows that failures caused by worn packing and worn gasket increased significantly at later years, from $16 \%$ to $35 \%$ and from zero to $24 \%$, respectively, while the portion of the failures due to worn seat decreased from about $45 \%$ to about 12\%. The analysis for proximate causes for water valves also show that gaskets begin to fail after about 12 years, causing about one quarter of the failures.

The analyses of failure modes and causes may explain the different shapes of the failure frequency curves between steam and water valves. For the water valves, in the earlier years, the main failure mode is the internal leak caused by worn seat and accumulation of corrosion products; however, in the later years, the main failure mode is the external leak caused by worn packing and worn gaskets.
Thus, it seems to take some years until packing and gaskets age and fail for the water valves. On the other hand, for steam valves, the main failure modes stay about the same over 19 years, with internal and external leaks contributing almost equally. This is mainly because packing failures start much earlier than those for the water valves, and continue to increase, causing the failure frequency of the steam valves to stay higher than that of the water valves. Since packing materials are usually PTFE, Aramid, and graphite, high temperature accelerates the aging degradation processes (Ref. 23).

\subsubsection{Valve operators}

\section{Failure Frequency}

The failures of valve operators caused approximately $15 \%$ of the RCIC system component failures (Figure 5.3). Figure 5.17 shows the effects of aging on the failure 


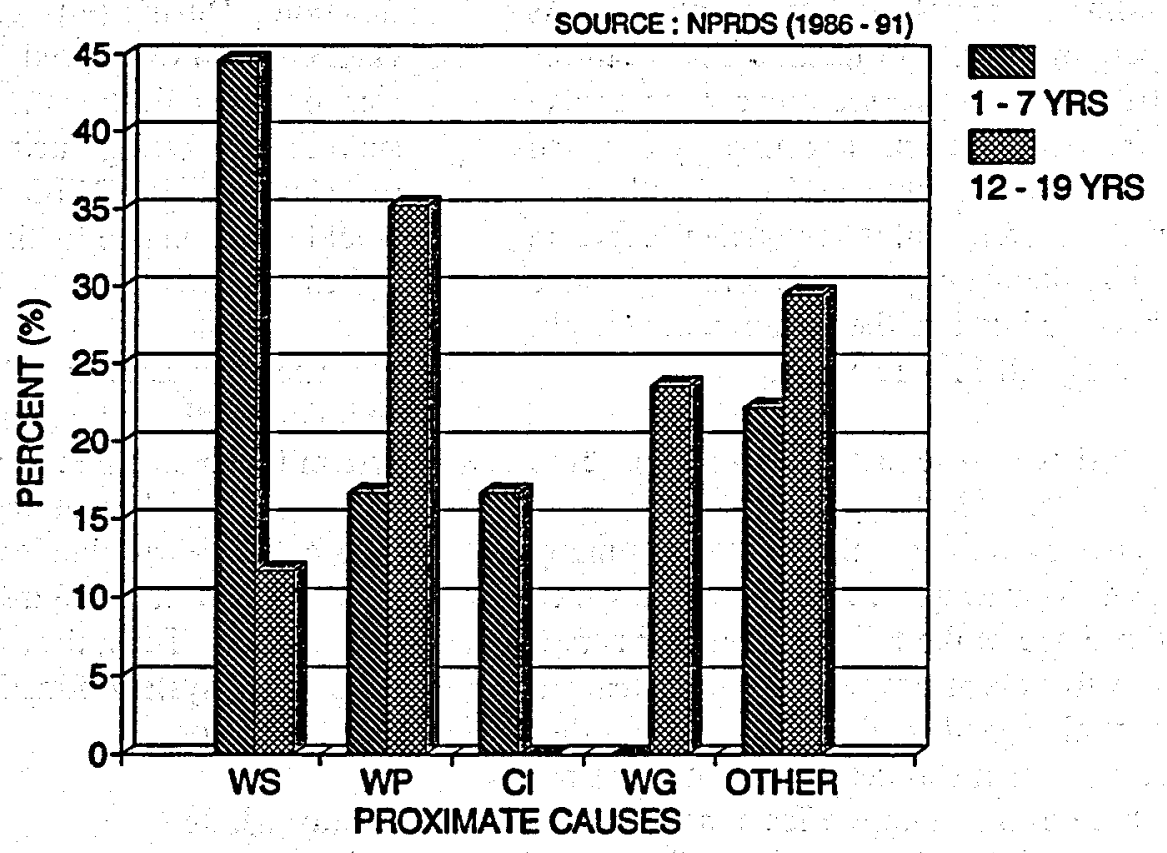

Figure 5.16. Proximate causes for water valve failures

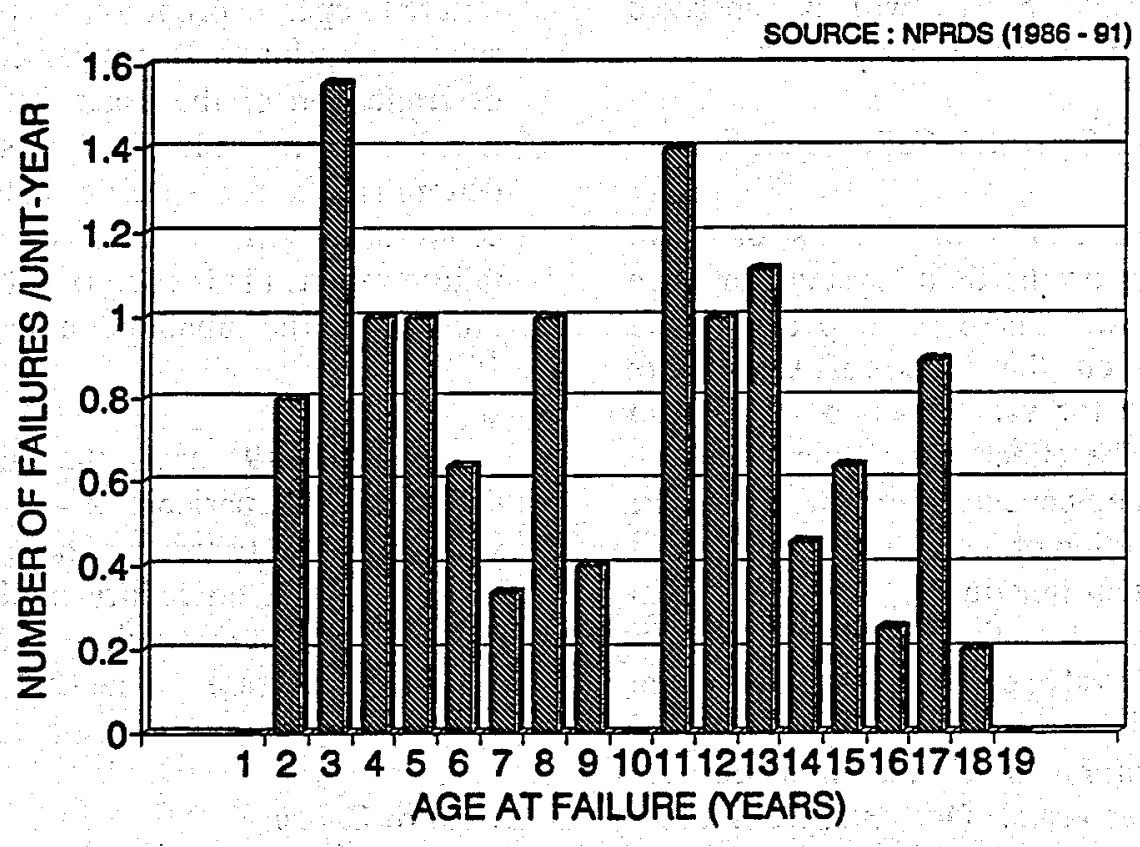

Figure 5.17. Normalized failure frequency for valve operators as a function of age at failure 
frequency, plotting the number of valve operator failures per unit-year as a function of component age at failure, normalized for 26 plants. As valve operators age, no dramatic change in the failure frequency can be seen, except that there are two frequency peaks, at around 3 years, and around 11 years. These peaks coincide with those in the system failure frequency curve in Figure 5.7, indicating that failures of valve operators contributed to the system failure peaks at $3-4$ years and $11-13$ years.

A valve operator has several subcomponents, which have different aging characteristics; over the years, many subcomponents are repaired and replaced, which affects the shape of the failure frequency curve. Also, the valve operators receive more frequent periodic testing and maintenance than other components, which can detect the aging-related failures before the aging effects accumulate. These may explain why the failure frequency curve is not a typical bath-tub curve and why the failure frequency decreases after the peaks. To understand what caused the two peaks, the failure modes and causes will be analyzed separately for different age groups next.

Effects of Valve Operator Failures on System

Figure 5.18 shows the effects of valve operator failures on the RCIC system for three different periods. These three periods were selected based on the shape of the failure frequency curve for valve operators shown in Figure 5.17. The effects of failures got more serious as the components age; a trend can be seen that the fraction of the failures that resulted in a loss of system function or degraded system operation increased as the valve operators got older. When the valve operators are older, from 14 - 19 years, about $20 \%$ of the failures caused the loss of system function, which is about twice that of the earlier years. One example is a loss of system function caused by a RCIC steam outboard isolation valve which would not open during an in-service inspection. The proximate cause was the failure of a motor. Another example is a failure of a turbine trip and throttle valve, which resulted in a loss of system function. During testing, this valve would not open due to a overspeed trip limit switch which was out of adjustment. In another incident, surveillance testing during the refueling outage revealed that the RCIC pump discharge valve would not open due to dirty contacts in the limit switch.

These examples show that the valve operators in the main train are important to the system function. In fact, valve operators caused the largest number of loss of system function failures; $28 \%$ of the loss of system function were due to the failures of valve operators (Figure 5.5). Thus, the aging of valve operators affects the system function and, in turn, the plant operation.

\section{Failure Mode}

The major valve operator failure modes are failure to operate as required, failure to close, and failure to open. An additional failure mode, failure to operate properly, was used for failures submitted prior to December 31, 1989 when a determination of the exact failure mode could not be determined. This was used when a determination for specific failure mode code could not be made from the content of the failure report. (This code is not to be applied to failure reports submitted after December 31, 1989)

Figure 5.19 shows the failure modes for three different periods, 2 - 6 years, $11-13$ years, and 14 - 19 years. There is no significant effect of aging on failure modes of the valve operators except that failure to close and failure to open increase somewhat as the valve operators age.

\section{Failure Cause}

There were several different causes for the failures of valve operators with no dominating ones (Figure 5.20). These included out of 


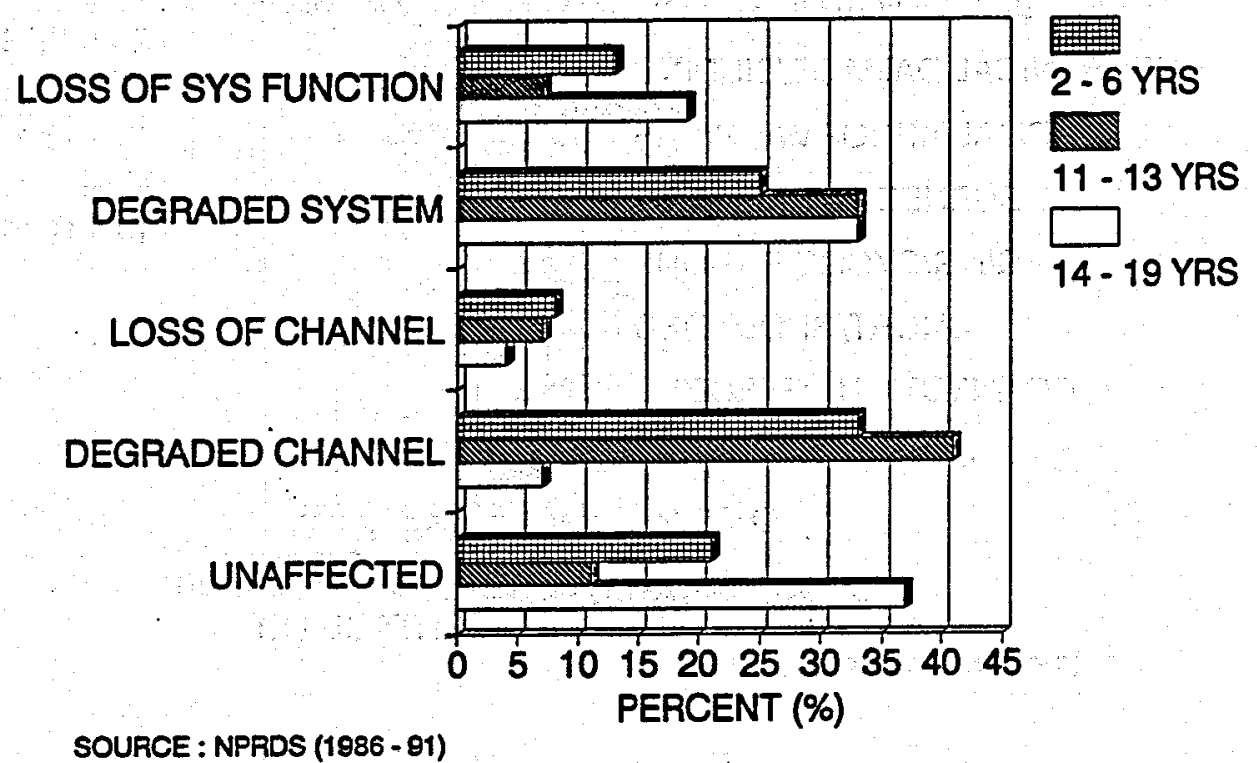

Figure 5.18. Effects of valve operator failures on the RCIC system

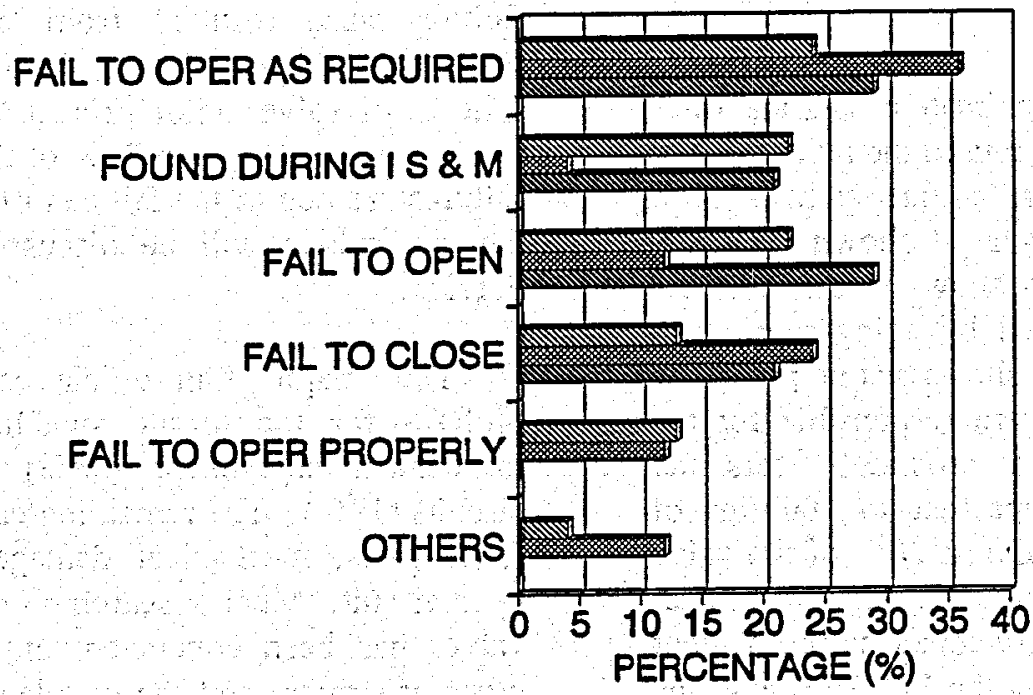

2.6 YRS

网

11 - 13 YRS

$14-19$ YRS

SOURCE : NPRDS (1986 - 91)

Figure 5.19. Failure modes for valve operators 


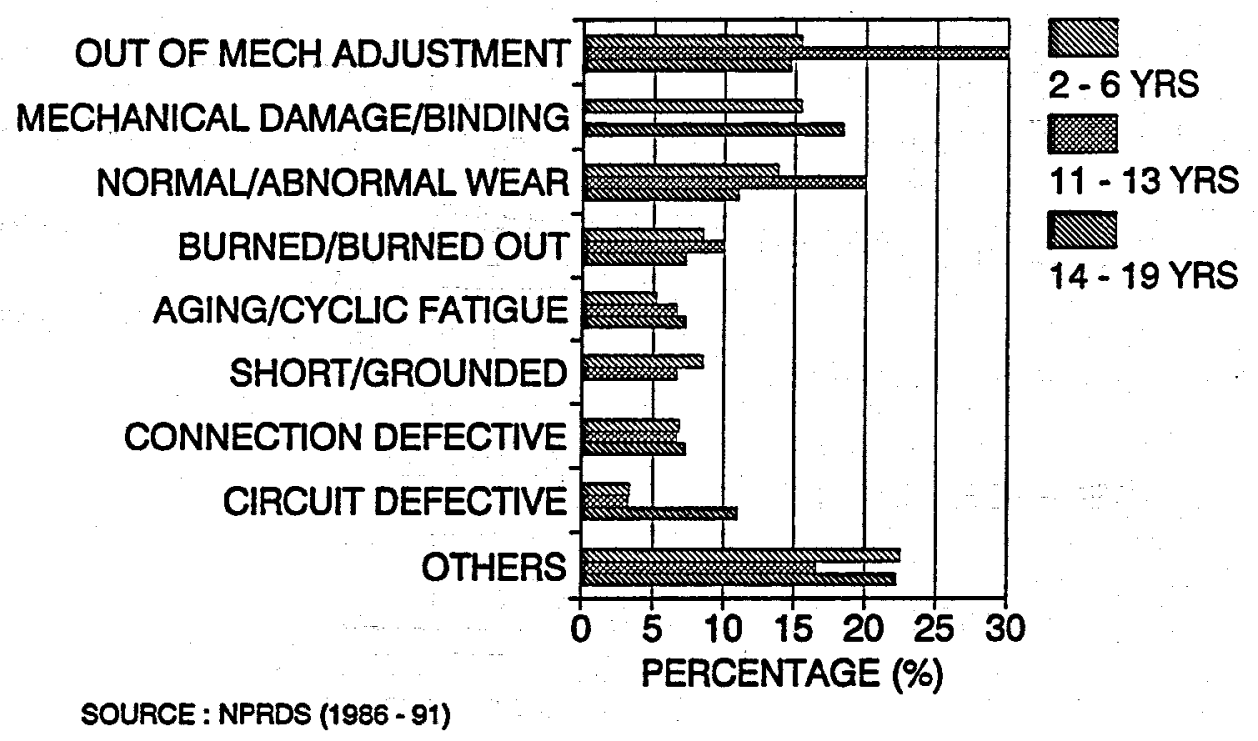

Figure 5.20. Failure causes for valve operators

mechanical adjustment, normal/abnormal wear, mechanical damage/binding, burned/burned out, and defective connection/loose parts. Others in this figure include dirty, foreign material, lubrication problem, blocked, and insulation breakdown.

The analysis for proximate causes identifies the subcomponents that caused the failures. The major ones are motor, torque switch, limit switch, and tripper finger, as shown in Figure 5.21. This figure also shows that motor and limit switch are affected by aging more than others. This figure also shows that no particular subcomponent failures are responsible for the two frequency peaks, at around 3 years and around 11 years, except that the failures of tripper fingers caused almost $20 \%$ of the valve operator failures during the $11-13$ years of age. It is also notable that dirty contacts caused about $8 \%$ of the failures during the $14-19$ years; this proximate cause was not reported until this period. The failure causes reported to NPRDS for the valve motors are burned/burned out (35\%), insulation breakdown (19\%), short/ground (19\%), and defective circuit (12\%). However, for motors, burned/burned, insulation breakdown, and short/ground are the same failure cause resulted from overheating or overload, which, in turn, is a result of the failures of valve motor protection devices. In other words, more than $73 \%$ of the valve motor failures are due to the failures of the protection devices, which will be discussed in Section. 5.1.3.5.

The major failure causes reported to NPRDS for the torque switches are out of mechanical adjustment (38\%) and defective circuits (19\%). The remaining causes are dirty, loose parts, mechanical damage/binding, and open circuit. Much research on motor-operated valves has been conducted under NPAR and other programs, and the detailed results of the component level research on valve operators are available in the references 24 and 25 . 


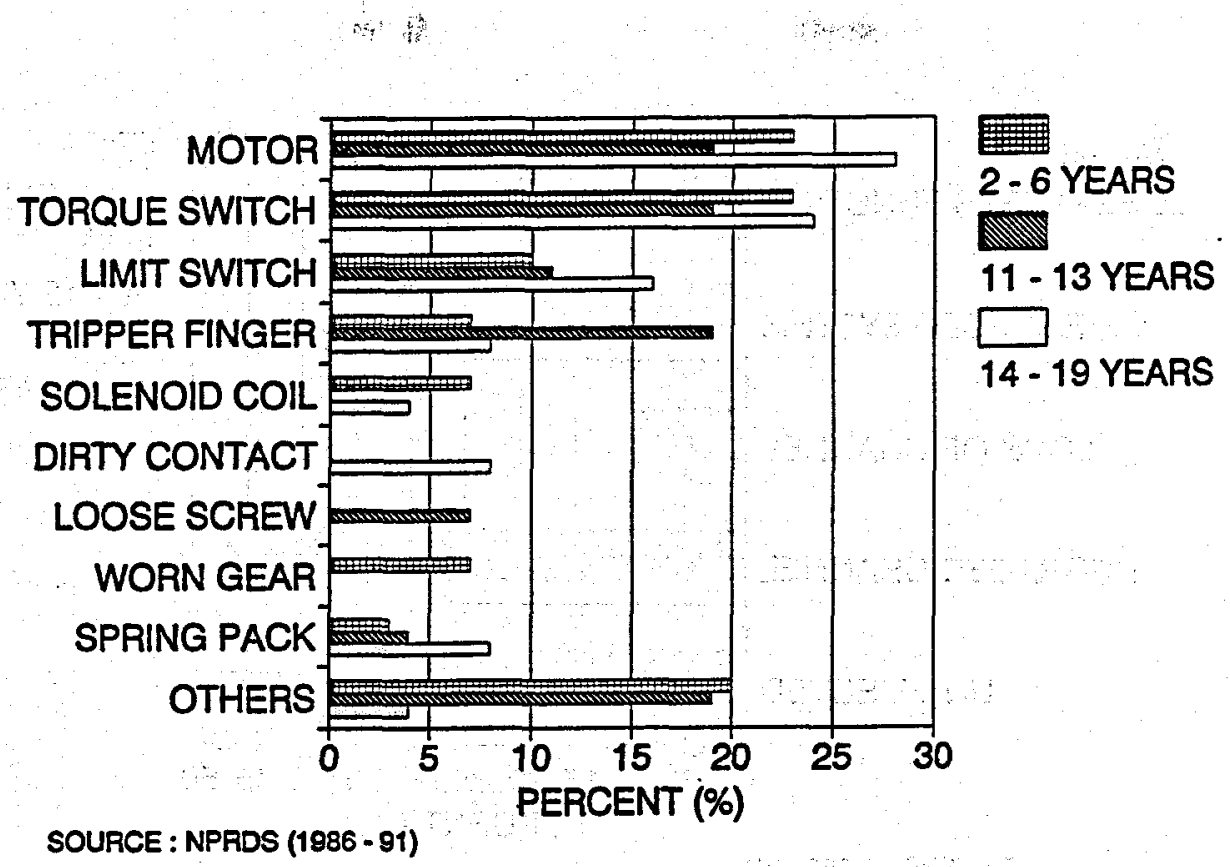

Figure 5.21. Proximate causes for valve operator failures

\subsubsection{Switches/Bistables}

Figure 5.3 shows that failures of switches and bistables contributed to about $20 \%$ of the RCIC system failures. Unlike PWR plants, many older BWR plants used process switches in the control logic of safety-related systems. Switches include pressure switches, temperature switches, level switches, differential pressure switches, and flow switches. Lately, several plants replaced them with analog modules and transmitters, but some did not. Also, the plants that began operation after 1984 are equipped with analog bistables from Rosemount, Models $510 \mathrm{DU}$ and $710 \mathrm{DU}$, while one plant uses an equivalent GE system (Ref. 26).

There were 178 reported failures of switches and bistables, of which $84 \%$ are from switches and the rest from bistables. Since switches and bistables function differently, these are discussed separately wherever necessary.
Effects of Switches/Bistable Failures on the RCIC System

Figure 5.22 shows that about $4 \%$ (number of failures: 6) of the switch failures caused a loss of RCIC system function. The significant effects of switch failures are the increased number of failures that caused degraded system operation as the switches get old; during the period 14 - 19 years, about 37\% of the switch failures caused such degradation.

About 17\% (number of failures: 5) of the bistable failures caused loss of RCIC function, and about $7 \%$ resulted in degraded system operation, suggesting that failures of the bistables usually have more serious effects on the RCIC system than failures of the switches.

\section{Failure Frequency}

Figure 5.23 shows the failure frequency for switches normalized with 26 plants. Failure 


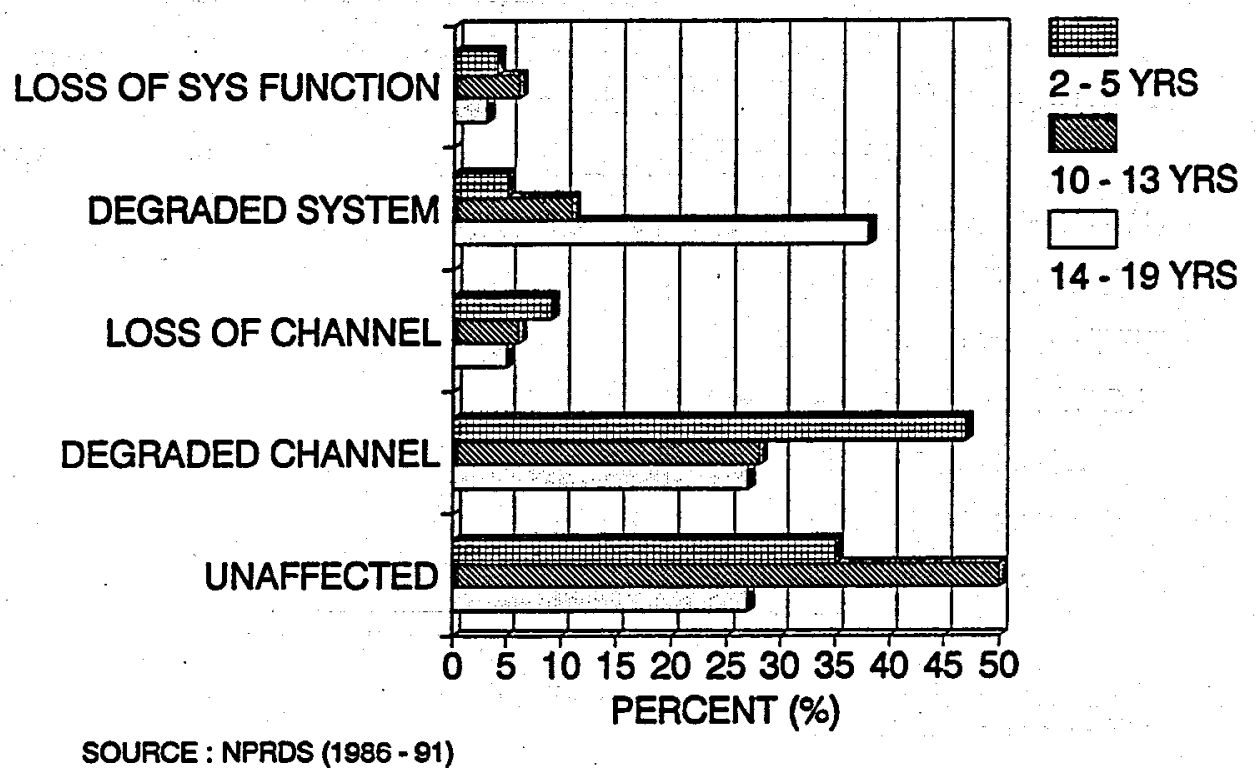

Figure 5.22. Effects of switch failures on RCIC system

frequency is rather high for the first 5 years, after which it decreases until the peak at 11 years. At 15 years, the frequency again begins to increase. The peaks at $3-4$ years and at 11 years coincide with those in the system failure frequency curve (Figure 5.7), which indicates that switches are one of the main components responsible for the system failure peaks. The failure frequency for bistables was not analyzed as there were too few data. However, the results from a detailed study on Rosemount $\mathbf{5 1 0}$ DU bistables showed that there were no significant effects of aging on failure frequency (Ref. 26). The failure frequency curve from this study shows an initial peak at $2-4$ years, and a second peak at $8-11$ years. It is generally known that bistables are more reliable than switches.
Failure Modes

The major failure modes for switches are failure to change state upon demand (33\%), high actuation (20\%), and failure to actuate properly $(17 \%)$, as shown in Figure 5.24. Others include fail to operate as required and spurious actuation. By contrast, the major failure modes for bistables are failure to change state upon demand (34\%), and spurious actuation (24\%).

The data reported as failures of switches/bistables are from at least five different types of switches, as well as bistables. Thus, due to the small population of each different type of switch and bistable, the analysis for failure causes provided only limited information. However, much more detailed information on causes and proximate causes of failures are 

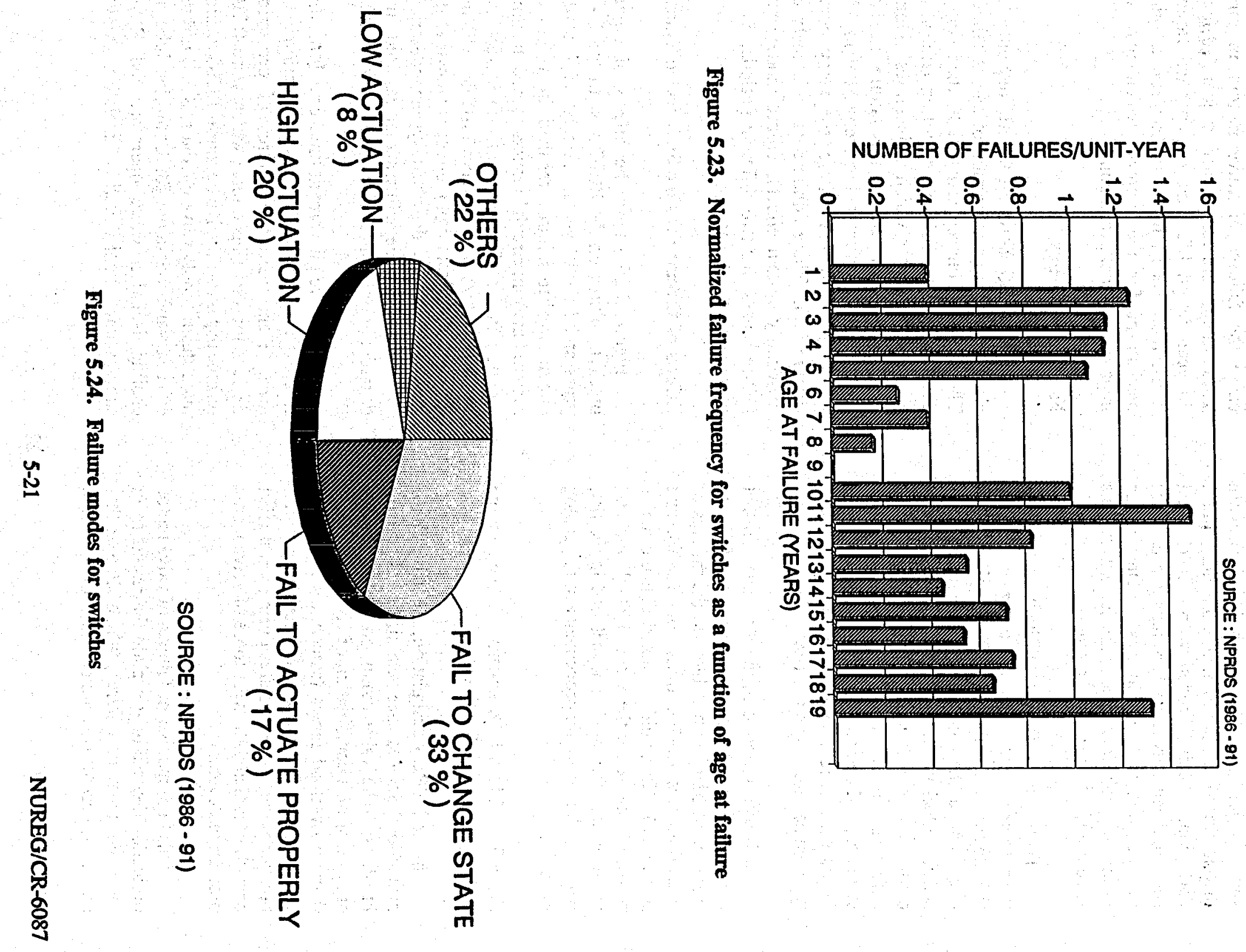
available in another component level aging assessment that focused on bistables and switches (Ref. 26). That study identified worn diaphragms, blocked/failed sensing lines, corrosion, and broken/worn mechanical subcomponents as major proximate causes for the pressure switch failures. One major proximate cause identified in the current analysis is ruptured or worn diaphragms.

There are three different types of temperature switches; one using a bimetal thermostat, one using a bulb and capillary, and one using a thermocouple as the temperature sensing mechanism. As a result, the failure causes differ for each type. For example, defective circuit boards, defective microswitches, and bad contacts were identified as the major proximate causes for the thermocoupletype temperature switches (Ref. 26).

It is also reported in the Reference 26 that the predominant proximate causes for the Rosemount $510 \mathrm{DU}$ bistables are the failures of potentiometers $(29 \%)$, transistors $(18 \%)$, and ICs (12\%). It should be noted that the major proximate cause for the earlier bistable models, the capacitor failure, is not included in the list, which is due to the improvements in the analog bistables.

\subsubsection{Circuit breakers (valve motor protection devices)}

In the NPRDS designation, the valve motor protection devices are classified as circuit breakers. The valve motor protection devices are one of or a combination of circuit breakers, thermal overload relays (sometimes fuse), and contactors. There were 64 reported circuit breaker aging-related failures during the studied period, of which $89 \%$ were those of valve motor protection devices.

This high number of failures of valve motor protection devices may explain the results from the valve operator failures, which showed that motor failures caused almost $25 \%$ of the valve operator failures (section 5.1.3.3). In other words, the failures of the protection devices cause the failures of valve motors in turn. These motors are conservatively qualified for a 40 year design life, and are operated rarely. Thus, there seems to be an accelerated aging mechanism for the motors, which may be improper thermal protection.

\section{Failure Frequency}

Figure 5.25 shows the failure frequency for circuit breakers as a function of age at failure. The failure frequency starts high, then slowly decreases to about half of the starting value at 11 years of age, after which it increases significantly. It is believed that this failure increase after 11 years contributed to the peak at $11-13$ years in the system failure frequency curve (Figure 5.7). These failure data were analyzed to identify system effects, failure modes, and failure causes, for two different periods, 1 - 7 years and $12-19$ years.

Effects of Circuit Breaker Failures on System

Figure 5.26 shows the effects of circuit breaker failures on the RCIC system for $1-7$ years and 12 - 19 years. Almost $15 \%$ of the circuit breaker failures resulted in a loss of system function; circuit breakers caused the third largest number of system function losses after valve operators and switches/bistables (Figure 5.5). A significant aging effect is shown as the increased cases of degraded system operation. The fraction of the failures that resulted in a degraded train/channel also increased with time.

There were nine circuit breaker failures that resulted in a loss RCIC system function. Of these, eight were the failures of protection devices for valve operators, which were RCIC turbine trip throttle valve operator, $\mathrm{RCIC}$ turbine main steam supply valve operator, RCIC turbine exhaust valve operator, $\mathrm{RCIC}$ turbine lube oil cooling isolation valve operator, and $\mathrm{RCIC}$ suppression pool suction isolation valve 


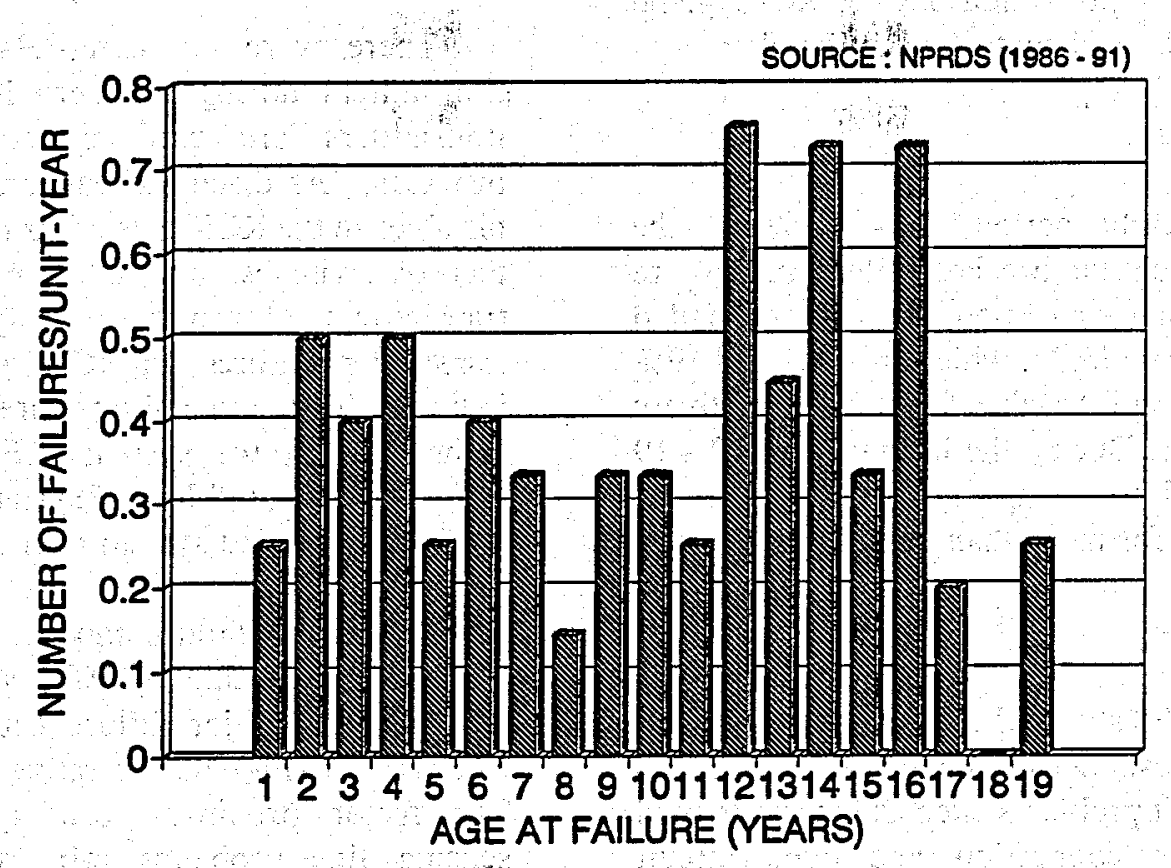

Figure 5.25. Normalized failure frequency for circuit breakers as a fumction of age at failure

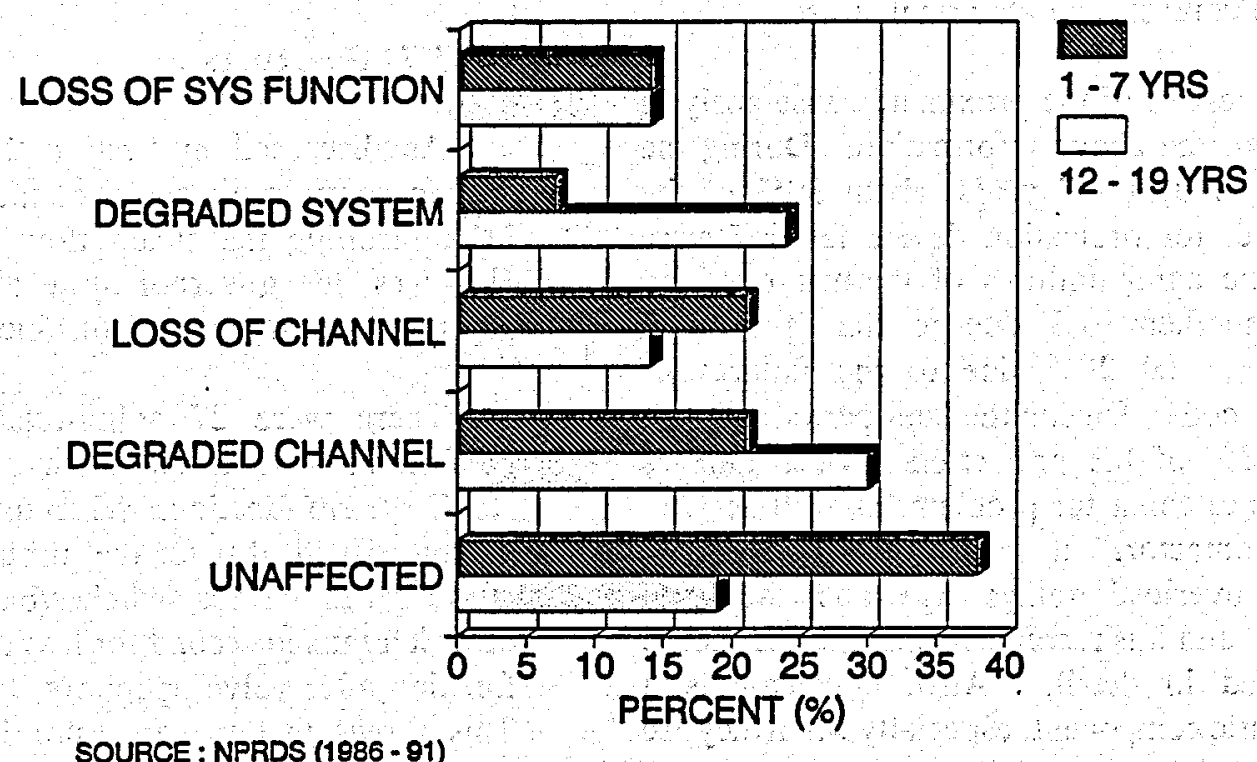

Figure 5.26. Effects of circuit breaker failures on RCIC system 
operator. The remaining one failure was also that of a motor protection device, $\mathrm{RCIC}$ gland seal vacuum blower motor circuit breaker.

\section{Failure Mode}

In the early period, $1-7$ years, the predominant circuit breaker failure modes are "failed to change state upon demand" and "failed to operate as required", which are $31 \%$ and $19 \%$ of the total circuit breaker failures, respectively (Figure 5.27). During the later period, 12 - 19 years, "failed to change state upon demand" predominates for more than half of the failures.

\section{Failure Cause}

Figure 5.28 shows the causes for the circuit breaker failures. During the earlier period, 1 7 years, circuit problems such as burned/burned out, defective connection and open circuit dominated. On the other hand, during the later period, 12 - 19 years, mechanical problems such as mechanical damage/binding and cyclic fatigue caused a significant number of the failures. The "others" category in this figure include lubrication problem, insulation breakdown, corroded contact, and abnormal stress.

The results of the proximate cause analysis agree with the above information. During the earlier period, $1-7$ years, about $30 \%$ of the valve operator protection device failures were due to the aging failures of thermal overload relays, another $30 \%$ due to the failures of contactors, and $20 \%$ due to the failures of contactor coils. During the later period, 12 - 19 years, $48 \%$ of the protection devices failures were due to contactor problems as well as $12 \%$ due to contactor. It seems that some of the thermal overload relays age and fail prematurely, and it is recommended that this should be studied in detail. Also, contactor is a problematic component, especially when they are old.

\subsubsection{Transmitters}

There were 40 aging-related failures of transmitters during the period studied. The transmitters are used in conjunction with bistables. As discussed earlier, the number of bistables in the RCIC system is much lower than that of switches, and the same is true with transmitters. However, the analysis of effects of transmitter failures on RCIC system function indicates that transmitters are an important component in the system. Four failures of transmitters caused loss of system function, and 6 caused degraded system operations.

The major failure modes are low output (35\%), failed output (23\%), and high output (20\%). The major failure causes are out of calibration (31\%) and defective circuits (23\%). The major proximate causes identified are sensing line problems (air in sensing line, blocked sensing line, etc.) (35\%), setpoint drift (25\%), failed sensor (16\%), burned out amplifier $(9 \%)$, and corroded wire $(6 \%)$. Due to the small number of data, no meaningful information on effects of aging on failure frequency was obtained.

\subsubsection{Governors}

As discussed in Section 2, the governor system controls the speed of the RCIC turbine by controlling the steam flow to the turbine. However, the governor system is treated as a separate system from the turbine in this report.

There were 27 aging-related failures of governors, of which 7 failures caused the loss of RCIC system function. When this number (7) is combined with that for the turbine (5), the total is as high as that for switches/bistables, failures of which ranked second for loss of RCIC system function after valve operators. (see Figure 5.5) This shows that the governor is an important component for the RCIC system operation. 


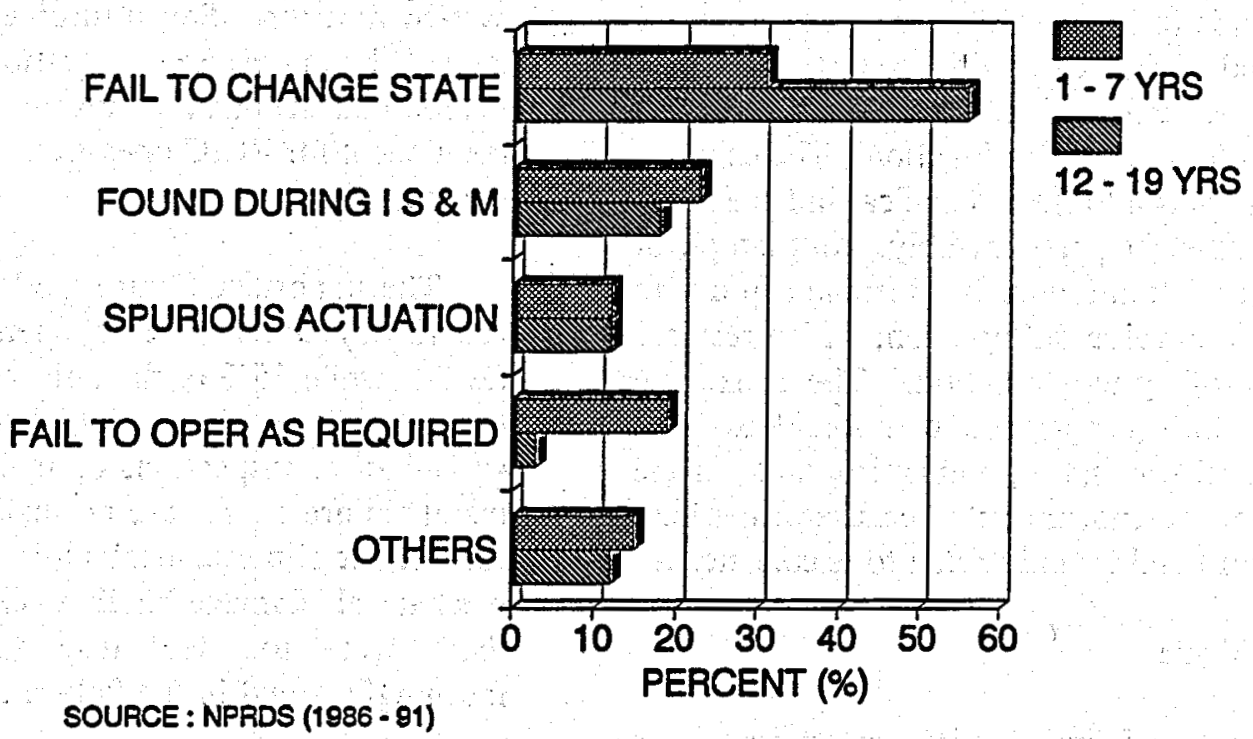

Figure 5.27. Failure modes for circuit breakers

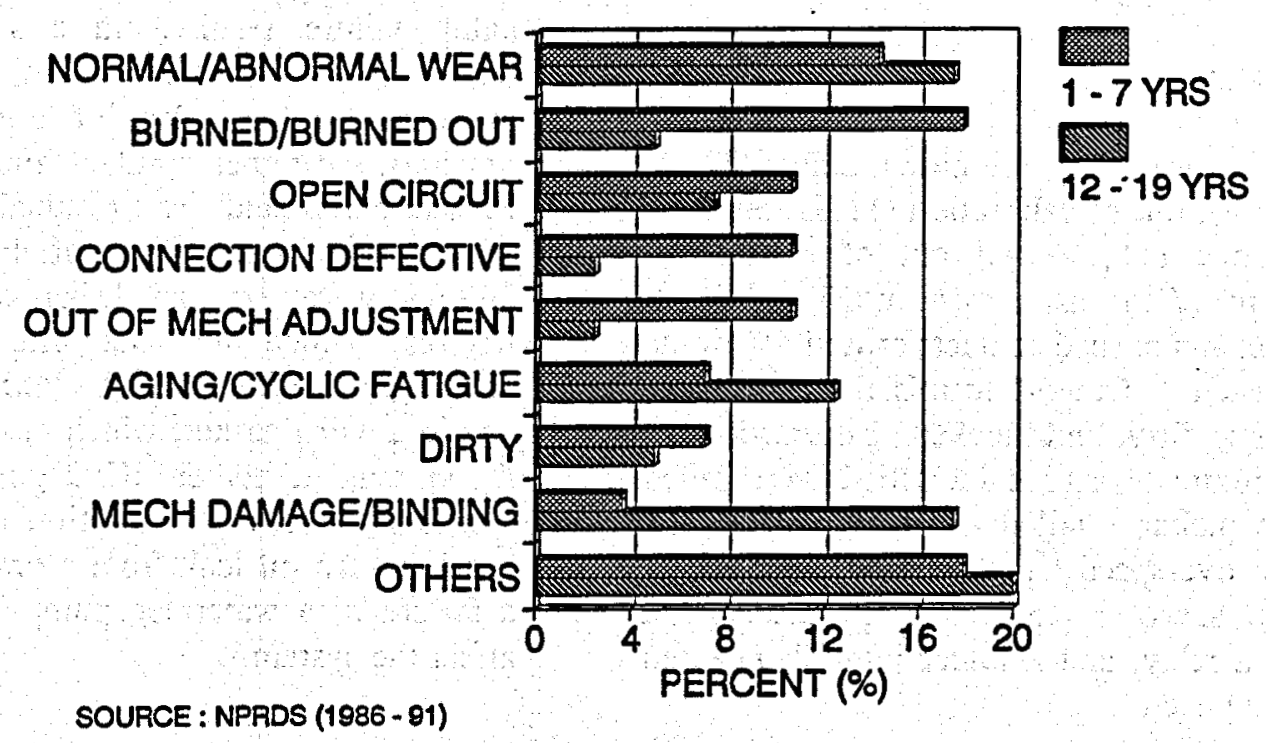

Figure 5.28. Failure causes for circuit breakers 
The governor system consists of a mechanical section and an electrical section. A typical example of mechanical section failure is the loss of speed control that resulted in an overspeed trip. In this incident, while the plant was at full power and during a surveillance test, the governor behaved erratically and tripped on overspeed causing a loss of system function. The cause of the failure was a loose mechanical linkage and a dirty overspeed tappet assembly. An example of electronic section failure is a turbine trip due to the governor valve failing open, which resulted in a loss of system function. The proximate cause for this occurrence was found to be a failed transistor and an embrittled cable in the electronic governor module because of the high temperature and humidity due to leaked steam.

\section{Failure Mode}

The major failure modes for governors are failure to control and failed/wrong output, which accounted for $25 \%$ of the failures each (Figure 5.29). The failure to control and failed/wrong output are due to the failures of mechanical and electronic sections, respectively. The other failure modes are fail to operate as required, found during testing, erratic output, and fail to start.

\section{Failure Cause}

The failure causes are circuit defect (33\%), wear (19\%), out of calibration (11\%), mechanical damage $(11 \%)$, and out of mechanical adjustment (7\%), as shown in Figure 5.30. Corrosion and burned contacts caused $4 \%$ of the failures each. "Others" in this figure includes loose parts, dirty, and blocked/obstructed. The major proximate causes identified were failed magnetic pickups, failed ramp generators, and worn out overspeed tappets. The failures of a hydraulic servo, a capacitor, a transistor, a resistor, a relay, and a solder joint also caused one failure each.

\subsubsection{Turbine}

There were 22 aging-related turbine failures, of which $5(23 \%)$ resulted in the loss of RCIC system function. Seven turbine failures (32\%) degraded the system's operation. This information indicates that the turbine is an important component for RCIC operation, even though the number of failures is low.

The important failure modes are failure to run $(20 \%)$ and failure to operate as required (20\%), while $35 \%$ of the failures were assigned to the failure mode, found during testing, surveillance, inspection, or maintenance. The major failure causes are normal/abnormal wear (28\%), out of mechanical adjustment $(22 \%)$ and mechanical damage/binding (11\%). Again, there were too few data to identify any meaningful trend in the failure frequency.

\subsubsection{Pumps}

There were 11 aging-related pump failures; 5 of them were RCIC pump failures, while the remainder included five water leg pump failures and one condensate pump failure. Both the RCIC pump and the water leg pump are essential for the system operation. One water leg pump failure resulted in a loss of system function, which was caused by a pump motor overload trip due to lack of lubrication for the bearings. Another similar failure and a condensate pump shaft leak resulted in a degraded system operation. Three of the RCIC pump failures were external leaks caused by seal failures, which did not affect the system operation; one failure was a lubrication oil leak due to a worn gasket, which also did not affect the system. Another RCIC pump failure was caused by excessive vibration due to a worn bearing. An oil leak from a drain plug caused a failure of a water leg pump, which did not affect the system. 


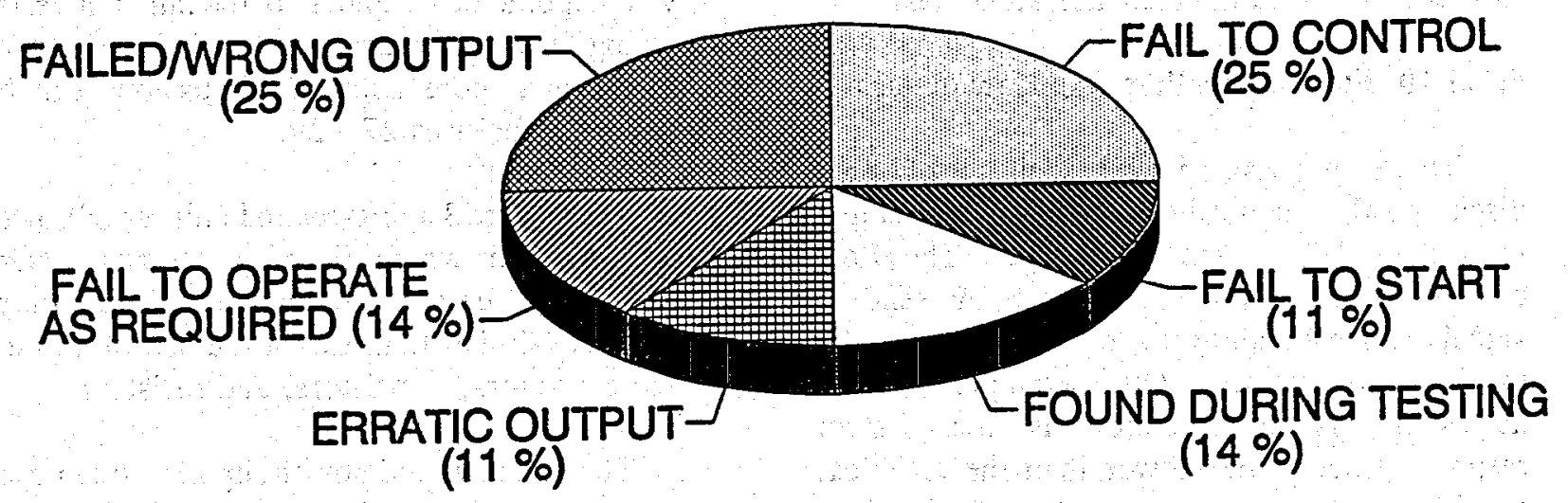

SOURCE : NPRDS (1986 - 91)

Figure 5.29. Failure modes for governors

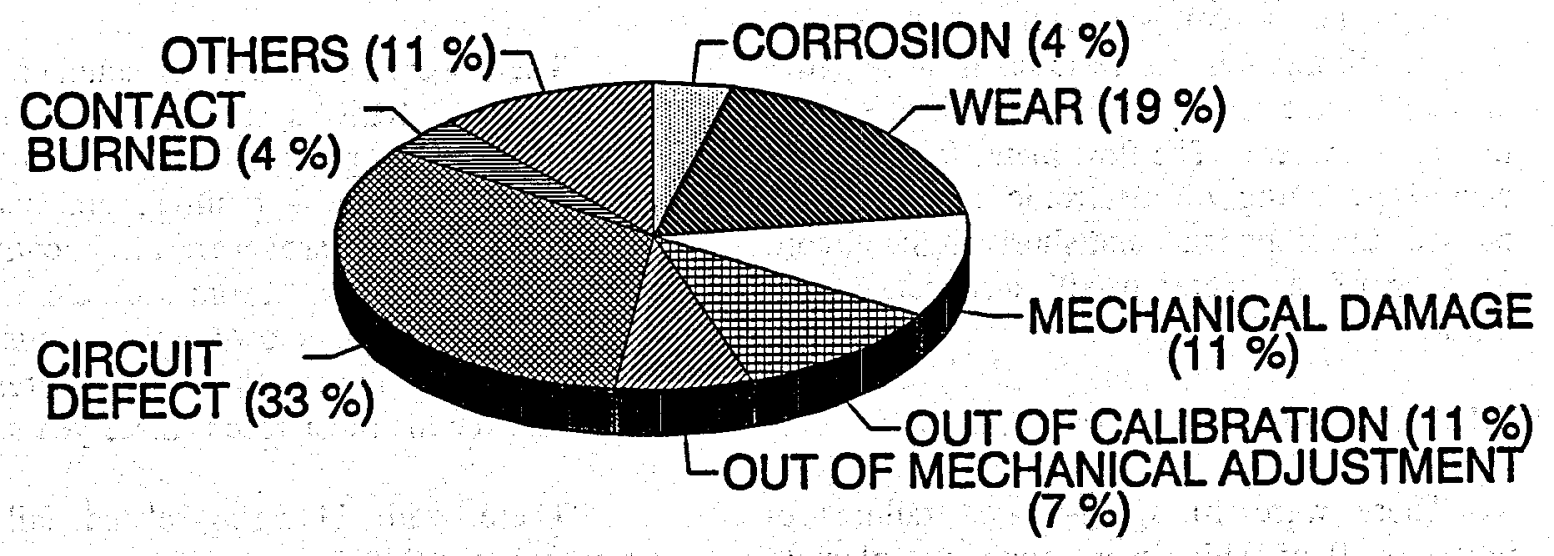

SOURCE : NPRDS $(1986-91)$

Figure 5.30. Failure causes for governors 
As shown above, the aging-related failures of pumps are mostly leakage of water or oil due to worn seal/gasket and worn bearings due to lack of lubrication. These failures could be prevented with proper aging management that includes improved maintenance schedules.

\subsubsection{Flow controllers and flow meters}

There were 7 aging-related failures of pump. discharge flow controllers, 3 of which resulted in a degraded system operation. The flow controller controls the flow rate by sending signals corresponding to the setpoint to the turbine governors. One example of the degraded system operation is the system response time being slower than the technical specification due to setpoint drift in the flow controller. Most of the controller failures were caused by electronic problems such as aged potentiostats, oxidized/corroded contacts, and degraded wires.

There were 6 aging-related failures of flow meters, which measure the pump discharge flow rate. The flow meter is also called a flow indicating controller. In an incident classified as a loss of system function, the flow meter was reading full flow, while the system was on standby; the system was declared inoperable. The remaining failures resulted in a degraded channel, not causing any significant effects on the RCIC system. The flow meter failures were caused by aging of electronic parts such as burned subcomponents and shorts in the circuit. Sticking of the meter needle also caused one failure.

\subsubsection{Inverters and power supplies}

There were 14 aging-related failures of inverters, 9 of which were from one plant (2 units). Most of the failures (8) were from the RCIC leak (steam and coolant) detection system. Due to the redundant channels, most of the inverter failures resulted in a loss of channel or degraded channel without a system level effect, except for one case, which resulted in a loss of system function due to the inverter failure for the flow control loop. The inverter failures were caused by aged capacitors, transistors, fuses, and resisters. Five failures were caused by a setpoint drift, and two by failed inverter cooling fans. Inverters were studied as a part of NPAR, and more detailed discussions can be found in references $27-29$.

There were 3 aging-related failures of power supplies, all of which did not cause any system level effects due to the redundancy. The failure causes are similar to those for the inverters, i.e., aged capacitors, transistors, and resisters.

The inverters and power supplies are known to be susceptible to aging-related failures due to a limited service life of capacitors (approximately 5 years), heat sensitivity of transistors, and aging of resisters. Thus, these electronic components should be included in the aging management.

\subsubsection{Other components}

The components that are discussed in this section are either not critical to RCIC system availability or those that did not fail frequently.

There were 16 failures of snubbers for the piping of the RCIC systems, 6 of which were reported by one plant. Low bleed in tension was the cause for 4 failures, and worn out bearings and worn seal were the known causes for one failure each. From the data analyzed, snubbers have not shown any serious agingrelated degradation, and no failures were reported for the most recent three years.

There were 11 aging-related failures of motors in the RCIC system. These motors drive condenser vacuum pumps or condensate pumps in the gland condensing train. As discussed previously, the failures of this auxiliary train do not usually affect the system function. About half of the motor failures were caused by worn brushes. 
Piping is a component that usually experiences aging degradation in the form of wall thinning and cracking. For the RCIC system, there was only one reported failure during the period studied. However, this component should be included in the aging management plan, since it takes many years until it shows the signs of aging degradation.

The other components which are insignificant in failure frequency or importance are indicators, recorders, integrating modules, computing modules, and relays. The failures of these components were not analyzed.

\subsection{Licensee Event Reports Analysis}

Though the information contained in the two national databases, NPRDS and LERs, duplicate each other to some extent, the LERs primarily contain information on system failures which occurred during plant operation. Typically, component degradations and failures which were discovered during regularly scheduled maintenance or during outages are not reported as an LER. Furthermore, after January 1, 1984, only safety significant events are reported to the LER database. Thus, the failures reported as LERs are considered to be more important for safe operation of plants than those reported to NPRDS. Also, LERs contain some information that was not reported to NPRDS.

Both the High Pressure Coolant Injection (HPCI) and RCIC are designed to operate either automatically or manually following a reactor pressure vessel isolation accompanied by a loss of coolant flow from the feedwater system in order to provide adequate core cooling and control RPV water level. When the RCIC system is declared inoperable, plant operators are required by Technical Specifications to enter a Limiting Condition of Operation (LCO) and immediately verify the operability of the HPCI system. Typically, plant operation is allowed to continue for a maximum of 14 days with RCIC inoperable, though some plant specific Technical
Specifications permit only 7 days. The majority of failures documented by the LERs reviewed did not result in any significant plant effect. Upon discovering the system degradation, actions are taken according to the Technical Specification requirements. The Technical Specifications also contain specific component inspection intervals to ensure system availability. Correct valve position is verified monthly, while pump and valve operability is required to be demonstrated quarterly. Typically, these operability inspections are performed in accordance with the requirements of Section XI of the ASME Boiler and Pressure Vessel Code, as discussed in Section 8.

In this section, the LERs from January, 1985 to April, 1992 are analyzed. Over 300 events that affected the operation of RCIC were reviewed; of these, only 132 (44\%) actually documented events caused by system and component failures. The remainder were due to procedural errors, inadequate or improper maintenance, Technical Specification violations such as missed inspection intervals, and design and installation errors. The 132 LERs which documented RCIC system failure or degradation were reviewed to determine the effects of aging. As shown in Figure 5.31, $45 \%$ of these reported occurrences were identified as being due to aging degradation, and $35 \%$ possibly due to aging, while the remaining $20 \%$ were non-agingrelated failures.

\subsubsection{Effects of Aging on Licensee Events}

As discussed, of 300 LERs due to RCICrelated events, 105 were caused by aging-related failures. If only the data from 1986 through 1991 are considered, it is quite clear that agingrelated failures are accounting for steadily increasing percentages of all the RCIC LERs generated, as shown in Figure 5.32. Noting that LERs represent failures that affected the system operation significantly, this agrees with the NPRDS analysis result for the same period (1986 - 1991) that showed aging-related failures 


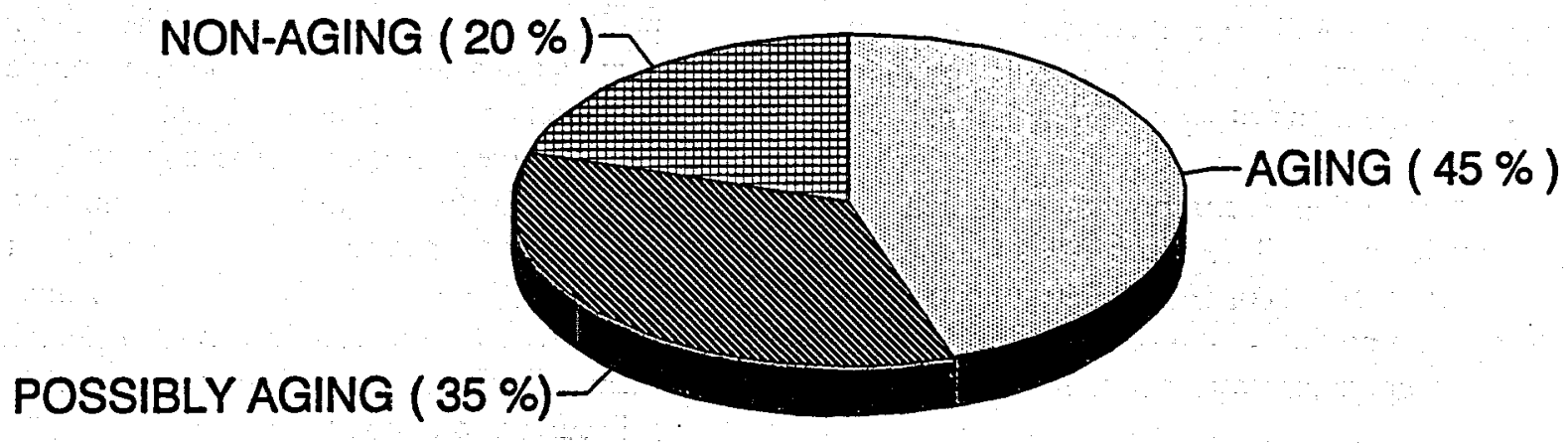

SOURCE : LERS (1985 - 92)

Figure 5.31. Fraction of aging-related component failures

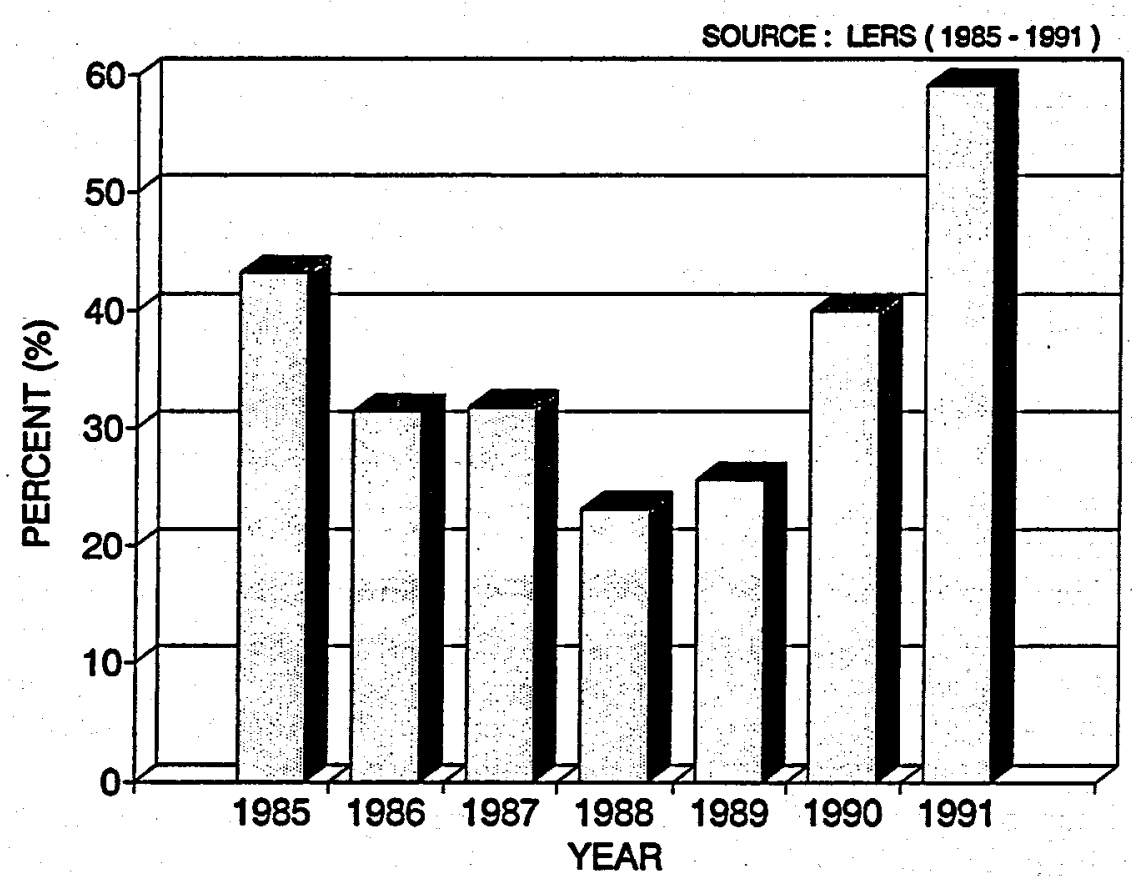

Figure 5.32. Fraction of LERs caused by aging-related failures 
have more serious effects on the system as the plants get older (Figure 5.2). There was a change in LER reporting guidelines in 1984, after which the total number shown in 1985 (Figure 5.32) may be due to the transition from the old criteria to the new one.

\subsubsection{Importance Ranking}

Figure 5.33 shows the number of failures for each component reported as the LERs. Thus, the importance ranking for the major RCIC components based on number of LERs is valve operators, switches/bistables, governors, valves, turbines, and flow controllers. Other failed components which resulted in LERs include RCIC room coolers and miscellaneous components (i.e., indicator light bulbs, snubbers).

These rankings differ from those obtained from the number of failures reported to NPRDS (section 5.1.2.1). The main difference between the two analyses is the importance of valves. Even though there were many valve failures, the failure mode analysis revealed that leakage, external and internal, is the predominant failure mode, and most do not cause a loss of system function. Consequently, most of the valve failures did not result in LERs.

The rankings based on the number of LERs are, in fact, very similar to those obtained from the NPRDS analysis using the criterion of "loss of system function", which is expected, because only those failures that affected the system function during the normal operation (standby) are reported as LERs. The additional information obtained from the LER rankings is that flow controller is also an important component since their failures affect the system function.

\subsubsection{Aging-Related Failures of Components}

\subsubsection{Valve operators}

There were 26 aging-related failures of valve operators, accounting for $25 \%$ of the
RCIC system component aging-related failures. Each failure reported resulted in valve inoperability, with the majority being found during quarterly valve exercising. The system was typically declared inoperable, and the appropriate Technical Specification LCO entered while repairs were performed. Though these failures were found during quarterly testing, it is important to note that the result of these occurrences may have been that the system may not have operated properly upon demand.

The proximate causes for the valve operator failures are shown on Figure 5.34. Of the known failure causes, failed torque switches, failed DC motors, and failed limit switches were most often reported. These findings are consistent with those from the NPRDS data analysis.

\subsubsection{Instrumentation and control failures}

When the component failures in the instrumentation and control (I\&C) system are combined, they accounted for $30 \%$ of all the aging-related failures. The components include switches, bistables, transmitters, flow meters and inverters. These devices are used to monitor system pressure, flow, and temperature, and to actuate needed components; RCIC is designed to actuate upon manual or automatic signals.

The proximate causes for the various I\&C component failures are shown in Figure 5.35. The primary failure cause was component degradation resulting in set point drift. Degraded and worn connections were also reported. Several sensors were found with oxidized and corroded terminal connections. In one instance, water from a flexible hose was found to be dripping on the instrument, resulting in a degraded connection. In several other examples, degraded connections on temperature switches were found. The root cause for one instance was traced to the repeated loosening and tightening required during instrument recalibration. Five LERs reported torn pressure 


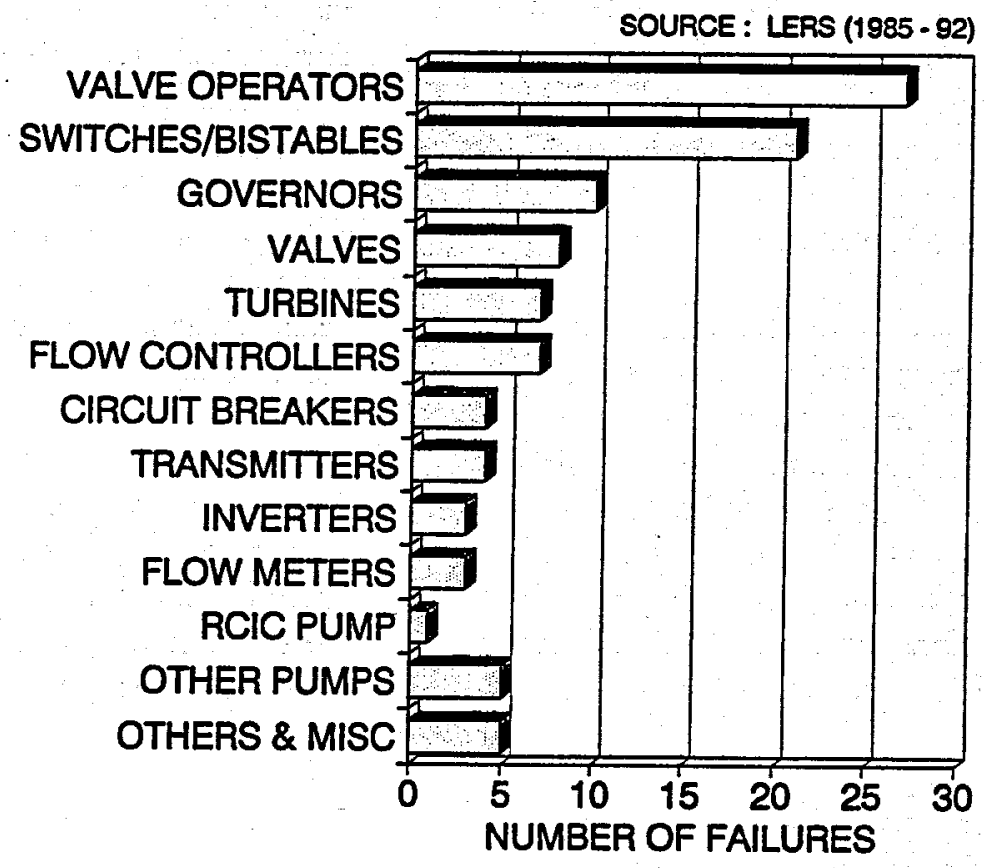

Figure 5.33. Number of aging-related component failures reported to LERs

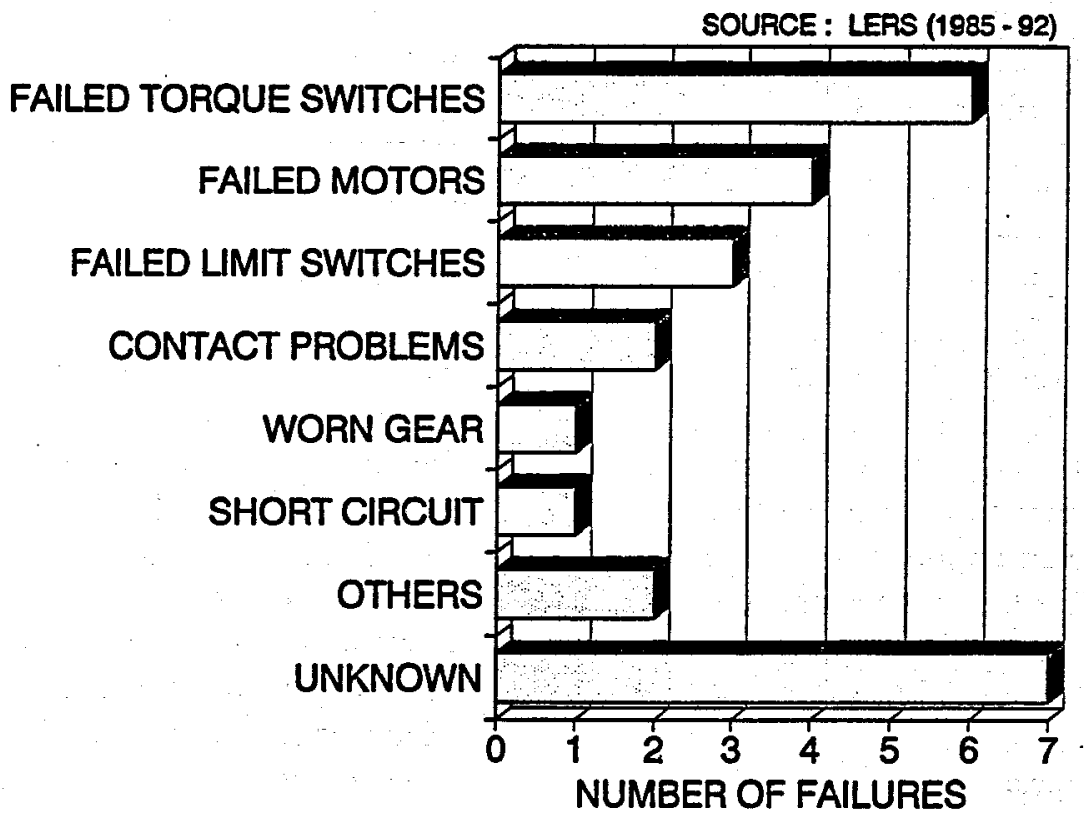

Figure 5.34. Proximate causes for valve operator failures 


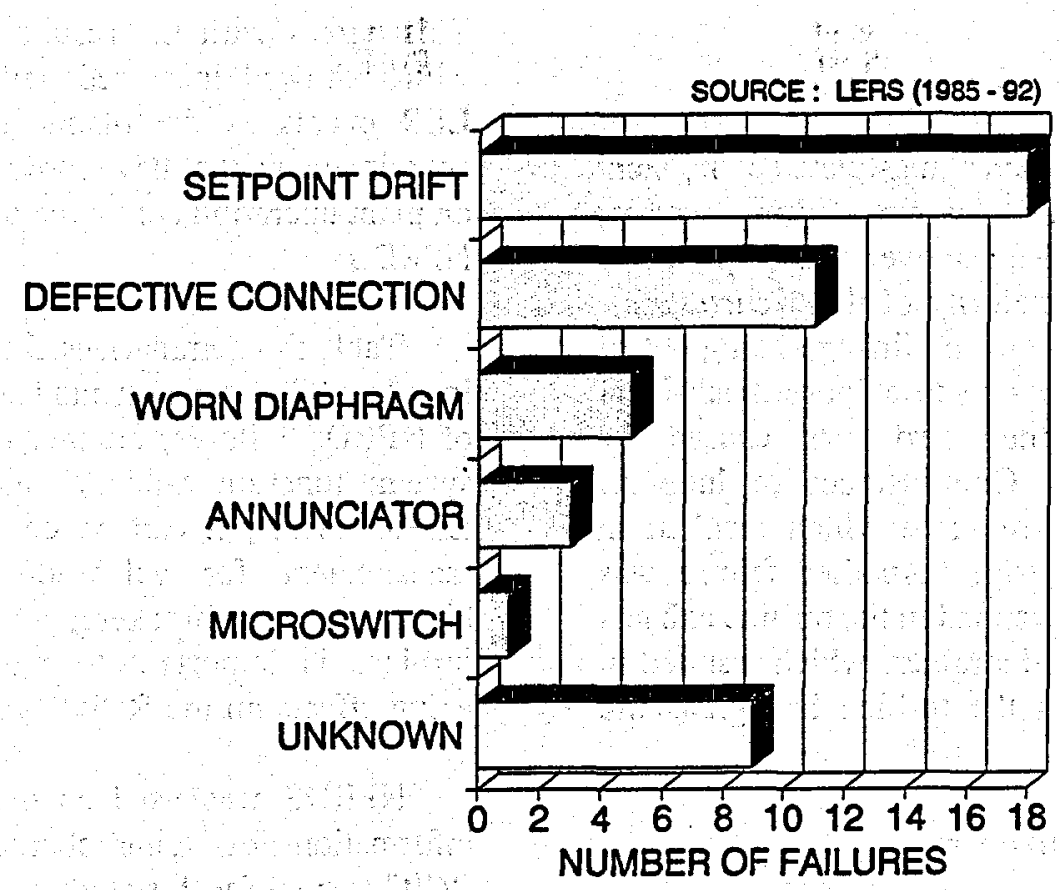

Figure 5.35. Proximate causes for instrumentation and control component failures

switch diaphragms which resulted in subsequent sensor replacement. Though this was a repeated occurrence, no root failure cause was reported. No failure causes were reported for 9 other component failures.

These failures commonly resulted in the generation of erroneous or spurious signals. Numerous examples of high steam line temperatures were reported due to thermocouple failures. Other instances were reported where faulty pump pressure switches indicated flow on an inoperable pump.

\subsubsection{Governors}

There were 10 failures of governors that resulted in LERs. The failure of the governor always resulted in degraded operation of the turbine, which in turn resulted in the pump being unable to provide the required flow. These degradations were commonly discovered during the quarterly surveillance tests on the pumps. Specific causes were attributed to degradation of the various subcomponents, including the control box, hydraulic actuator, cabling, and turbine tachometer.

\subsubsection{Valves}

During the time period studied, eight valves failures caused LERs. Of these occurrences, five were check valve failures, and three MOV failures. Of the five check valve failures, only three provided failure causes. Degraded and broken check valve internals resulted in preventing the valve actuator from moving properly. No failure cause information was provided for the MOV failures.

These valve failures resulted in erroneous pressure and temperature indications due to internal leakage past seats, turbine trip due to high exhaust pressure, and system overpressurization leading to component damage due to an exhaust valve failing to open. 


\subsubsection{Turbines}

There were eight turbine failures, accounting for $8 \%$ of the RCIC system aging-related component failures. Of the known failure causes, degradation of mechanical overspeed trip linkage accounted for the majority of the occurrences. One failure was due to the linkage being out of adjustment, another due to a loose mechanical connection, and the third was caused by mechanical wear. One instance of lube oil contamination was reported which resulted in turbine overspeed trip. Another failure was attributed to steam trapped in the turbine exhaust line due to a plugged strainer, which resulted in water leaking from the turbine bed plate and shaft.

\subsubsection{Flow controllers}

There were seven flow controller failures that resulted in LERs, all of which were due to electronic problems. Three failures were caused by the controller sending erroneous output signals to the governor, which resulted in a turbine trip due to overspeed. Proximate failure causes involving a faulty solder joint, dirty contact, and a fuse caused one failure each.

\subsection{Summary}

From January 1986 to December 1991,920 RCIC component failures were reported to NPRDS, of which $87 \%$ were aging-related. Between January 1985 and April 1992, 132 LER events were caused by failures of RCIC components, of which $80 \%$ were aging-related. This contribution of aging-related failures to the LER events increased as the plants got older.

The NPRDS data analysis showed that the effects of the component failures on the RCIC system function become more and more serious as the components age. From $1986-87$, about $22 \%$ of the component failures resulted in loss of system function or degraded system operation, which increased to $30 \%$ and $36 \%$ for the periods 1988 - 89 and 1990 - 91, respectively.
This agrees with the results of LER analysis, which showed increased aging failures in the LER events as the plants got older. LERs contain events that have more significant effects on plant operation compared to those reported to NPRDS.

Table 5.3 summarizes the importance rankings for RCIC components based on the number of NPRDS failures, number of NPRDS loss of system function failures, and the number of LERs. Thus, it can be concluded that aging management for valve operators, switches/ bistables, circuit breakers, governors, valves and turbines is important to reduce and mitigate aging effects on the RCIC system.

NPRDS was used as the main source of information for aging characterization of the RCIC system for this study because the database is much larger than LERs. However, the latter were also analyzed for validation of NPRDS analysis results and for additional information.

Out of the 31 BWR units that have RCIC systems, 26 were selected for normalization based on the number of failures reported. The failure frequency curve for the RCIC system shows peaks at $3-4$ years of age, and $11-13$ years. After studying the failure frequencies for the seven important components, it was found that failures of valves and switches/ bistables are the primary cause of the peak at $3-4$ years; failures of valve operators also contributed to this peak. The second peak at $11-13$ years is due to an increase in failures of valves, switches/bistables, circuit breakers, and valve operators.

There are two major groups of valves, steam valves and water valves in a RCIC system, and it is important to know which group of valves is more susceptible to aging degradation; analysis shows that the failure frequencies for the steam valves are much higher. Steam valves operate under a harsher environment than water valves; therefore, more attention should be paid to their maintenance. 
Table 5.3 Importance Ranking for RCIC Components

\begin{tabular}{|c|c|c|c|}
\hline \multirow{2}{*}{ Ranking } & \multicolumn{3}{|c|}{ Criteria } \\
\hline & $\begin{array}{c}\text { Number of NPRDS Aging- } \\
\text { related failures } \\
\text { (Total number: } 798 \text { ) }\end{array}$ & $\begin{array}{l}\text { Number of NPRDS } \\
\text { Loss of System } \\
\text { Function Failures } \\
\text { (Total number: 70) }\end{array}$ & $\begin{array}{l}\text { Number of LERs } \\
\text { (Total number: } 105 \text { ) }\end{array}$ \\
\hline 1 & Valves & Valves Operators & Valve operators \\
\hline 2 & Switches/Bistables & Switches/Bistables & Switches/Bistables \\
\hline 3 & Valve Operators & Circuit Breakers & Governors \\
\hline 4 & Circuit Breakers & Governors & Valves \\
\hline 5 & Transmitters & Valves & Turbines \\
\hline 6 & Governors & Turbines & Flow Controllers \\
\hline 7 & Turbines & Transmitters & Pumps \\
\hline 8 & Pumps & Pumps & Transmitters \\
\hline
\end{tabular}





\section{ANALYSIS OF PLANT OPERATING EXPERIENCE}

Plant specific data were analyzed to supplement the data from the national databases. An operating BWR plant was visited, and corrective maintenance data on the RCIC system were collected. The purpose was to validate the findings from the national databases, and to provide insight into current inspection, surveillance, and monitoring practices.

The selected plant is less than 10 years old, which is younger than the majority of the BWR plants. At this plant, the RCIC system is usually not a contributor to plant downtime, because the system can be worked on while the plant is in operation, as long as the RCIC downtime is limited to 14 days. In practice, to provide time for the unexpected, RCIC work is normally scheduled for about 5 days. For this plant, system or component failures have not made the RCIC system unavailable. One notable maintenance problem at this plant is that the normally closed steam supply valve to the RCIC turbine has repeatedly leaked.

\subsection{Database}

The database at this plant contains information that appears on the work orders. There were almost 2,000 maintenance records on RCIC for the most recent 5 years, including the following efforts:

Preventive Maintenance (PM)

Corrective Maintenance (CM)

Surveillance Tests (ST)

Design Change (DC)

Predictive Maintenance (PD)

Planned Maintenance (PL)

Refueling Task (RE)

Among these records, $\mathrm{CM}$ data are most relevant for this aging analysis, and only these are analyzed in this section. The rest of the information is reviewed in the Section 8 ,
Inspection, Surveillance, and Monitoring (IS\&M) Practices.

The RCIC corrective maintenance history at this plant is divided into two separate database files, RCIC cooling subsystem file, and RCIC turbine/steam subsystem file. The latter includes the turbine, the governor valve, the turbine trip throttle valve, and all the steam valves. The RCIC cooling subsystem includes the rest of the system such as the water system, the gland seal system, and the lube oil system. In addition to the system data analysis, separate analyses were also conducted for these two subsystems to gain more insights from these data.

\subsection{RCIC System Data Analysis}

When the data for the two subsystems are combined, the total number of failures were 115; $77 \%$ of them were due to aging, and $6 \%$ possibly due to aging, totalling $83 \%$. The rest were non-aging failures (Figure 6.1). These data are consistent with national database findings showing $87 \%$ of the failures being related to aging.

Figure 6.2 shows the number of failures for each component during the 5 year period. From the failures due to aging and possibly aging, the component most frequently failed is the valve operator (37\%), followed by valves (23\%), and bistables/switches (7\%). The most noticeable difference between these findings and those from the national database is the failures of bistables/ switches; only $7 \%$ of the failures were caused by bistables/switches, compared with $20 \%$ in the national database. This is because the newer plants have much fewer switches than the old ones. As discussed earlier, the plants that began operation after 1984 are all equipped with bistables (trip units) and transmitters with much fewer switches. Older plants use a large number of switches in place of trip units. The trip units (Rosemount 510 or 710 units) are known to experience fewer failures than the switches. 


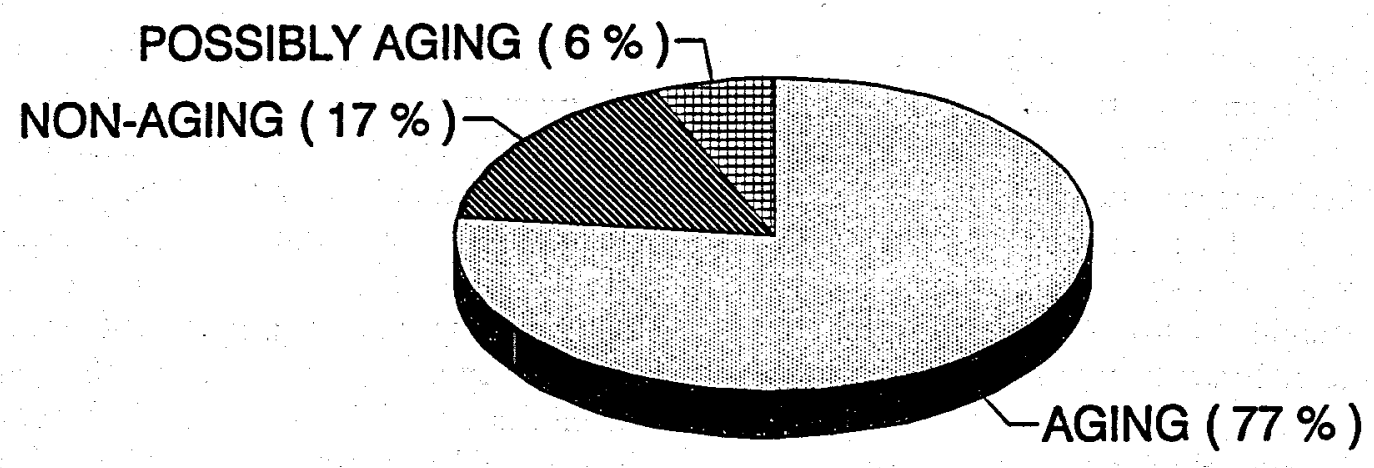

SOURCE : PLANT SPECIFIC DATA

Figure 6.1. Aging fraction for plant specific RCIC data

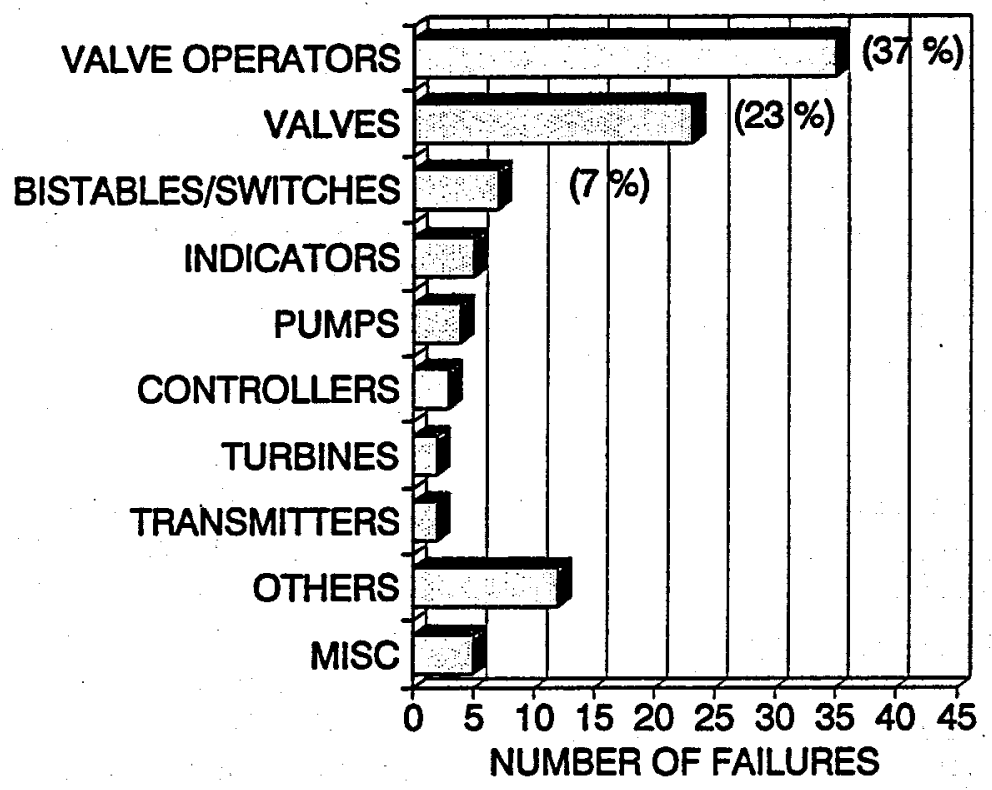

SOURCE : PLANT SPECIFIC DATA.

Figure 6.2. RCIC system components that failed 
The national database showed that valves are the most frequently failed component, causing about $30 \%$ of all the aging-related failures. However, for this plant, valves are the second most failed component, contributing about $23 \%$. The NPRDS data analysis showed that more than $35 \%$ of the valve failures, especially during the earlier years ( $<10$ years), were caused by worn seat/disc, with about $27 \%$ by packing failures. For this plant, only one valve failure was caused by a worn seat during the 5 year period, with more than $60 \%$ attributed to packing failures. This is probably because of the improved materials for the seat and disc in the newer valves.

In this plant, valve operators failed most frequently contributing to $37 \%$ of all agingrelated failures, which is much higher than the $23 \%$ the NPRDS database showed (valve operators and circuit breakers combined). These data did not differentiate between the valve operator and the circuit breaker, while the NPRDS treated them as separate components. The high percentage for valve operator failures at this plant does not mean a higher failure rate than the national average; because of the fewer failures of the bistables/switches and the valves, the relative percentage for the valve operators became higher. It should be noted that only a portion of the failures that received corrective maintenance are reported to NPRDS. This is because not all the $\mathrm{CM}$ failures meet the reporting criteria, and also because reporting to NPRDS is voluntary. Thus, the number of CM failures should not be compared with the failure frequency from the NPRDS analysis.

\subsection{RCIC Cooling Subsystem}

There were $44 \mathrm{CM}$ records on the RCIC cooling system, of which 31 (70\%) were component failures due to aging, $2(5 \%)$ were possibly due to aging, and the rest $(25 \%)$ were non-aging failures. From the failures due to aging and possibly due to aging, the component most frequently failed is the motor operator (33\%), followed by the motor operated valve
$(9 \%)$, and the solenoid valve $(9 \%)$, as shown in Figure 6.3. Trip units, a pump, manual valves, and indicators each caused $6 \%$ of the failures. Transmitters caused $3 \%$ of the failures. "Others" in this figure include check valves, relays, signal conditioners, strainers and miscellaneous components.

Half of the motor operator failures were caused by bad/dirty contacts, and the rest were due to out of adjustment limit switches, burnt motor, bad spring pack, and a missing screw. These proximate failure causes are consistent with those identified in the national database analyses. All of the motor operated valve failures were leaks due to packing failures. As discussed previously, it is believed that the absence of valve failures caused by worn seats and discs can be attributed to improved seat and disc materials.

\subsection{RCIC Turbine/Steam Subsystem}

There were 70 failures in the RCIC turbine/steam system during the most recent 5 years, of which $57(81 \%)$ were due to aging, 5 (7\%) possibly due to aging, and the rest (11\%) were non-aging failures. The components that caused the most failures are motor operators and motor operated valves, accounting for $22 \%$ of the aging failures each (Figure 6.4). Air operators caused $3 \%$ of the failures and other valve operators, $15 \%$, followed by switches/bistables (7\%), controllers (5\%) and indicators (5\%). Other components that caused less than $3 \%$ of the failures each include gland seal condenser, turbine, transmitter, filter, computer, and miscellaneous components.

The major proximate causes of the motor operator failures were bad/dirty contacts of limit switches, loose screws, and bad circuit breaker contacts. Out of adjustment limit switch was the major proximate cause for the failures of valve operators other than motor operators. These findings are consistent with those from the national database analyses. Packing failures caused most of the motor-operated steam valve 


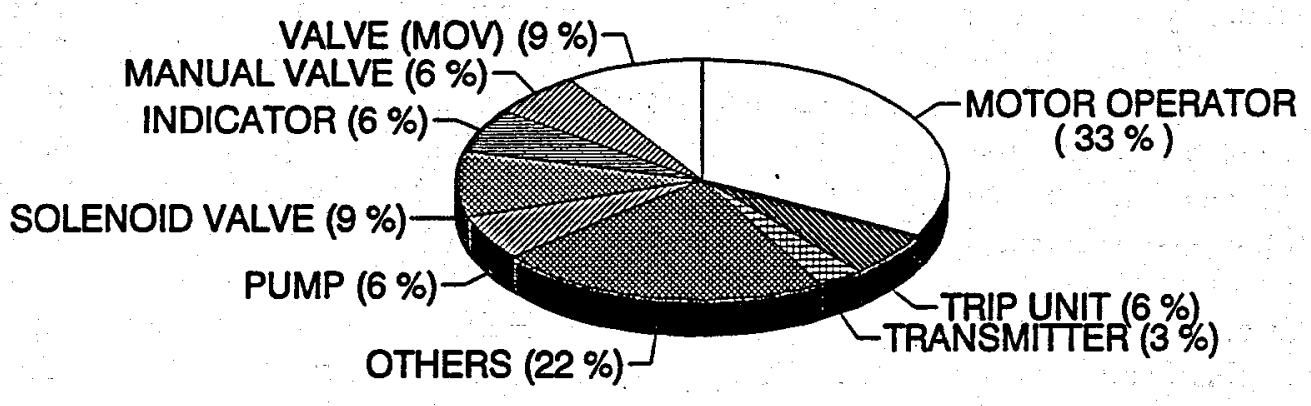

SOURCE : PLANT SPECIFIC DATA

Figure 6.3. RCIC cooling subsystem components that failed

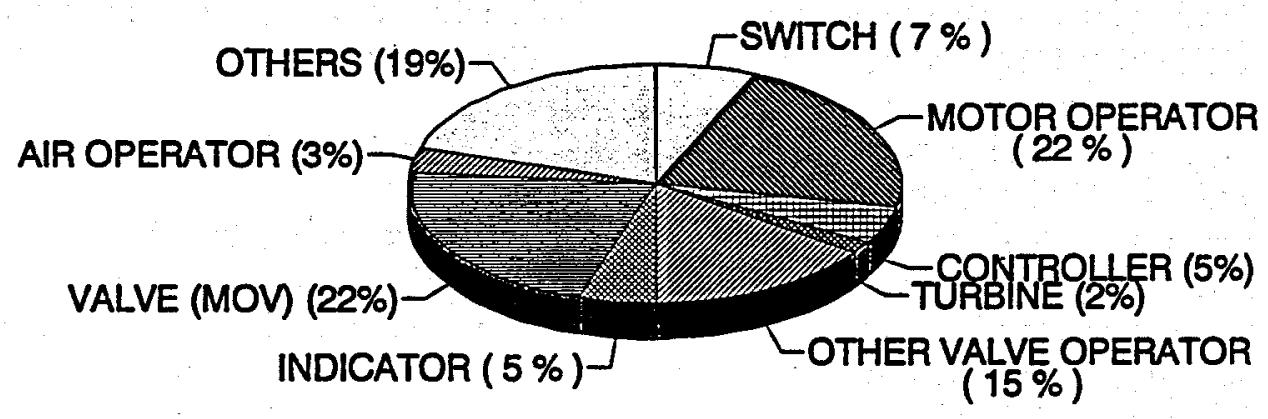

SOURCE : PLANT SPECIFIC DATA

Figure 6.4. RCIC steam subsystem components that failed

failures $(69 \%)$, resulting in leaks. Dirty internals and worn seat caused one failure each. The fact that failures due to worn seats is lower than the national average can be attributed to improved materials, as discussed earlier.

One significant difference between these two subsystems is the number of failures for motoroperated valves; the number of valve failures in the cooling water subsystem (3) is lower than in the steam subsystem (13), similarly motor operator failures for each subsystem are 11 and 13, respectively (Figure 6.5). A major finding from the national database analysis was that the aging degradation of steam valves is much more pronounced than that of water valves; therefore, it is concluded that more attention should be paid to steam valves. The plant specific data clearly confirm that the operational stresses, especially temperature, for the steam subsystem are more severe, and hence, aging degradation of the valves is accelerated. 
SOURCE : PLANT SPECIFIC DATA

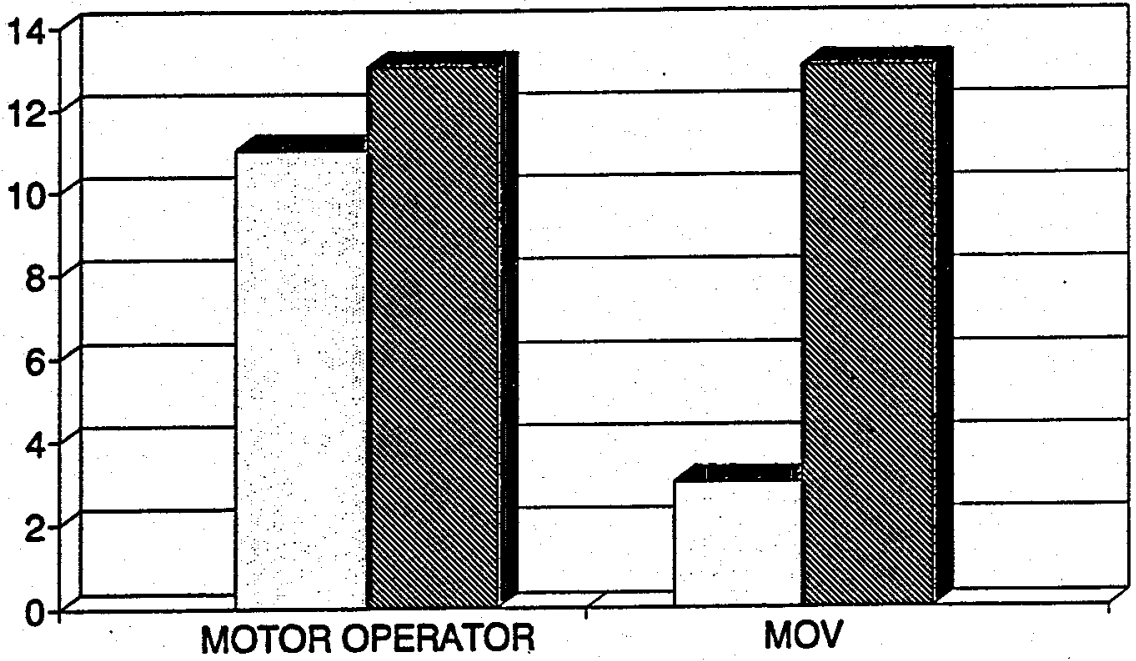

$\square$ Cooling Subsystem Steam Subsystem

Figure 6.5. Failures of motor operators and motor-operated valves in RCIC cooling and steam subsystems 



\section{PROBABIIISTIC UNAVAILABIITY ANALYSIS}

As components and systems age, there may be an increase in failure rate due to unchecked aging degradation, which could result in a decrease in system availability. Thus, a system unavailability analysis was made to simulate the effects of uncontrolled aging on the availability of the RCIC system. The objective of this analysis was to identify the types of $\mathrm{RCIC}$ failures that could be related to aging, and to estimate the impact on total system unavailability if key RCIC components degrade and fail.

In evaluating the safety significance of aging-related failures of components, it is necessary to include the information from a probabilistic analysis because of the different importance, population, and failure rates of many components in the RCIC system. The probabilistic unavailability analysis also provided this information.

\subsection{Analysis Methodology}

Although the RCIC system has hundreds of potential failure mechanisms, only a handful are probabilistically significant. A fault-tree analysis identified the following important mechanisms: pump failure to start/run, valve failures to open, instrumentation failures, and maintenance unavailability. This input can be used in the RCIC aging analysis to emphasize the comparatively limited subset of system failures (attributable to aging or other factors) that can significantly affect system availability.

The Peach Bottom plant, as analyzed in the PRA and IRRAS (Ref. 12, 30), was used for this study; its fault-tree was modified to model the turbine-driven pump in more detail.

The IRRAS code was used to analyze the RCIC fault tree. The estimate of RCIC base case unavailability was developed using the basic event data from the Peach Bottom PRA (Ref. 12) and other generic data bases. Those basic events (i.e., component failures, maintenance unavailability) that could be caused by agingrelated degradation were identified. A parametric study then was performed for these basic events to determine the potential impact on system unavailability as the base case failure rates are increased.

Section 2 discussed the RCIC designs in detail. However, a brief review is given again to assist in understanding of the RCIC fault tree, given in Appendix B.

The Reactor Core Isolation Cooling System is a single train system consisting of a steamdriven turbine and a pump, with associated valves and piping to deliver makeup water to the reactor vessel.

Following any reactor shutdown, steam continues to be generated because of the heat produced by radioactive decay of fission products. Steam normally flows to the main condenser through the Main Steam Isolation Valves (MSIVs) and the turbine bypass valves. If the condenser is isolated, steam flows to the suppression pool via safety/relief valves. Fluid removed from the reactor vessel normally is made up by the feedwater pumps, supplemented by leakage from the control rod drive system. If feedwater is unavailable, the RCIC system starts automatically on receipt of a reactor vessel low water level 2 signal, or is manually started by the operator from the main control room, and delivers its design flow within $\mathbf{3 0}$ seconds. The system will shutdown automatically upon recovery of reactor water level or upon receipt of an Auto-Isolation signal at certain signaled malfunctions.

The RCIC pump suction is usually from the Condensate Storage Tank (CST). The volume of water available is sufficient to allow RCIC operation for 8 hours after shutdown. A lowlevel alarm is energized when the level in the condensate storage tank falls to the minimum required to meet the design requirements of the RCIC/HPCI. If the CST is unavailable, the 
backup supply of cooling water for the RCIC is the suppression pool. The pump discharges to the feedwater line outside containment. Makeup water is delivered into the reactor vessel through the feedwater sparger.

The RCIC pump is directly coupled to a turbine driver. The turbine steam supply comes from one main steam line upstream of the MSIVs.

In the normal system lineup, all components required for initiating RCIC are independent of $A C$ power. Only power from the station battery is required to operate the system. The power source for the turbine-pump unit is the steam generated in the reactor vessel by decay heat, which is piped directly to the turbine.

Although the RCIC system has a sizeable number of components, some are less important to the system's operation than others. This study focussed on those components that directly support RCIC injection into the reactor vessel. For example, the loop level system, test return and minimum flow lines were not modeled because these malfunctions would not prevent system from operating.

\subsection{Base Case Analysis}

The base case system unavailability is $\mathbf{5 . 0}$ E-2. Table 7.1 shows the cutsets for the base case; Table 7.2 shows the major contributors to system unavailability, grouped by component type. The contribution to system unavailability due to system instrumentation failures, maintenance unavailability, pump failures to start/run, and the valve failures groups are all roughly about $20 \%$.

As shown in Table 7.2, the failures of system instrumentation are dominated by spurious isolation (i.e., high steam line flow, low pump suction pressure, and high turbine exhaust pressure). The majority of the system isolations can be initiated by one instrument, which makes the system susceptible to single failures. The RCIC system cannot be reset until the isolation signal is cleared.

Maintenance unavailability is a traditional source of RCIC unavailability. The data used herein is from the Peach Bottom PRA (Ref. 12); generic values are approximately 3 times higher.

The pump category is comprised of the main RCIC pump (which has been evaluated separately from the turbine) and the skidmounted vacuum and condensate pumps. The failure of the latter pumps will not directly affect RCIC operation. However, long-term leakage of steam from the turbine seals has the potential to isolate the system on a valid high pump room temperature signal.

Valve failures are the last of the dominant contributors to RCIC unavailability. This category consists of those valves that have an active system function:

- pressure control valve (PCV) on the cooling line to the lube oil cooler (FO23),

- normally closed (NC) barometric condenser vacuum tank PCV, (FO96).

- NC steam line admission valve to the $\mathrm{RCIC}$ turbine (MV131/FO45),

- NC RCIC pump discharge valve (MV21/FO13),

- NC MOV on the cooling line to the lube oil cooler (MV132/FO46), and

- suppression pool suction line MOV (MV41/FO31).

Other valves which do not have to change position for successful RCIC operation could only cause the system to fail by spuriously closing and then failing to open. This type of failure is much less significant than the major failure mechanisms and is not modeled in this study.

The relative importance of a group of components to overall system unavailability is a function of the basic event failure probability of 
Table 7.1 RCIC Base Case

Cut Set Report

\begin{tabular}{|c|c|c|c|c|}
\hline Cut No. & \% Total & \% Cut Set & Frequency & Cut Sets \\
\hline & 22.1 & 22.1 & $1.100 \mathrm{E}-002$ & RCI-SYS-MA-UNAVA \\
\hline 2 & 40.2 & 18.0 & $9.000 \mathrm{E}-003$ & RCI-ASI-HW-SPUR \\
\hline 3 & 48.6 & 8.4 & $4.200 \mathrm{E}-003$ & RCI-PMP-FS-P0219 \\
\hline 4 & 57.0 & 8.4 & 4.200E-003 & RCI-PMP-FS-P0220 \\
\hline 5 & 64.8 & 7.8 & 3.883E-003 & ESW-TRA-HW-RCCLR \\
\hline 6 & 70.9 & 6.0 & $3.000 \mathrm{E}-003$ & RCI-MOV-CC-MV132 \\
\hline 7 & 76.9 & 6.0 & $3.000 \mathrm{E}-003$ & RCI-MOV-CC-MV131 \\
\hline 8 & 82.9 & 6.0 & 3.000E-003 & RCI-MOV-CC-MV21 \\
\hline 9 & 86.3 & 3.4 & $1.700 \mathrm{E}-003$ & RCI-TUR-FS-2DS38 \\
\hline 10 & 89.8 & 3.4 & $1.700 \mathrm{E}-003$ & RCI-PMP-FS-2DS38 \\
\hline 11 & 91.8 & 2.0 & $1.000 \mathrm{E}-003$ & RCI-ASL-HW-4295 \\
\hline 12 & 93.8 & 2.0 & $1: 000 \mathrm{E}-003$ & RCI-ASP-HW-2840 \\
\hline 13 & 95.8 & 2.0 & $1.000 \mathrm{E}-003$ & RCI-RDD-LKS-RD01 \\
\hline 14 & 96.9 & 1.1 & 5.660E-004 & ESF-ASL-HW-LHRCI \\
\hline 15 & 97.5 & 6 & $3.000 \mathrm{E}-004$ & RCI-AOV-VF-PCV96 \\
\hline 16 & 98.1 & .6 & $3.000 \mathrm{E}-004$ & RCI-MOV-FC-MVO1 \\
\hline 17 & 98.7 & .6 & $3.000 \mathrm{E}-004$ & RCI-HOV-FC-MVO2 \\
\hline 18 & 99.3 & .6 & $3.000 \mathrm{E}-004$ & RCI-AOV-VF-PCV23 \\
\hline 19 & 99.8 & .4 & $2.280 \mathrm{E}-004$ & RCI-HXX-PG-E212 \\
\hline 20 & 100.0 & .3 & $1.610 \mathrm{E}-004$ & ESF-XHE-FO-HPSAT \\
\hline 21 & 100.0 & .2 & $1.250 \mathrm{E}-004$ & RCI-ICC-HW-FIC91 \\
\hline 22 & 100.0 & .2 & $1.000 \mathrm{E}-004$ & RCI-CKV-HW-CV19 \\
\hline 23 & 100.0 & .2 & $1.000 \mathrm{E}-004$ & RCI-CKV-HW-V030 \\
\hline 24 & 100.0 & .2 & $1.000 E-004$ & RCI-CKV-HW-CVSO \\
\hline 25 & 100.0 & .2 & $1.000 \mathrm{E}-004$ & RCI-CKV-HW-HCO10 \\
\hline 26 & 100.0 & .2 & 1.000E-004 & RCI-CKV-HW-F028 \\
\hline 27. & 100.0 & .0 & $4.000 \mathrm{E}-005$ & RCI-MOV-PG-F060 \\
\hline 28 & 100.0 & .0 & $4.000 \mathrm{E}-005$ & RCI-XVM-PG-F049 \\
\hline 29 & 100.0 & .0 & $4.000 E-005$ & RCI-MOV-PG-MV16 \\
\hline 30 & 100.0 & .0 & 4.000E-005 & RCI-MOV-PG-MV18 \\
\hline 31 & 100.0 & .0 & $4.000 \mathrm{E}-005$ & RCI-MOV-PG-MV15 \\
\hline 32 & 100.0 & .0 & $4.000 \mathrm{E}-005$ & RCI-XVM-PG-XV7 \\
\hline 33 & 100.0 & .0 & $4.000 E-005$ & RCI-MOV-HW-MV2O \\
\hline 34 & 100.0 & .0 & 4.000E-005 & RCI-XVM-HW-CSTO1 \\
\hline 35 & 100.0 & .0 & 4.000E-005 & RCI-XVM-HW-HC018 \\
\hline 36 & 100.0 & .0 & 4.000E-005 & RCI-XVM-PG-F002 \\
\hline 37 & 100.0 & .0 & 1.335E-005 & ESF-ASL-HW-LLRCI \\
\hline 38 & 100.0 & .0 & 1.021E-005 & DCP-TRA-HW-250V \\
\hline 39 & 100.0 & .0 & $5.216 \mathrm{E}-006$ & DCP-TRA-HW-125V \\
\hline 40 & 100.0 & .0 & $3.000 \mathrm{E}-008$ & CST-DEP-NO-WATER \\
\hline
\end{tabular}


Table 7.2. A List of the Component Groups Selected for the RCIC System Parametric Study

\begin{tabular}{|c|c|c|c|c|}
\hline \multirow[b]{2}{*}{ Group Description } & \multicolumn{3}{|c|}{ Coontributing brsic erren! } & \multirow{2}{*}{ 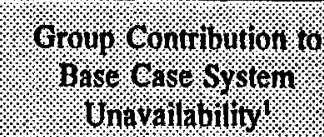 } \\
\hline & Description & Notation: & Unavailability & \\
\hline System instrumentation failures & $\begin{array}{l}\text { Spurious isolations }{ }^{2} \\
\text { Vacuum tank pressure switch } \\
\text { Vacuum tank level switch } \\
\text { System actuation circuitry }\end{array}$ & $\begin{array}{l}\text { RCIC-ASI-HW-SPUR } \\
\text { RCIC-ASP-HW-2840 } \\
\text { RCIC-ASL-HW-4295 } \\
\text { RCIC-ACT-HW-RCIC }\end{array}$ & $\begin{array}{l}9.0 \mathrm{E}-3^{2} \\
1.0 \mathrm{E}-3 \\
1.0 \mathrm{E}-3 \\
1.0 \mathrm{E}-3\end{array}$ & $24 \%$ \\
\hline Check valve failures to open & 5 system check valves & RCIC-CKV-HW- & 1.0E-4 each & $1 \%$ \\
\hline Turbine control valves fail closed & Governor valve trip/throttle valve & $\begin{array}{l}\text { RCI-HOV-FC-MVO2 } \\
\text { RCI-MOV-FC-MVO1 }\end{array}$ & $\begin{array}{l}3.0 \mathrm{E}-4 \\
3.0 \mathrm{E}-4 \\
\end{array}$ & $1 \%$ \\
\hline Lube oil cooler plugging & & RCI-NXX-PG-E212 & $2.28 \mathrm{E}-4$ & $<1 \%$ \\
\hline Turbine flow controller failure & & RCI-ICC-HW-FIC91 & $1.25 \mathrm{E}-4$ & $<1 \%$ \\
\hline Maintenance unavailability ${ }^{3}$ & & RCI-SYS-MA-UNAVA & $1.1 \mathrm{E}-2$ & $22 \%$ \\
\hline Pump failures to start/run & $\begin{array}{l}\text { main pump } \\
\text { vacuum pump } \\
\text { condensate pump }\end{array}$ & $\begin{array}{l}\text { RCI-PMP-FS-2DS38 } \\
\text { RCI-PMP-FS-PO219 } \\
\text { RCI-PMP-FS-PO220 }\end{array}$ & $\begin{array}{l}1.7 \mathrm{E}-3 \\
4.2 \mathrm{E}-3 \\
4.2 \mathrm{E}-3\end{array}$ & $20 \%$ \\
\hline Turbine exhaust rupture disk leaks or fails & - & RCI-RDD-LKS-RD01 & $1.0 \mathrm{E}-3$ & $2 \%$ \\
\hline Turbine mechanical failure & - & RCI-TUR-FS-2DS38 & $1.7 \mathrm{E}-3$ & $3 \%$ \\
\hline $\begin{array}{l}\text { System MOVs and PCVs fail to function on } \\
\text { demand }\end{array}$ & $\begin{array}{l}2 \text { pressure control and } 4 \text { motor } \\
\text { operated valves }\end{array}$ & $\begin{array}{l}\text { RCI-AOV-VF-PCV } \\
\text { RCI-MOV-CC-MV }\end{array}$ & $\begin{array}{l}3.0 \mathrm{E}-4 \\
3.0 \mathrm{E}-3\end{array}$ & $19 \%$ \\
\hline
\end{tabular}

1. Other basic events such as operator error and support system failures comprise the balance of the RCIC base case unavailability. These events have been excluded from the parametric study.

2. The spurious isolations (RCI-ASI-HW-SPUR) is a super component that is comprised of approximately 15 single instrument failures. Five of these failures are the major contributors to this unavailability. There are also four isolations that require two out of two logic. These are not significant contributors to this category.

3. Maintenance unavailability includes scheduled testing maintenance (i.e., inservice testing and preventative maintenance) and unscheduled (corrective) maintenance. Corrective maintenance activities can be expected to increase as the system ages. 
the component and the number of times it occurs in the fault tree. Thus, from Table 7.2, maintenance unavailability, as a single basic event, is important because of its relatively high probability of 1.1 E-2. The instrumentation, valve and pump groups, on the other hand, all have individual failure estimates in the 1 to $4 \mathrm{E}$ 3 range. However, these groups have multiple components that, in the aggregate, are major contributors to RCIC system unavailability.

Other contributors that are less significant on a group basis are mechanical failures of the RCIC turbine (3\%), and leakage from ruptured disks in the turbine exhaust line. Each consists of a single basic event with component failure estimates that are approximately equal to a valve. So, as a component, the turbine is as important as the steam admission valve. However, on a group basis, the valves dominate because of their sheer numbers.

The remaining groups contribute $1 \%$ or less to RCIC unavailability, in the $1 \mathrm{E}-4$ range, primarily due to lower individual component unavailability.

\subsection{Parametric Study for Aging Effects}

To simulate the potential effects of uncontrolled system aging, a parametric study was performed to determine the potential impact on total system unavailability as the base-case failure rates are increased. The contributing basic event unavailabilities for each group were increased by factors of 2,5 , and 10 , and the total system unavailability was recalculated. As an upper limit, all of the basic events of Table 7.2 were simultaneously increased.

Table 7.3 gives the results of this analysis. The four major contributors to the base-case system unavailability, pumps, MOVs/PCVs, instrumentation and maintenance unavailability have a similar influence on RCIC system unavailability. For example, when the instrumentation failure rate is increased by a factor of 5 , the total system unavailability increases by a factor of 1.8. At ten times, the total system failure rate increases to 2.8 times the base case, and accounts for approximately 75 $\%$ of the system unavailability.

These results, although significant, are influenced by the lack of a dominant contributor to the system failure rate. For example, if pumps comprised $50 \%$ of the base case failure rate, the parametric study would show approximately twice the sensitivity to the pump failure rate than it currently does.

Maintenance unavailability was included in this analysis since aging degradation can increase the downtime necessary for maintenance. The parametric study shows that the effects of an increase in the maintenance unavailability rate on total unavailability are similar to those for instrumentation, MOVs/PCVs, and pumps. However, no data are available to estimate the effects of aging on increase in downtime for maintenance.

In conclusion, the failure rates of the following components are affected by aging, and, in turn, they affect the availability of the RCIC system:

- Switches/bistables,

- Pumps,

- MOVs and PCVs,

\subsection{Summary}

The unavailability analysis using a probabilistic approach is useful in identifying important components which should receive additional aging management attention. The fault-tree analysis identified pump failure to start/run, valve failures to open, instrumentation failures, and maintenance as the main causes for the RCIC system unavailability for this specific design analyzed. Further analysis using the IRRAS code found that the base-case system unavailability is $5.0 \times 10^{-2}$, and that the contribution to system unavailability due to system instrumentation failures, maintenance 
Table 7.3. Results of the Parametric Study

\begin{tabular}{|c|c|c|c|c|}
\hline Group Bescription & Traneric & Gangelset & $\begin{array}{l}\text { Toral Systern } \\
\text { Unavilabiity: }\end{array}$ & Unavailability \\
\hline Base Case & 1 & Base & $5.0 \mathrm{E}-2$ & 1.0 \\
\hline Instrumentation Failures & $\begin{array}{l}2 \\
5 \\
10\end{array}$ & $\begin{array}{l}\text { ASI-2 } \\
\text { ASI-5 } \\
\text { ASI-10 }\end{array}$ & $\begin{array}{l}6.0 \mathrm{E}-2 \\
9.2 \mathrm{E}-2 \\
1.4 \mathrm{E}-1\end{array}$ & $\begin{array}{l}1.2 \\
1.8 \\
2.8\end{array}$ \\
\hline Check valve failures & & $\begin{array}{l}\text { CKV-2 } \\
\text { CKV-5 } \\
\text { CKV-10 }\end{array}$ & $\begin{array}{l}5.0 \mathrm{E}-2 \\
5.2 \mathrm{E}-2 \\
5.4 \mathrm{E}-2\end{array}$ & $\begin{array}{l}1.0 \\
1.0 \\
1.1\end{array}$ \\
\hline Turbine control valve failures & $\begin{array}{l}2 \\
5 \\
10\end{array}$ & $\begin{array}{l}\text { HOV-2 } \\
\text { HOV-5 } \\
\text { HOV-10 }\end{array}$ & $\begin{array}{l}5.0 \mathrm{E}-2 \\
5.2 \mathrm{E}-2 \\
5.5 \mathrm{E}-2\end{array}$ & $\begin{array}{l}1.0 \\
1.0 \\
1.1\end{array}$ \\
\hline $\begin{array}{l}\text { Lube Oil cooler plugging } \\
\qquad\end{array}$ & $\begin{array}{l}2 \\
5 \\
10\end{array}$ & $\begin{array}{l}\text { HXX-2 } \\
\text { HXX-5 } \\
\text { HXX-10 }\end{array}$ & $\begin{array}{l}5.0 \mathrm{E}-2 \\
5.1 \mathrm{E}-2 \\
5.2 \mathrm{E}-2\end{array}$ & $\begin{array}{l}1.0 \\
1.0 \\
1.0\end{array}$ \\
\hline Turbine flow controller failure & $\begin{array}{l}2 \\
5 \\
10\end{array}$ & $\begin{array}{l}\text { ICC-2 } \\
\text { ICC-5 } \\
\text { ICC-10 }\end{array}$ & $\begin{array}{l}5.0 \mathrm{E}-2 \\
5.0 \mathrm{E}-2 \\
5.1 \mathrm{E}-2\end{array}$ & $\begin{array}{l}1.0 \\
1.0 \\
1.0\end{array}$ \\
\hline Maintenance unavailability & $\begin{array}{l}2 \\
5 \\
10 \\
\end{array}$ & $\begin{array}{l}\text { MAI-2 } \\
\text { MAI-5 } \\
\text { MAI-10 }\end{array}$ & $\begin{array}{l}6.0 \mathrm{E}-2 \\
9.2 \mathrm{E}-2 \\
1.4 \mathrm{E}-1\end{array}$ & $\begin{array}{l}1.2 \\
1.8 \\
2.8\end{array}$ \\
\hline Pump failures & $\begin{array}{l}2 \\
5 \\
10\end{array}$ & $\begin{array}{l}\text { PMP-2 } \\
\text { PMP-5 } \\
\text { PMP-10 }\end{array}$ & $\begin{array}{l}5.9 \mathrm{E}-2 \\
8.8 \mathrm{E}-2 \\
1.3 \mathrm{E}-1\end{array}$ & $\begin{array}{l}1.2 \\
1.8 \\
2.6\end{array}$ \\
\hline Rupture disk failure & $\begin{array}{l}2 \\
5 \\
10\end{array}$ & $\begin{array}{l}\text { RDD-2 } \\
\text { RDD-5 } \\
\text { RDD-10 }\end{array}$ & $\begin{array}{l}5.1 \mathrm{E}-2 \\
5.4 \mathrm{E}-2 \\
5.8 \mathrm{E}-2\end{array}$ & $\begin{array}{l}1.0 \\
1.1 \\
1.2\end{array}$ \\
\hline Turbine mechanical failure & $\begin{array}{l}2 \\
5 \\
10\end{array}$ & $\begin{array}{l}\text { TUR-2 } \\
\text { TUR-5 } \\
\text { TUR-10 }\end{array}$ & $\begin{array}{l}5.1 \mathrm{E}-2 \\
5.6 \mathrm{E}-2 \\
6.4 \mathrm{E}-2\end{array}$ & $\begin{array}{l}1.1 \\
1.1 \\
1.3\end{array}$ \\
\hline MOV and PCVs fail to function & $\begin{array}{l}2 \\
5 \\
10\end{array}$ & $\begin{array}{l}\text { VLV-2 } \\
\text { VLV-5 } \\
\text { VLV-10 }\end{array}$ & $\begin{array}{l}5.9 \mathrm{E}-2 \\
8.6 \mathrm{E}-2 \\
1.3 \mathrm{E}-1\end{array}$ & $\begin{array}{l}1.2 \\
1.7 \\
2.6\end{array}$ \\
\hline All components & $\begin{array}{l}2 \\
5 \\
10 \\
\end{array}$ & $\begin{array}{l}\text { ALL-2 } \\
\text { ALL-5 } \\
\text { ALL-10 }\end{array}$ & $\begin{array}{l}9.3 \mathrm{E}-2 \\
2.1 \mathrm{E}-1 \\
3.8 \mathrm{E}-1\end{array}$ & $\begin{array}{l}1.9 \\
4.2 \\
7.6\end{array}$ \\
\hline
\end{tabular}

1 Factor $=$ Parametric System Unavailability/Base Case Unavailability

2 Maintenance unavailability includes scheduled testing maintenance (i.e., inservice testing and preventative maintenance) and unscheduled (corrective) maintenance. Corrective maintenance activities can be expected to increase as the system ages. 
unavailability, pump failures to start/run and the valve failures groups are all about $20 \%$. Also, this analysis ranked the importance of RCIC components: switches/bistables, pumps, and valve operators.

The parametric study for the uncontrolled aging degradation showed that, when the failure rate of one of the three important components doubles, the total system unavailability increases by a factor of 1.2. When the rates increases by factors of 5 and 10, the total system unavailability increases by a factor of 1.8 and 2.8 , respectively. The potential importance of independent aging related effects on system unavailability is underscored by increasing the failure rates of potential impact of aging by factors of 2,5 , and 10 . Although the potential impact of aging is generally more pronounced on multiple train systems, it is also significant for RCIC. When the failure rates of all the components are increased, due to uncontrolled aging, by factors of 2,5 , and 10 , the system unavailability increases by a factor of $1.9,4.2$, and 7.6, respectively. These results show that if the aging degradation of these components is not properly controlled, and the failure rates increase over time, the aging-related failures will lead to an increased RCIC system unavailability.

It should be noted that this analysis was conducted for one BWR design, only to show the potential effects of uncontrolled aging on RCIC system unavailability. Also, the failure rate data used for this analysis are from a limited source. Thus, the results should be used with care. However, this type of analysis can be a useful tool to identify important components which should receive additional aging management attention if it is performed on a plant specific basis. 


\section{INSPECTION, SURVEILLANCE, AND MONITORING (IS\&M) PRACTICES}

Inspection, surveillance, and monitoring methods were reviewed to provide a preliminary look at what is being done to detect and mitigate aging degradation in the RCIC system.

\subsection{Failure Detection Methods}

The NPRDS database was reviewed to find out how the component failures are detected; the results for the seven important components are shown in Figures 8.1 - 8.7. Operational abnormality is a failure detected while the component is in service (operating or standby). For valve operators, circuit breakers, and pumps, these are all demand faults; for switches, they are demand faults and out of specification failures. For valves and transmitters, most of the operational abnormalities are due to leakage and out of specification failures, respectively.

Surveillance testing detected most of the failures of bistable/switches, valves, turbines, and valve operators. On the other hand, the fraction of failures detected by surveillance testing for circuit breakers, transmitters, and pumps are $40 \%, 30 \%$, and $18 \%$, respectively.

It is desirable that most failures are detected during inspections, surveillance testing, and monitoring (IS\&M), and very few during operation. Thus, another criterion that can be used to assess the effectiveness of the IS\&M practices is identifying what fraction of failures is detected by operational abnormality; the fraction for each component is shown in Figure 8.8 .

For valve operators, pumps, and transmitters, the fraction of failures that occurred during operation is $18 \%$ each, which is much higher than that for turbines, valves, or bistables/switches; for circuit breakers, it is even higher at $27 \%$. Thus, improvements to current IS\&M procedures for valve operators, pumps, transmitters, and circuit breakers may be possible to detect the failures before they affect the system function.

\subsection{System Testing}

Every 18 months, RCIC Functional and Flow Verification are performed to determine the operability of the RCIC System (150 psig test) in conformance with the requirements of the Technical Specifications.

\subsection{Component Testing}

Components are tested and examined periodically to ensure their operational readiness and structural integrity. The RCIC pump is tested in accordance with Section XI of the ASME Boiler and Pressure Vessel Code, which requires quarterly measurements of pump speed, flow, vibration and head. The pumps are tested through a full flow test line back to the CST. The performance parameters are measured and compared to reference valves. Degraded performance will require either an increase in the testing frequency or corrective action, depending on the degree of degradation.

Valves are also tested in accordance with Section XI. Valves are exercised quarterly, or during cold shutdowns if quarterly testing is impractical. Check valves are full-flow tested. The power-related valves are all exercised with their stroke time measured and evaluated for degraded performance. Valves with fail-safe actuations are tested quarterly by observing the generation of the actuator upon loss of power. The RCIC containment isolation and pressure isolation valves are additionally tested for leaks once every two years in accordance with Section $X I$. Any valve with remote position indication is observed locally at least once every 2 years to verify that the indication is correct.

All passive pressure retaining components are pressure tested in accordance with Section $\mathrm{XI}$ once every three years, and hydrostatically tested once every ten years. Additionally, $25 \%$ 
of welds are non-destructively tested once every ten years, in accordance with Section XI.

The relief valves are set-point tested once every 5 years, and rupture disks are replaced every 5 years. In addition to the Section XI testing requirements, licensees are also required to test the RCIC pump and valves in accordance with the technical specifications. Pump flow is verified quarterly at normal steam pressure, and every 18 months at reduced pressure. The valves position is verified every 31 days and valve actuation is verified every 18 months.
RCIC component testing is summarized in Table 8.1.

EPRI published a guide on Terry turbine control systems, NP-6909 (Ref. 31) that gives detailed instructions on the maintenance, calibration, adjustment, and repair of turbine control systems, e.g., for the overspeed trip assembly and governor valve. Additionally, General Electric provides operational and maintenance instructions, which may be included in the licensees preventative maintenance programs.

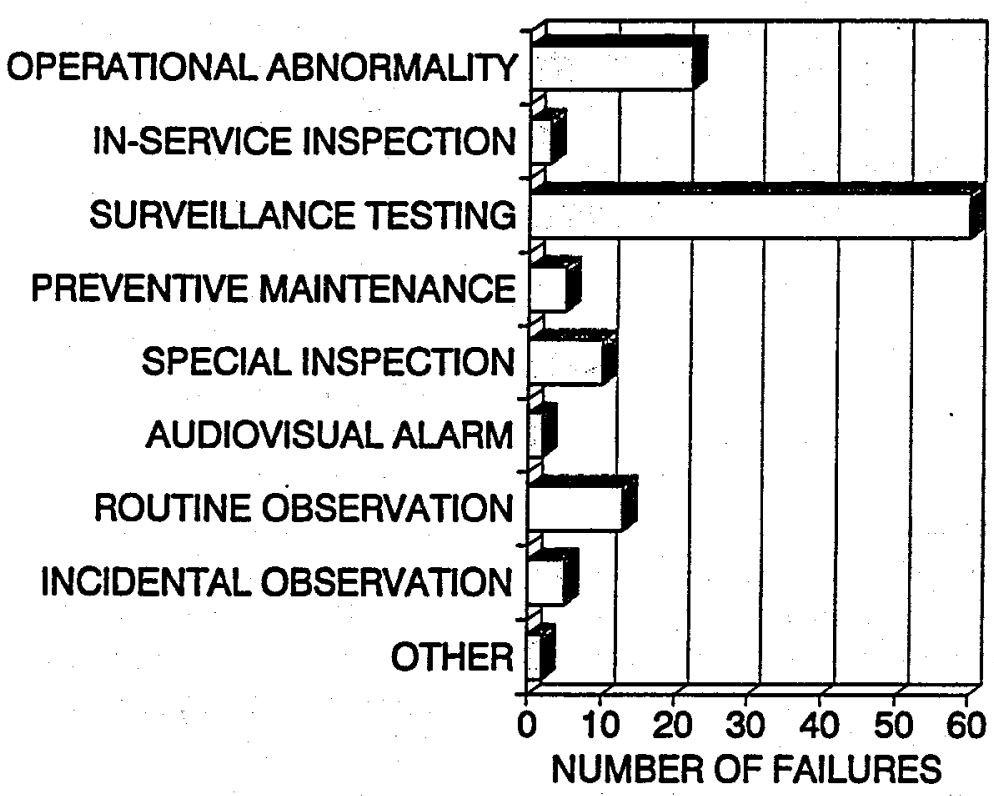

SOURCE : NPRDS (1986 - 91)

Figure 8.1 Failure detection for valve operators 


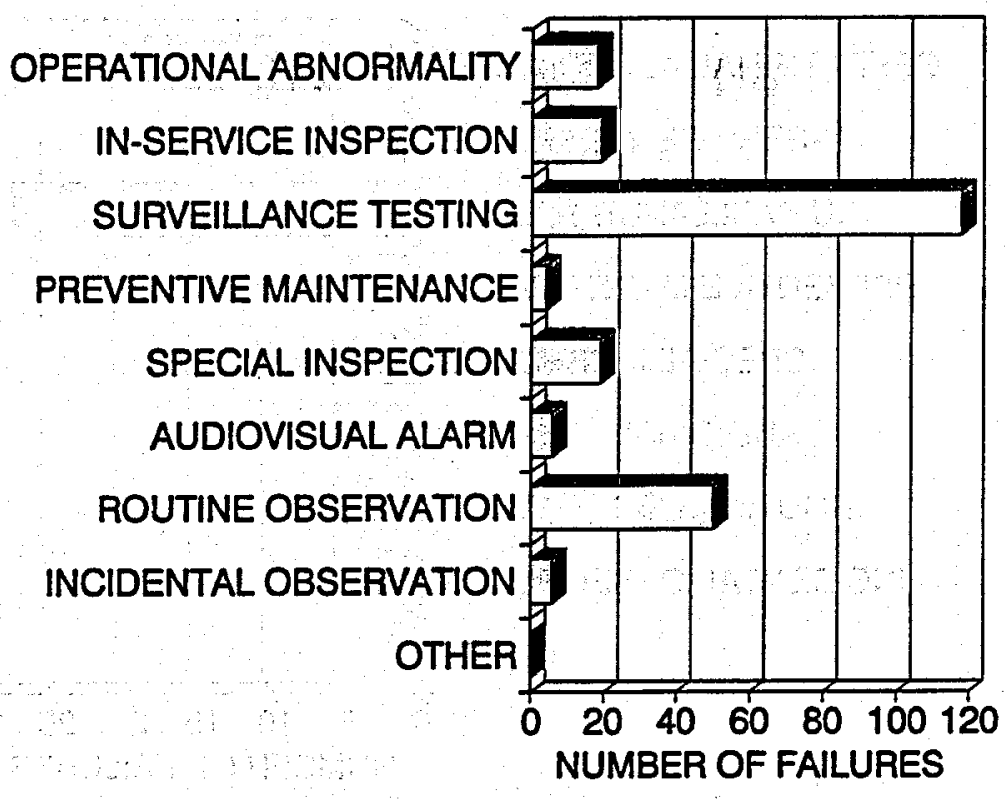

SOURCE : NPRDS (1986 - 91)

Figure 8.2 Failure detection for valves

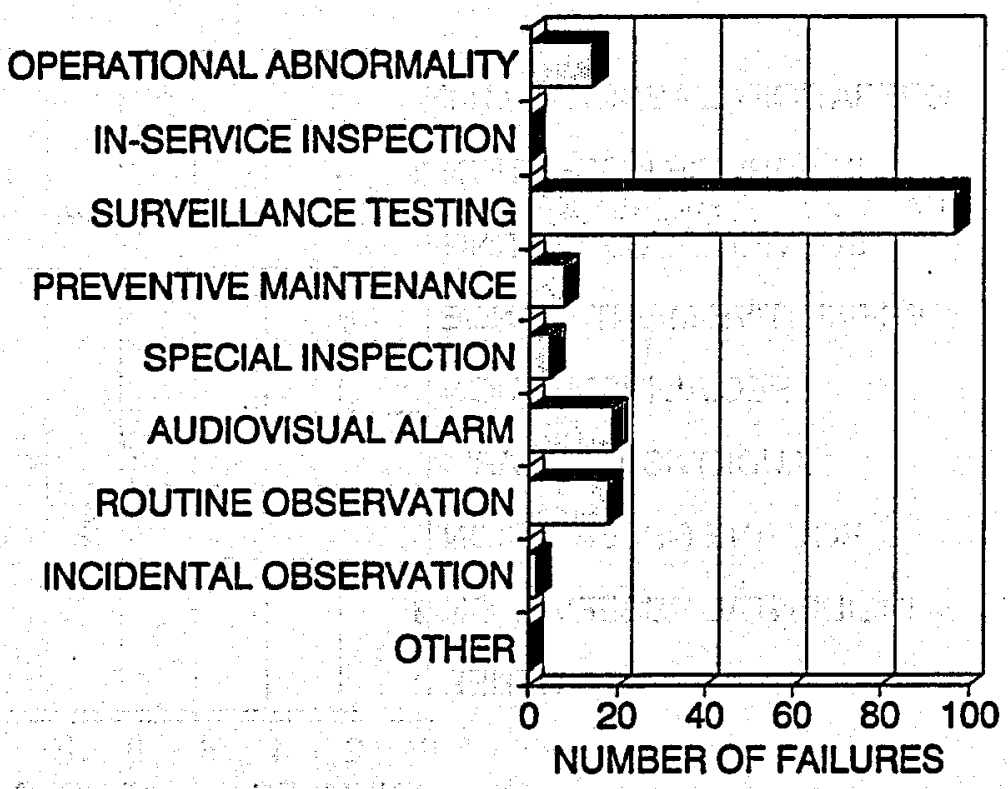

SOURCE : NPRDS (1986 - 91)

Figure 8.3 Failure detection for bistables/switches 


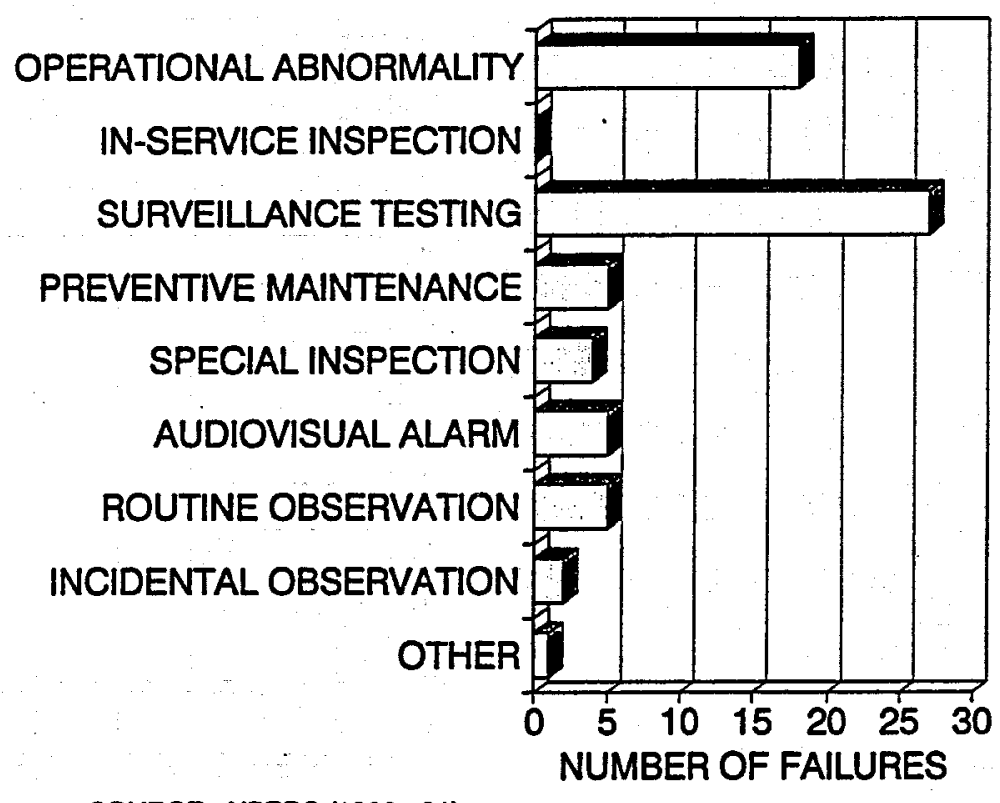

SOURCE : NPRDS (1986 - 91)

Figure 8.4 Failure detection for circuit breakers

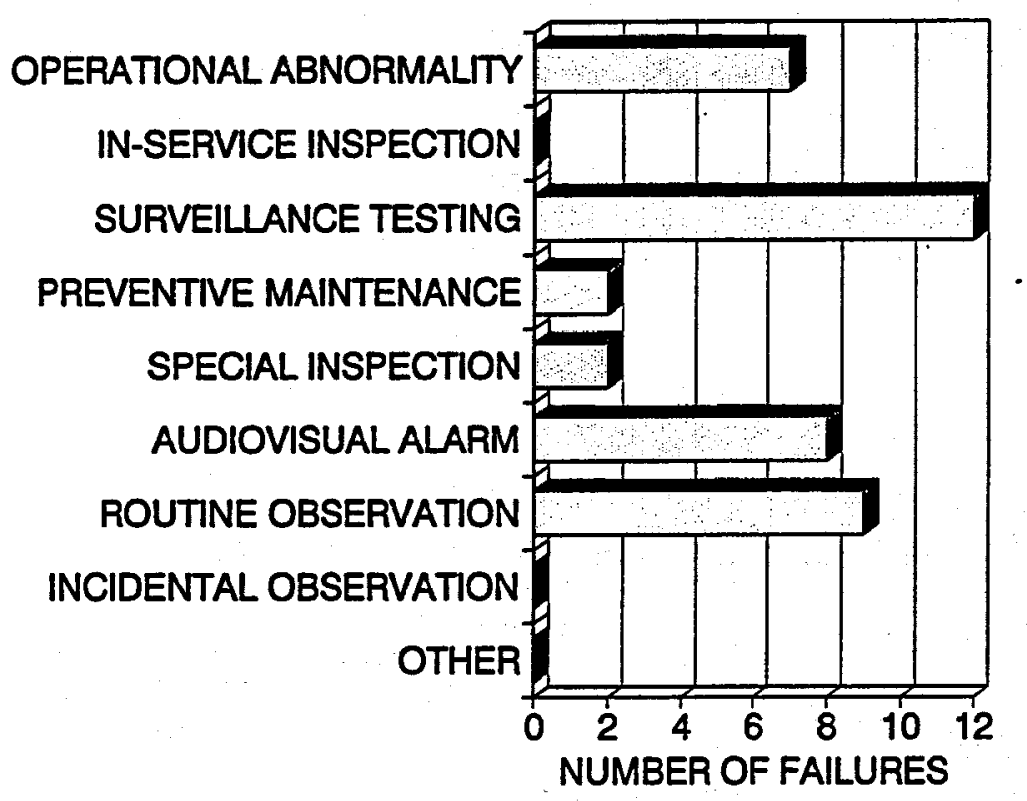

SOURCE : NPRDS (1986 - 91)

Figure 8.5 Failure detection for transmitters 


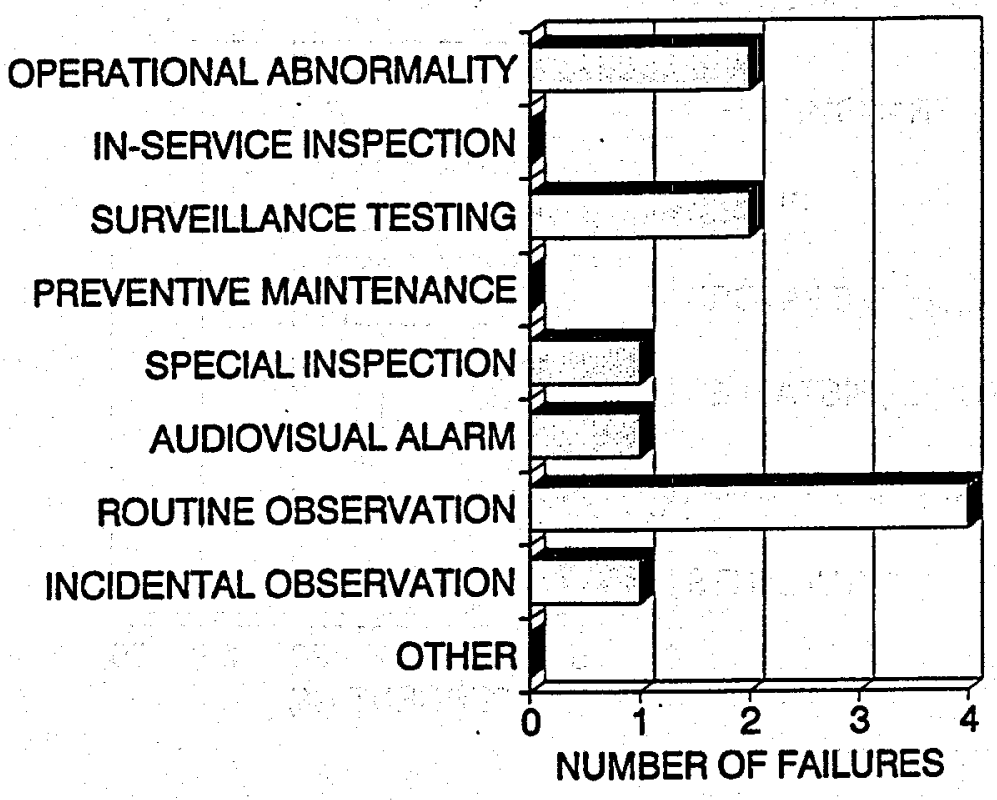

SOURCE : NPRDS (1986 - 91)

Figure 8.6 Failure detection for pumps

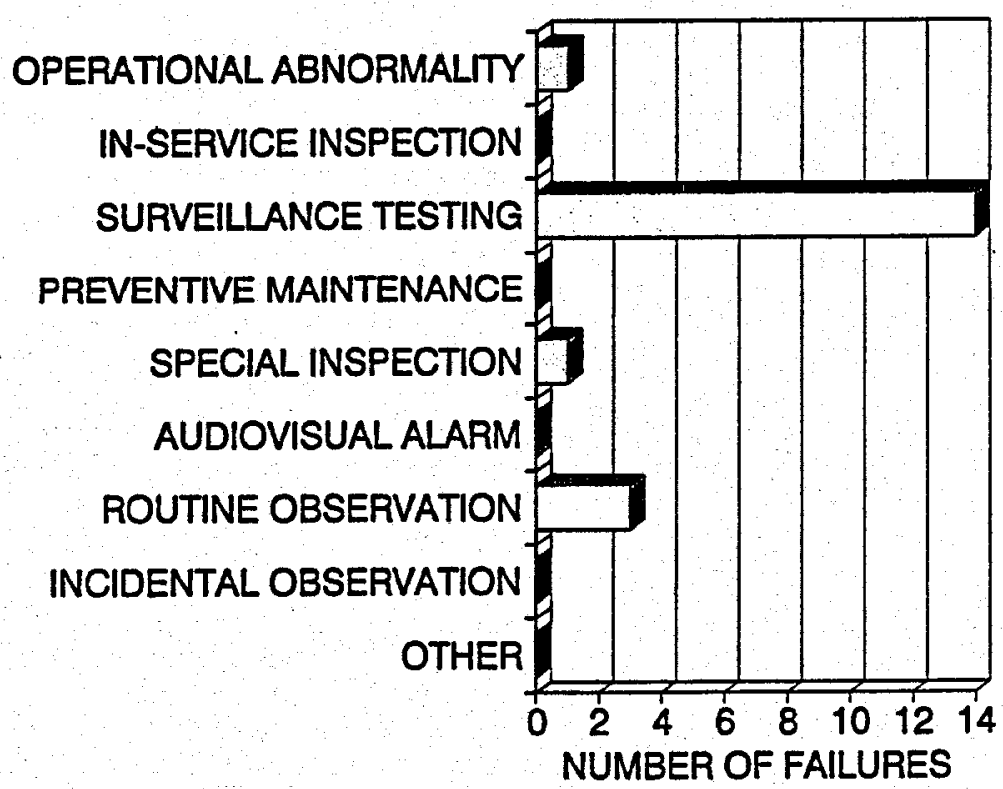

SOURCE : NPRDS (1986 - 91)

Figure 8.7 Failure detection for turbine 


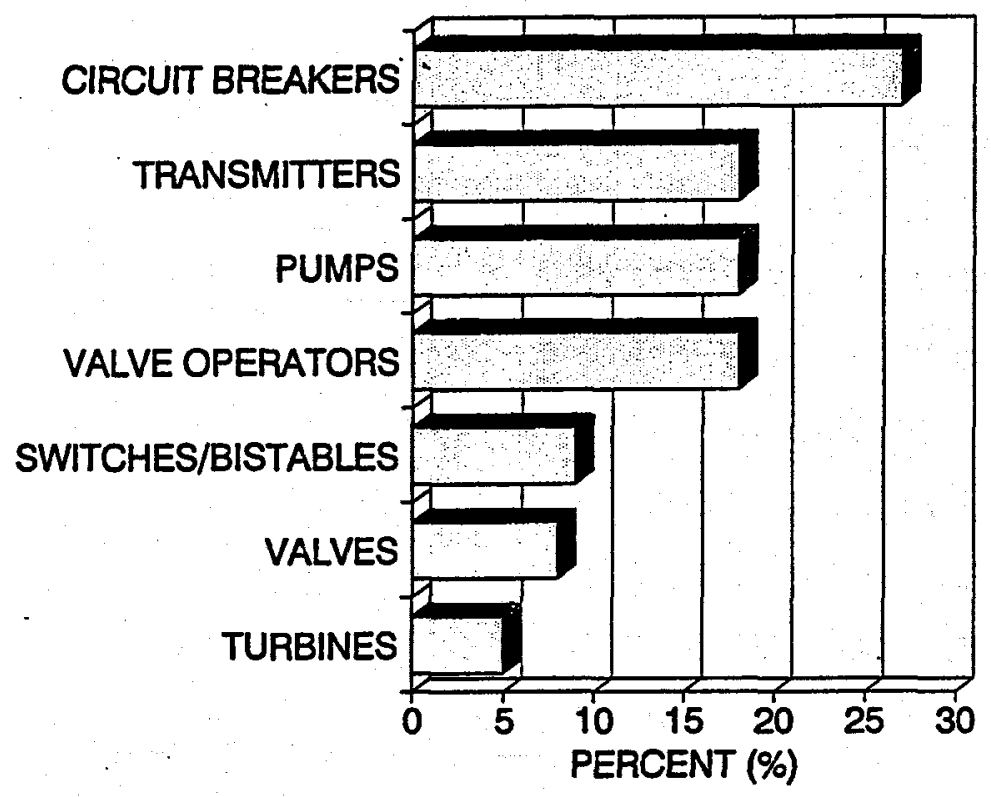

SOURCE : NPRDS (1986-91)

Figure 8.8 The fraction of the failures detected by operational abnormality 
Table 8.1 Summary of RCIC Component Tests and Inspections

\begin{tabular}{|c|c|c|}
\hline Component & IS\&M Practice & Frequency \\
\hline \multirow[t]{7}{*}{ Valves } & $\begin{array}{l}\text { Verify position indication } \\
\text { Verify correct position }\end{array}$ & 31 days \\
\hline & Verify stroke time ${ }^{1,2}$ & Quarterly/cold shutdown \\
\hline & Verify full stroke (check valves) ${ }^{1}$ & Quarterly/cold shutdown \\
\hline & Verify valve seat leakage $e^{1,3}$ & 2 years \\
\hline & Verify relief valve set pressure' & 5 years \\
\hline & $\begin{array}{l}\text { Verify automatic valves actuate to } \\
\text { correct position during simulated } \\
\text { automatic actuation }{ }^{2}\end{array}$ & 18 months \\
\hline & $\begin{array}{l}\text { Verify suction for system is } \\
\text { automatically transferred from CST to } \\
\text { suppression pool on Low CST Level } \\
\text { signal }^{2}\end{array}$ & 18 months \\
\hline \multirow[t]{4}{*}{ Pump/Turbine } & $\begin{array}{l}\text { Verify pump develops adequate flow } \\
\text { when steam supply to the turbine is } \\
150 \pm 15 \text { psig }\end{array}$ & 18 months \\
\hline & Verify pump head within limits ${ }^{1}$ & Quarterly \\
\hline & Verify pump flow within limits ${ }^{1,2}$ & Quarterly \\
\hline & Verify pump vibration within limits ${ }^{1}$ & Quarterly \\
\hline \multirow[t]{4}{*}{ Piping } & $\begin{array}{l}\text { Verify no system external leakage } \\
\text { during inservice test }{ }^{1}\end{array}$ & 3 years \\
\hline & Hydrostatically test system ${ }^{1}$ & 10 years \\
\hline & $\begin{array}{l}\text { Non-destructively examine sample of } \\
\text { piping welds }\end{array}$ & 10 years \\
\hline & $\begin{array}{l}\text { Visually examine and test piping } \\
\text { supports/snubbers } 1.2\end{array}$ & 18 months \\
\hline
\end{tabular}

1. ASME Section XI requirement

2. Technical Specification requirement

3. Appendix $\mathrm{J}$ requirement 


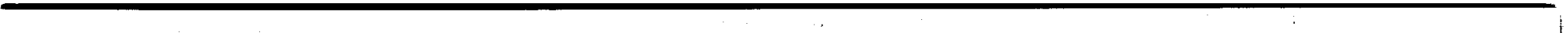




\section{SUMMARY OF RESULTS}

The RCIC system is an important safetyrelated system, providing makeup water to the reactor vessel of a BWR for core cooling when the reactor is isolated from the main condenser with the feedwater system unavailable. The loss of RCIC system contributes to four of the eight representative accident sequences developed in NUREG/CR-5692, Generic Risk Insights for General Electric Boiling Water Reactors.

RCIC is especially important to the BWR 5 and 6 plants since, in the Station Blackout (SBO) sequences, it is the only system that is independent of $\mathrm{AC}$ power. These plants have a motor-driven, high pressure core spray system instead of the turbine-driven high pressure coolant injection system found in earlier plants.

Because RCIC is a standby system, it experiences less aging degradation due to wear, erosion and vibration compared to continuously operating systems. However, the aging degradation caused by corrosion and dirt accumulation may be more prevalent due to the stagnant conditions during standby periods. Testing is an important source of stress for some standby components (e.g., turbines, pumps, valve operators) that may contribute to premature failures. Since this system is categorized as a safety-related system, components are more frequently tested to assure their operability. Thus, one possible means to minimize the aging degradation is optimizing the test frequencies. However, this should be based on formal, systematic analysis on beneficial and adverse effects of frequent tests.

From January 1986 to December 1991, 920 RCIC component failures were reported to the Nuclear Plant Reliability Data System (NPRDS), of which $87 \%$ were aging-related. Between January 1985 and April 1992, 132 Licensee Event Reports (LER) were identified as caused by failures of RCIC components, of which $80 \%$ were aging-related. This contribution of agingrelated failures to the LER events increased as the plants got older. Plant specific data from an operating BWR showed the plant conducted 144 corrective maintenance actions on the RCIC system over 5 years, and $83 \%$ of these were due to aging-related failures. These failure data clearly show that aging causes most of the failures in the RCIC system.

NPRDS data analysis showed that the effects of the component failures on the RCIC system function become more and more serious as the components age. During the period of 1986 87 , about $22 \%$ of the component failures resulted in loss of system function or degraded system operation, which increased to $30 \%$ and $36 \%$ for the periods of 1988 - 89 and 1990 91 , respectively. This agrees with the results of LER analysis that showed increased agingrelated failures in the LER events as the plants get older. LERs contain events that are more safety significant compared to those reported to NPRDS.

The main and auxiliary trains of the RCIC system do not have redundancy; the High Pressure Coolant Injection (HPCI) system or the High Pressure Core Spray system (HPCS) is the main back-up to the RCIC system. There is only limited redundancy in its instrumentation and control (I\&C) subsystem. Therefore, many more losses of system function due to component failures occur compared to other safety systems.

For effective aging management, it is valuable to rank the importance of the RCIC components, i.e., prioritization. Table 9.1 shows these rankings obtained using four different criteria: number of aging-related failures reported to NPRDS, number of loss of system function failures reported to NPRDS, number of aging-related failures as LERs, and contribution to system unavailability. The information for the last criterion was obtained by conducting a probabilistic analysis. Valves fail most often mainly because they are more numerous than other components, but they are ranked 5th when the criterion of number of loss 
Table 9.1 Importance Ranking for RCIC

Components

\begin{tabular}{|c|l|l|l|l|}
\hline \multirow{2}{*}{ Ranking } & \multicolumn{4}{|c|}{ Criteria } \\
\cline { 2 - 5 } & $\begin{array}{c}\text { Number of NPRDS } \\
\text { Aging-related } \\
\text { failures }\end{array}$ & $\begin{array}{c}\text { Number of NPRDS } \\
\text { Loss of System } \\
\text { Function Failures }\end{array}$ & $\begin{array}{c}\text { Number of } \\
\text { LERs }\end{array}$ & Unavailability \\
\hline 1 & Valves & Valves Operators & $\begin{array}{l}\text { Valve } \\
\text { operators }\end{array}$ & $\begin{array}{l}\text { Switches/ } \\
\text { Bistables }\end{array}$ \\
\hline 2 & Switches/Bistables & Switches/Bistables & $\begin{array}{l}\text { Switches/ } \\
\text { Bistables }\end{array}$ & Pumps \\
\hline 3 & Valve Operators & Circuit Breakers & Governors & Valve Operators \\
\hline 4 & Circuit Breakers & Governors & Valves & \\
\hline 5 & Transmitters & Valves & Turbines & \\
\hline 6 & Governors & Turbines & Flow \\
Controllers & \\
\hline 7 & Turbines & Transmitters & Pumps & \\
\hline 8 & Pumps & Pumps & Transmitters & \\
\hline
\end{tabular}

of system function failures is used. The reason is because the main failure mode for valves is leakage, which generally degrades the system operation, but does not necessarily cause a loss of system function. On the other hand, the failure frequency of the governors is low, but most of their failures cause a loss of system function, putting them in a higher rank when the criterion of number of loss of system function failures is used.

The fault-tree analysis identified pump failure to start/run, valve failures to open, instrumentation failures, and maintenance as the main causes of RCIC system unavailability. Further analysis using the IRRAS code found that the base-case system unavailability is $5.0 \mathrm{x}$ $10^{-2}$, and that the contribution to system unavailability due to these four groups is roughly equal, at about $20 \%$ each. The components whose failures are responsible for the system unavailability are switches/bistables, pumps, and valve operators. The unavailability analysis is, in fact, based on the product of importance of the component and the failure rate, which is equivalent to combining the other three criteria, which are failure frequency (number of NPRDS aging-related failures) and the importance to safety (number of NPRDS loss of system function failures, number of LERs). Thus, the resulting ranking (Table 9.1) agrees with the rankings obtained from the other criteria, except for the pump. This analysis showed that $\mathrm{RCIC}$ pumps are very important due to their significant role in the accident scenario, despite a generally low failure rate.

This study shows that if only one criterion is used for prioritization, important components may be overlooked. For example, number of failures is the criterion most commonly used; however, this would not identify governors and pumps as important components. Based on the four criteria examined in this study for 
prioritizing components, it is concluded that aging management of valve operators, switches/ bistables, governors, valves, circuit breakers, and pumps is important to reduce and mitigate the aging effects on the RCIC system. These components should receive the highest priority in aging management programs.

Out of the 31 BWR units that have RCIC systems, 26 were selected for a failure frequency analysis based on the number of failures reported by each. The failure frequency curve for the RCIC components shows that it peaks at 3 - 4 years of age, followed by another peak at 11 - 13 years. Since this curve represents the combined failure frequency for seven major components, it is important to know which ones contributed to the peaks of the system failure frequency curve.

After studying the effects of aging on failure frequencies for the seven important components in the RCIC system, it was found that failures of valves and switches/bistables are the primary cause of the peak at 3-4 years. The failures of valve operators also contributed to this peak. The second peak at $11-13$ years is due to the increased failures of valves, switches/bistables, circuit breakers, and valve operators.

There are two major groups of valves in a RCIC system, steam valves and water valves, and it is important to know which is more susceptible to aging. The analysis of NPRDS data shows that the failure frequencies for steam valves are much higher than those for water valves. This is believed to be due to the fact that steam valves operate under harsher environmental stresses than water valves, therefore, more attention should be paid to their maintenance. The analysis of the plant-specific data verified this. The aging characteristics for the major components, obtained from the analysis of the operational data, are summarized in Table 9.2.

The parametric study simulating uncontrolled aging degradation showed that, when the failure rate of one of the three important components (i.e., switches/bistables, pumps, and MOVs/PCVs) doubles, the total system unavailability increases by a factor of 1.2. When the rate increases by factors of 5 and 10 , the total system unavailability increases by a factor of 1.8 and 2.8 , respectively. The potential importance of independent aging related effects of system unavailability is underscored by increasing the failure rates of all components subject to aging by factors of 2,5 , and 10. Although the potential impact of aging is generally more pronounced on multiple train systems, it is also significant for RCIC. When the failure rates of all the components are increased, due to uncontrolled aging, by factors of 2,5 , and 10 , the system unavailability increases by a. factor of $1.9,4.2$, and 7.6, respectively. These results show that if the aging degradation of these components is not properly controlled, and the failure rates increase over time, the aging-related failures will lead to an increased RCIC system unavailability.

A review of operating data shows that most failures are detected by surveillance tests. However, for valve operators, pumps, and transmitters, about $18 \%$ of the failures for each occurred during operation. For circuit breakers, about $27 \%$ of the failures occurring during operation. Thus, improvements to current IS\&M procedures for valve operators, pumps, transmitters, and circuit breakers may be possible to detect the failures before they affect the system function. 
Table 9.2 Aging Characteristics for RCIC Components

\begin{tabular}{|c|c|c|c|}
\hline Components & Failure Mode & Failure Cause/Mechanism & Proximate Cause \\
\hline Valves & $\begin{array}{l}\text { - External leak } \\
\text {-Internal leak } \\
\text { - Fail to close } \\
\text { - Fail to open }\end{array}$ & $\begin{array}{l}\text { - Normal/abnormal wear } \\
\text { - Dirt accumulation } \\
\text { - Out of adjustment } \\
\text { - Fatigue } \\
\text { - Corrosion }\end{array}$ & $\begin{array}{l}\text { - Worn seat/disc } \\
\text { - Worn packing } \\
\text { - Worn gasket } \\
\text { - Corrosion } \\
\text { product } \\
\text { accumulation }\end{array}$ \\
\hline Valve Operators & $\begin{array}{l}\text {-Fail to operate } \\
\text { as required } \\
\text { - Fail to open } \\
\text { - Fail to close } \\
\text { - Found during } \\
\text { IS\&M }\end{array}$ & $\begin{array}{l}\text { - Normal/abnormal wear } \\
\text { - Out of mechanical } \\
\text { adjustment } \\
\text { - Mechanical damage } \\
\text { - Burned/burned out } \\
\text { - Defective connection }\end{array}$ & $\begin{array}{l}\text { - Failed Torque } \\
\text { switch } \\
\text {-Failed Motor } \\
\text { - Failed Limit } \\
\text { switch } \\
\text { - Failed Tripper } \\
\text { finger }\end{array}$ \\
\hline Switches & $\begin{array}{l}\text { - Fail to change } \\
\text { state } \\
\text { - High actuation } \\
\text { - Low actuation } \\
\text { - Fail to actuate } \\
\text { properiy }\end{array}$ & $\begin{array}{l}\text { - Normal/abnormal wear } \\
\text { - Set point drift } \\
\text { - Out of calibration } \\
\text { - Defective circuits }\end{array}$ & -Sticking float \\
\hline Bistables & $\begin{array}{l}\text {-Fail to change } \\
\text { state } \\
\text { - Spurious } \\
\text { actuation } \\
\end{array}$ & $\begin{array}{l}\text {-Defective circuits } \\
\text {-Burned/burned out }\end{array}$ & $\begin{array}{l}\text { - Failed Transistor } \\
\text { - Dirty Contacts } \\
\text { - Failed Relay }\end{array}$ \\
\hline Circuit Breakers & $\begin{array}{l}\text {-Fail to change } \\
\text { state } \\
\text {-Fail to operate } \\
\text { as required } \\
\text { - Spurious } \\
\text { actuation }\end{array}$ & $\begin{array}{l}\text { - Normal/abnormal } \\
\text { - Mechanical damage } \\
\text { - Fatigue } \\
\text { - Burned/burned out }\end{array}$ & $\begin{array}{l}\text { - Failed Contactor } \\
\text { - Failed Contactor } \\
\text { coil } \\
\text { - Failed Thermal } \\
\text { Overload Relay }\end{array}$ \\
\hline Governors & $\begin{array}{l}\text {-Fail to control } \\
\text { - Fail to start }\end{array}$ & $\begin{array}{l}\text { - Circuit defect } \\
\text { - Out of calibration } \\
\text { - Wear } \\
\text { - Mechanical damage } \\
\text { - Out of adjustment }\end{array}$ & $\begin{array}{l}\text {-Worn-out } \\
\text { Overspeed } \\
\text { tappet } \\
\text { - Failed Ramp } \\
\text { generator } \\
\text {-Failed Magnetic } \\
\text { pickup }\end{array}$ \\
\hline
\end{tabular}


Table 9.2 (Cont'd)

\begin{tabular}{|c|c|c|c|}
\hline Components & Failure Mode & Failure Cause/Mechanism & Proximate Cause \\
\hline Transmitters & $\begin{array}{l}\text { - Low output } \\
\text { - Failure output } \\
\text { - High output }\end{array}$ & $\begin{array}{l}\text {-Out of calibration } \\
\text { - Defective circuit }\end{array}$ & $\begin{array}{l}\text {-Electronic Drift } \\
\text {-Sensing Line } \\
\text { Problems } \\
\text { - Failed Sensor } \\
\text { - Burned-out } \\
\text { amplifier }\end{array}$ \\
\hline Turbine & -Fail to run & - Normal/abnormal wear & $\begin{array}{l}\text {-Worn/loose } \\
\text { mechanical parts }\end{array}$ \\
\hline Pump & -Fail to run & - Normal/abnormal wear & $\begin{array}{l}\text {-Worn seal } \\
\text {-Worn gasket } \\
\text {-Worn bearing }\end{array}$ \\
\hline
\end{tabular}





\section{CONCLUSIONS}

As a result of this Phase I study, aging processes in the RCIC system are better understood through aging characterization of the system and components. The components most frequently affected by aging degradation and those that need priority aging management are identified by the suggested importance rankings. The information obtained from this study provides technical basis upon which future work can be performed.

The following specific findings were obtained:

- Most RCIC component failures reported to NPRDS are due to aging-related degradation (87\%). The analysis of the corrective maintenance records of an operating BWR plant also showed that $83 \%$ of the RCIC component failures are due to aging-related degradation.

- The effects of the component failures on the RCIC system function become more and more serious as the components age. During the period of $1986-87$, about $22 \%$ of the component failures resulted in loss of system function or degraded system operation, which increased to $30 \%$ and $36 \%$ for the periods of $1988-89$ and $1990-91$, respectively.

- Based on failure data analysis and unavailability analysis which utilized PRA techniques, it was concluded that the aging management for valve operators, switches, governors, circuit breakers, and pumps is important to reduce and mitigate aging effects on the RCIC system.

- The system failure frequency curve has two peaks, at $3-4$ years and $11-13$ year. The failures of valves and switches/bistables mainly caused the system failure frequency peak at 3-4 years. The failures of valve operators also contributed to this peak. The second peak is due to the increased failures of valves, switches/bistables, circuit breakers, and valve operators.

- The failure frequency for the steam valves are much higher than that for the water valves. Steam valves operate in a harsher environment than water valves; suggesting that more attention should be paid to the maintenance of steam valves.

- Most component failures in the RCIC system are detected by surveillance tests. However, current IS\&M procedures for valve operators, pumps, transmitters, and circuit breakers should be reviewed to identify improvements that may be possible to enable detection of failures before they affect the system function.

The results of this Phase I study showed that most of the failures in the RCIC system are due to aging and that proper aging management is needed to mitigate aging-related failures. 



\section{REFERENCES}

1. Blahnik, D. E., et al., "Insights Gained From Aging Research", NUREG/CR-5643, BNL-NUREG-52323, March, 1992.

2. Gunther, W.E., et al., "Operating Experience and Aging-Seismic Assessment of Battery Chargers and Inverters," NUREG/CR-4564, June 1986.

3. Subudhi, M., et al., "Improving Motor Reliability in Nuclear Power Plants," NUREG/CR-4939, June 1987.

4. Taylor, J., et al., "Seismic Endurance Tests of Naturally Aged Small Electric Motors," BNL Report A-3270-11-85, November 1985.

5. Subudhi, M., et al., "Operating Experience and Aging-Seismic Assessment of Electric Motors," NUREG/CR-4234, June 1985.

6. Greenstreet, W.L., et al., "Aging and Service Wear of Motor Operated Valves Used in Engineered Safety Feature Systems of Nuclear Power Plants;" NUREG/CR4234, June 1985.

7. Greenstreet, W.L., et al., "Aging and Service Wear of Check Valves Used in Engineered Safety-Feature Systems of Nuclear Power Plants," NUREG/CR-4302, December 1985.

8. Bacanskas, V.P., "Aging and Service Wear of Solenoid-Operated Valves Used in Safety Systems at Nuclear Power Plants," NUREG/CR-4819, March 1987.

9. Adams, M.L., "Aging and Service Wear of Auxiliary Feedwater Pumps for PWR Nuclear Power Plants," NUREG/CR-4597, July 1986.
10. Morris, B.M., Vora, J.P., "Nuclear Plant Aging Research Program Plan," NUREG1144 , July 1985 .

11. Carolina Power \& Light Company, "Carolina Power \& Light Company Brunswick Steam Electric Plants Units 1 and 2, Probabilistic Risk Assessment", April 1988.

12. Kolaczkowski, A. M., et al., "Analysis of Core Damage Frequency: Peach Botton, Unit 2 Internal Events", NUREG/CR4550, Vol.4, Rev. 1, Pt. 1, August 1989.

13. U.S. NRC, "Standard Review Plan", NUREG-0800, July 1981.

14. U.S. NRC, "Probabilistic Risk Assessment Technology Training Program-BWR Technology, March 28-31, 1989 - Course Documentation," Chattanooga, TN.

15. Travis, R. et al, "Generic Risk Insights for General Electric Water Reactors, NUREG/CR-5692, BNL-NUREG-52282, May 1991.

16. U.S. NRC, "Severe Accident Risks: An Assessment for Five U.S. Nuclear Power Plants,: NUREG-1150, December 1990.

17. U.S. NRC, IE Information Notice 82-26, "RCIC and HPCI Turbine Exhaust Check Valve Failures", July 1982.

18. U.S. NRC, Information Notice 86-14, Supplement 2, "Overspeed Trips of AFC, HPCI and RCIC Turbines", August 1991.

19. U.S. NRC, Information Notice $90-45$, "Overspeed of Turbine-driven Auxiliary Feedwater Pumps and Overpressurization of the Associated Piping Systems", July 1990. 
20. U.S. NRC, IE Bulletin 85-03, "Motor Operated Valve Common Mode Failures During Transients Due to Improper Switch Settings", November 1985.

21. U.S. NRC, Generic Letter $89-10,10$ CFR 50.54, "Safety-Related Motor-Operated Valve Testing and Surveillance", June 1989.

22. The Institute of Nuclear Power Operation, "NPRDS Reporting Guidance Manual," INP089-001, Rev. 4, December 1992.

23. Lofaro, R., Gunther, W., Subudhi, M., Lee, B., "Aging Assessment of Component Cooling Water Systems in Pressurized Water Reactors", NUREG/CR-5693, BNLNUREG-52283, June 1985.

24. Greenstreet, W.L., Murphy, G.A., and Eissenberg, D.M., "Aging and Service Wear of Electric Motor-Operated Valves Used in Engineered Safety Feature Systems of Nuclear Power Plants," NUREG/CR4234 Vol. 1, ORNL-6170/V1, June 1985.

25. Haynes, H.D., "Aging and Service Wear of Electric Motor-Operated Valves Used in Engineered Safety Feature Systems of Nuclear Power Plants-Aging Assessment and Monitoring Method Evaluations," NUREG/CR-4234 Vol. 2, ORNL-6170/V2, August 1989.

26. Lee, B.S, Villaran, M., Subudhi, M., "Aging Assessment of Bistables and Switches in Nuclear Power Plants," NUREG/CR-5844, BNL-NUREG-52318, January 1993.

27. Gunther, W.E., Subudhi, M., and Taylor, J.H., "Operating Experience and Aging-Seismic Assessment of Battery Chargers and Inverters," NUREG/CR4564, BNL-NUREG-51971, June 1986.

28. Gunther, W.E., Lewis, R., and Subudhi, M., "Detecting and Mitigating Battery Charger and Inverter Aging," NUREG/CR-5051, BNL-NUREG-52108, August 1988.

29. Gunther, W.E., "Testing of a Naturally Aged Battery Charger and Inverter," NUREG/CR-5192, BNL-NUREG-52158, September 1988.

30. U.S. NRC, "Integrated Reliability and Risk Analysis System (IRRAS), Version 4.0, NUREG/CR-5813, Vol. 1, January 1992.

31. NUMAC, "Terry Turbine Control Guide", EPRI-NP-6909, September 1990. 



\section{RCIC SYSTEM DESIGN INFORMATION}

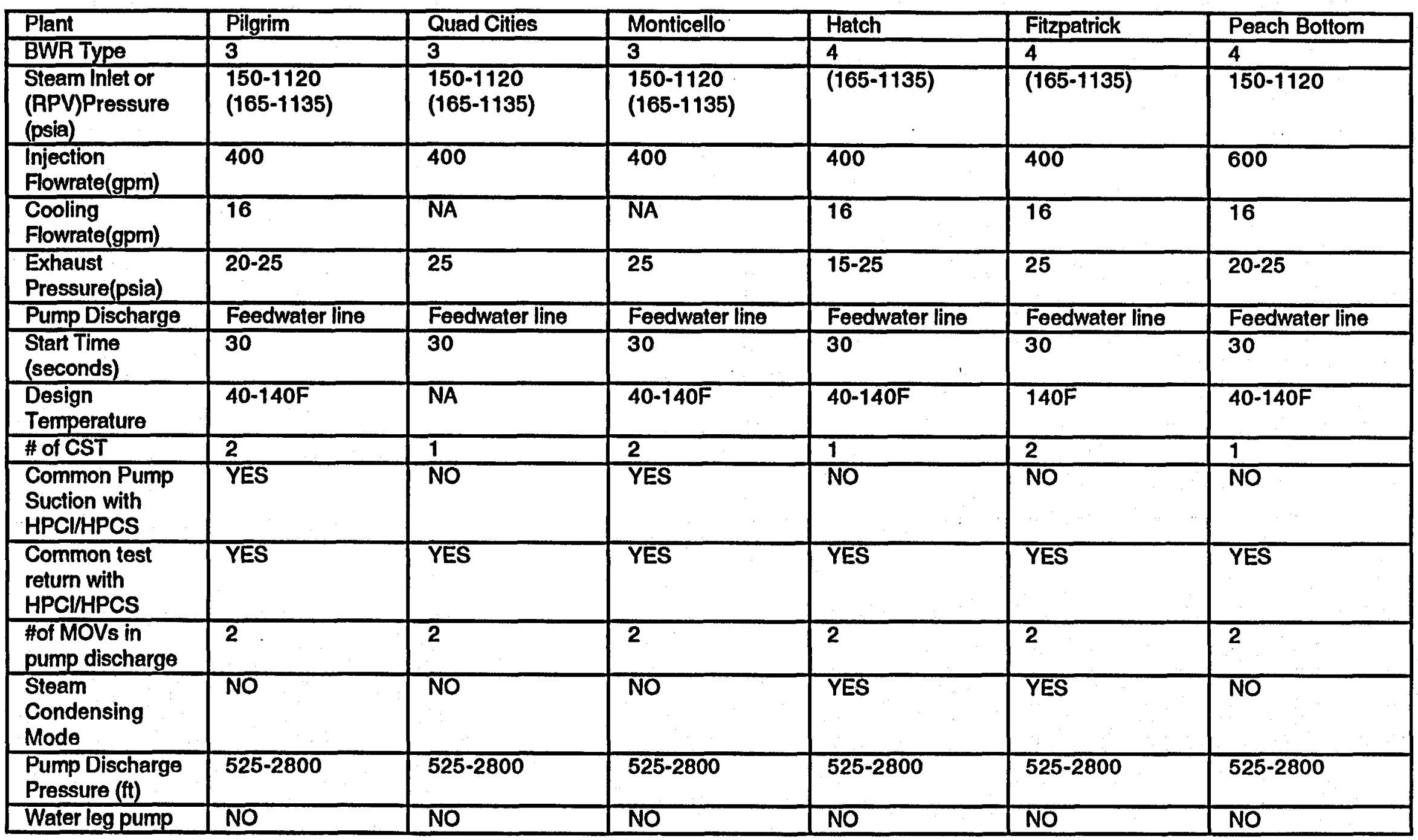


RCIC SYSTEM DESIGN INFORMATION

\begin{tabular}{|c|c|c|c|c|c|c|}
\hline Plant & Susquehanna & NMP2 & LaSalle & WNP2 & GrandGulf & Perry \\
\hline BWR Type & 4 & 5 & 5 & 5 & 6 & 6 \\
\hline $\begin{array}{l}\text { Steam Inlet or } \\
\text { (RPV)Pressure } \\
\text { (psia) }\end{array}$ & $(165-1172)$ & $(165-1173)$ & $(165-1155)$ & $(165-1155)$ & $\begin{array}{l}150-1177 \\
(165-1192)\end{array}$ & $(165-1192)$ \\
\hline $\begin{array}{l}\text { Injection } \\
\text { Flowrate(gpm) }\end{array}$ & 600 & 600 & 600 & 600 & 800 & 700 \\
\hline $\begin{array}{l}\text { Cooling } \\
\text { Flowrate(gpm) }\end{array}$ & 16 & 25 & 16 & $16-25$ & $16-25$ & 16 \\
\hline $\begin{array}{l}\text { Exhaust } \\
\text { Pressure(psia) }\end{array}$ & $15-25$ & 25 MAX. & 25 & $15-25$ & $15-25$ & 25 \\
\hline $\begin{array}{l}\text { Pump } \\
\text { Discharge }\end{array}$ & Feedwater line & RPV Head Spray & APV Head Spray & APV Head Spray & Feedwater line & RPV Head Spray \\
\hline $\begin{array}{l}\text { Start Time } \\
\text { (seconds) }\end{array}$ & 30 & 30 & 30 & 30 & 30 & 30 \\
\hline $\begin{array}{l}\text { Design } \\
\text { Temperature }\end{array}$ & $40-140 \mathrm{~F}$ & $40-140 \mathrm{~F}$ & $40-140 \mathrm{~F}$ & $40-140 \mathrm{~F}$ & $40-140 \mathrm{~F}$ & $40-140 \mathrm{~F}$ \\
\hline \# of CST & 1 & 1 & 1 & 2 & 1 & 1 \\
\hline $\begin{array}{l}\text { Common Pump } \\
\text { Suction with HPCIn }\end{array}$ & $\begin{array}{l}\text { YES } \\
\text { PCS }\end{array}$ & NO & NO & YES & YES & YES \\
\hline $\begin{array}{l}\text { Common test } \\
\text { retum with } \mathrm{HPCl} / \mathrm{H}\end{array}$ & $\begin{array}{l}\text { YES } \\
\text { cS }\end{array}$ & NO & NO & YES & YES & YES \\
\hline $\begin{array}{l}\text { \#of MOVs in } \\
\text { pump discharge }\end{array}$ & 2 & 1 & 1 & 1 & 1 & 1 \\
\hline $\begin{array}{l}\text { Steam } \\
\text { Condensing Mode }\end{array}$ & Unit 2 Only & YES & YES & NO & YES & YES \\
\hline $\begin{array}{l}\text { Pump } \\
\text { Developed Head (f) }\end{array}$ & $525-2940$ & $610-2980$ & $610-2850$ & $610-2890$ & $610-2980$ & $610-2980$ \\
\hline Water leg pump & $\begin{array}{l}\text { NO-Use CST } \\
\text { header pressure }\end{array}$ & YES-AC & NO & YES-DC & $\begin{array}{l}\text { NO-Use CST } \\
\text { header pressure }\end{array}$ & YES-AC \\
\hline
\end{tabular}


RCIC SYSTEM DESIGN INFORMATION

\begin{tabular}{|c|c|c|c|c|c|c|}
\hline Plant & River Bend & & & & & \\
\hline BWR Type & 6 & & & & & \\
\hline $\begin{array}{l}\text { Steam Inlet or } \\
\text { (RPV)Pressure } \\
\text { (psia) }\end{array}$ & (165-1192) & & & & & \\
\hline $\begin{array}{l}\text { Injection } \\
\text { Flowrate(gpm) }\end{array}$ & 600 & & & & & \\
\hline $\begin{array}{l}\text { Cooling } \\
\text { Flowrate(gpm) }\end{array}$ & $16-25$ & & & & & \\
\hline $\begin{array}{l}\text { Exhaust } \\
\text { Pressure(psia) }\end{array}$ & 25 & & & & & \\
\hline Pump Discharge & RPV Head Spray & & & & & \\
\hline $\begin{array}{l}\text { Start Time } \\
\text { (seconds) }\end{array}$ & 30 & & & & & \\
\hline $\begin{array}{l}\text { Design } \\
\text { Temperature }\end{array}$ & $40-140 \mathrm{~F}$ & & & & & \\
\hline \# of CST & 1 & & & & & \\
\hline $\begin{array}{l}\text { Common Pump } \\
\text { Suction with } \\
\text { HPCI/HPCS }\end{array}$ & YES & & & & & \\
\hline $\begin{array}{l}\text { Common test } \\
\text { return with } \\
\text { HPCINHPCS }\end{array}$ & YES & & & & & \\
\hline $\begin{array}{l}\text { \#of MOVs in } \\
\text { pump discharge }\end{array}$ & 1 & & & & & \\
\hline $\begin{array}{l}\text { Steam } \\
\text { Condensing } \\
\text { Mode }\end{array}$ & NO & & & & & \\
\hline $\begin{array}{l}\text { Pump } \\
\text { Developed Head } \\
\text { (ft) }\end{array}$ & $610-2980$ & & & & & \\
\hline Water leg pump & YES-AC & & & & & \\
\hline
\end{tabular}


11

n.

Appendix B

RCIC Fault Tree

B-1 


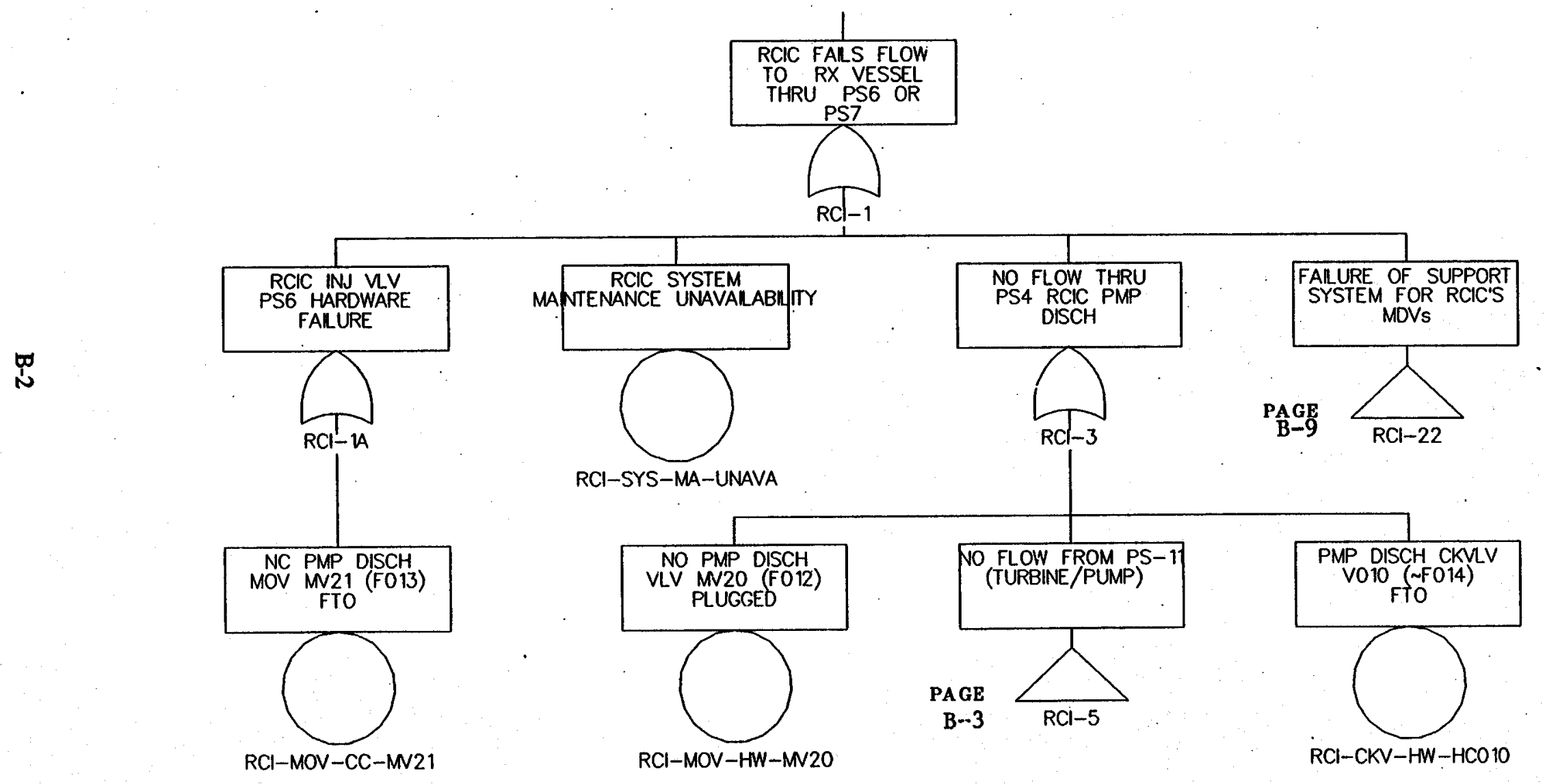

Figure B.1 RCIC system fault tree 


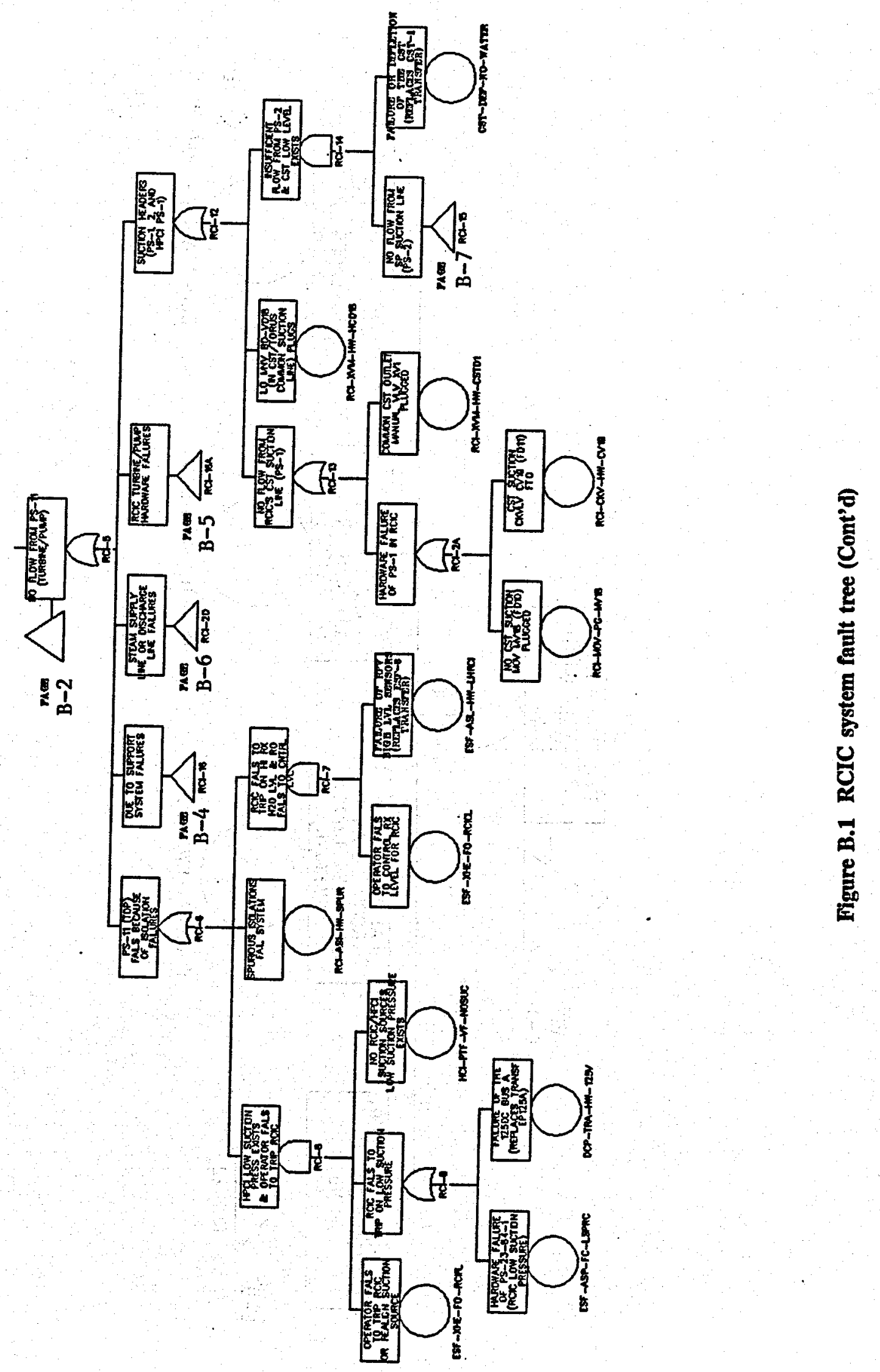




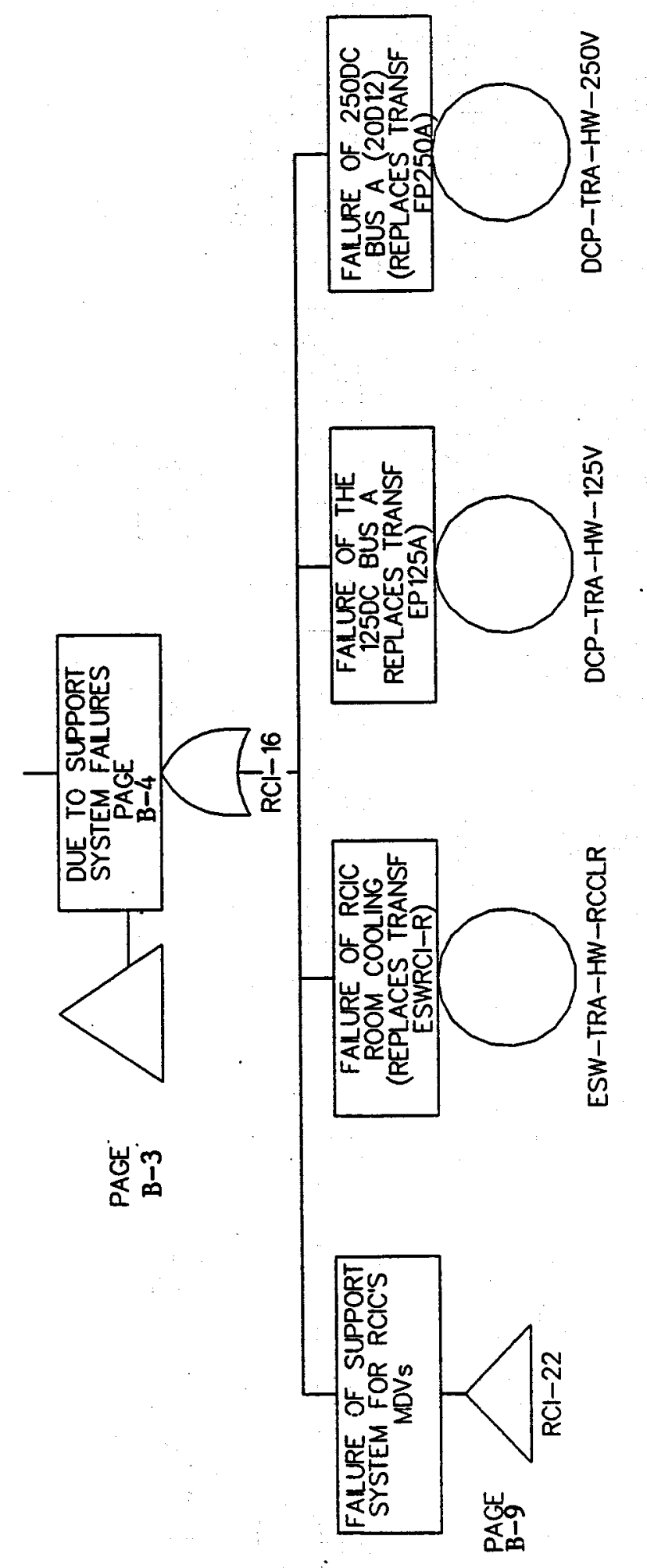

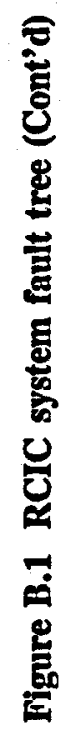




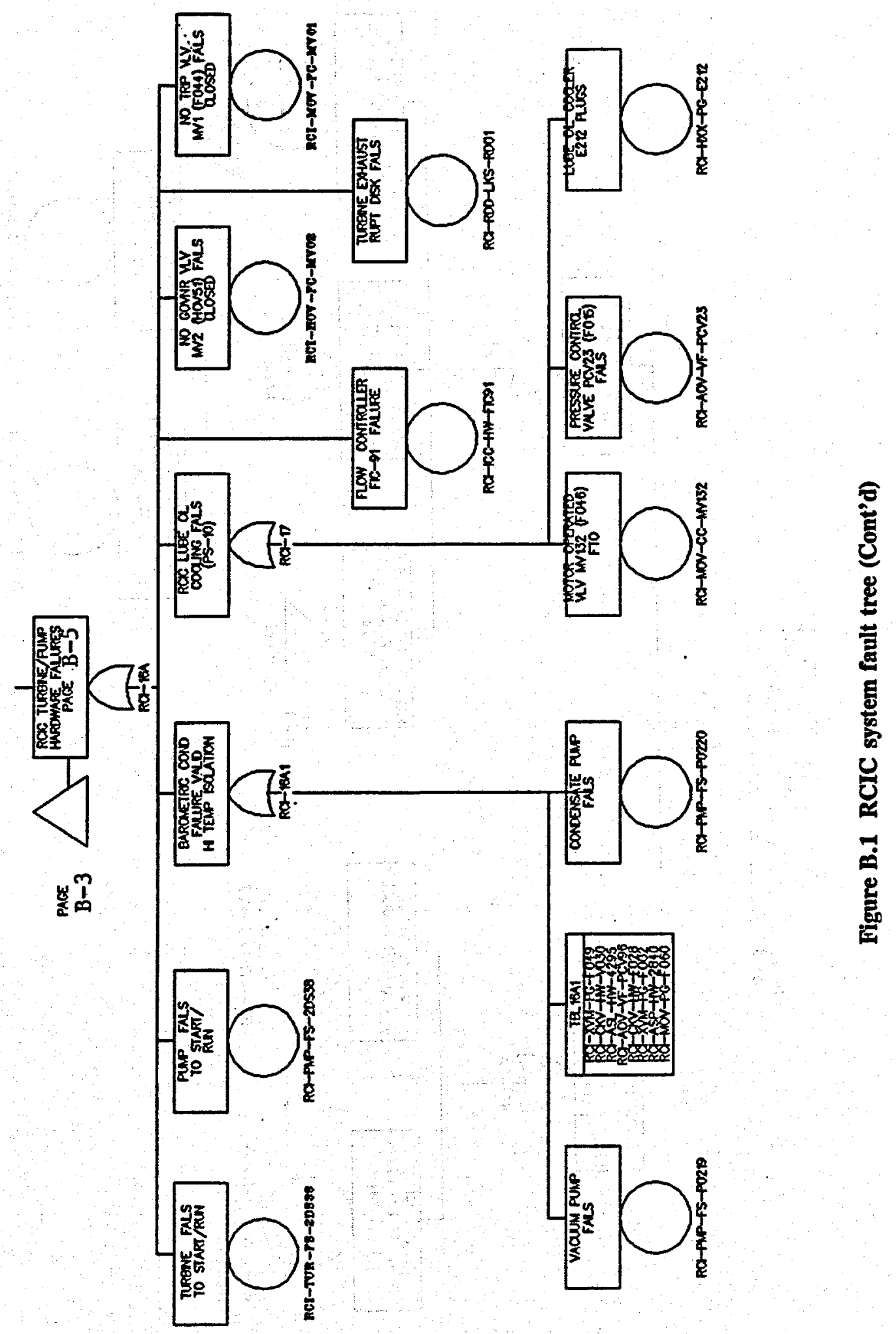

B-5 


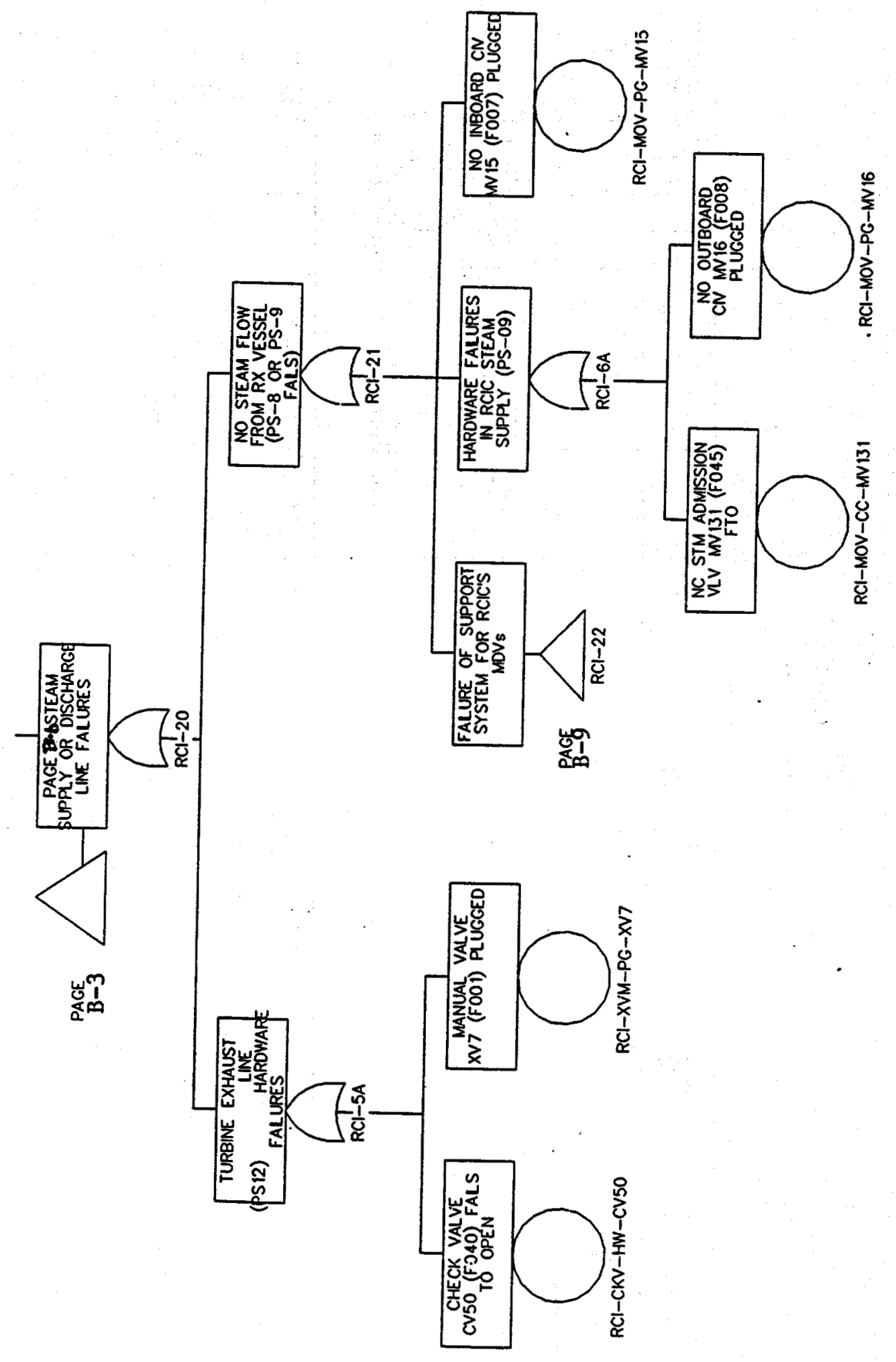

है 


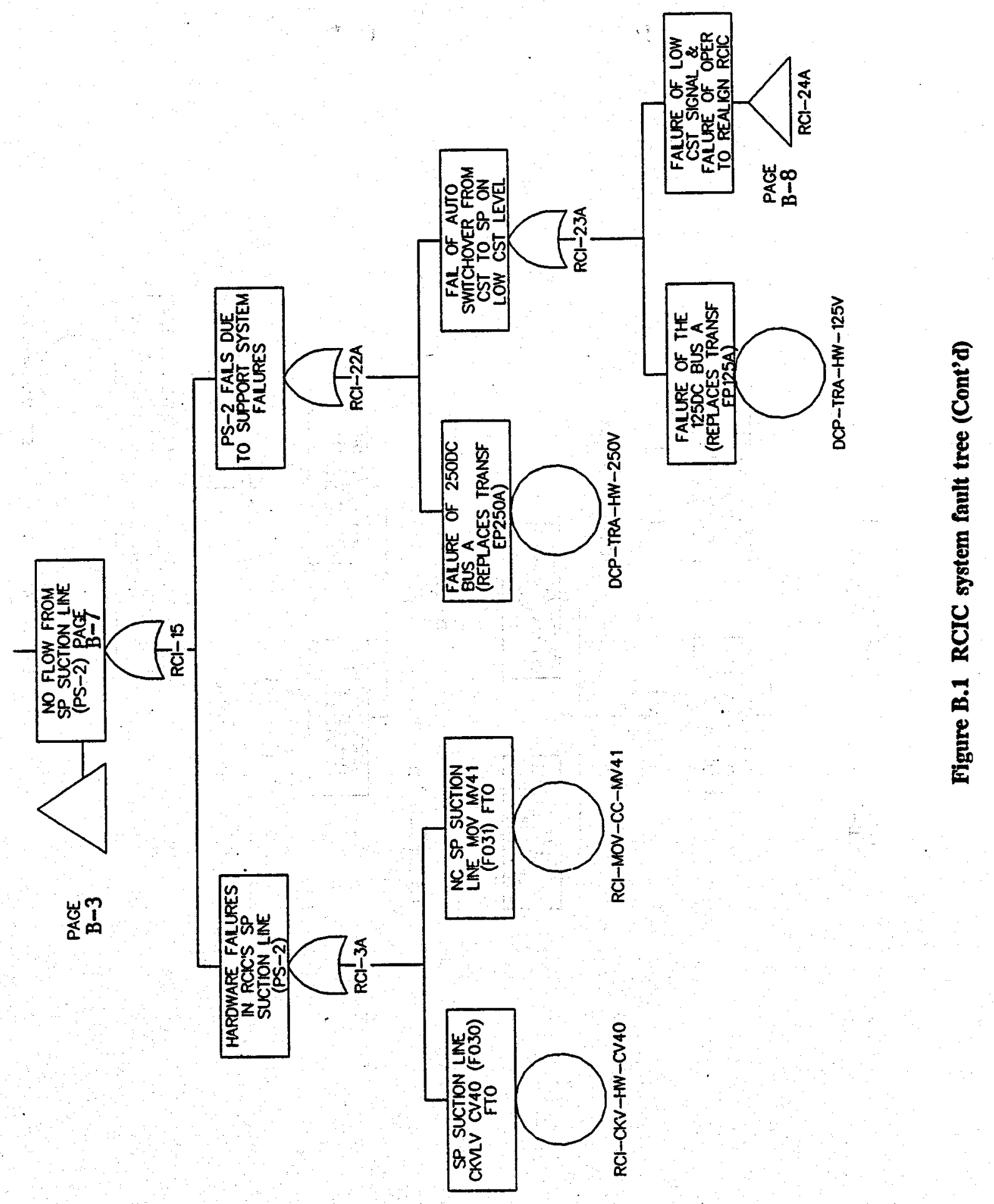




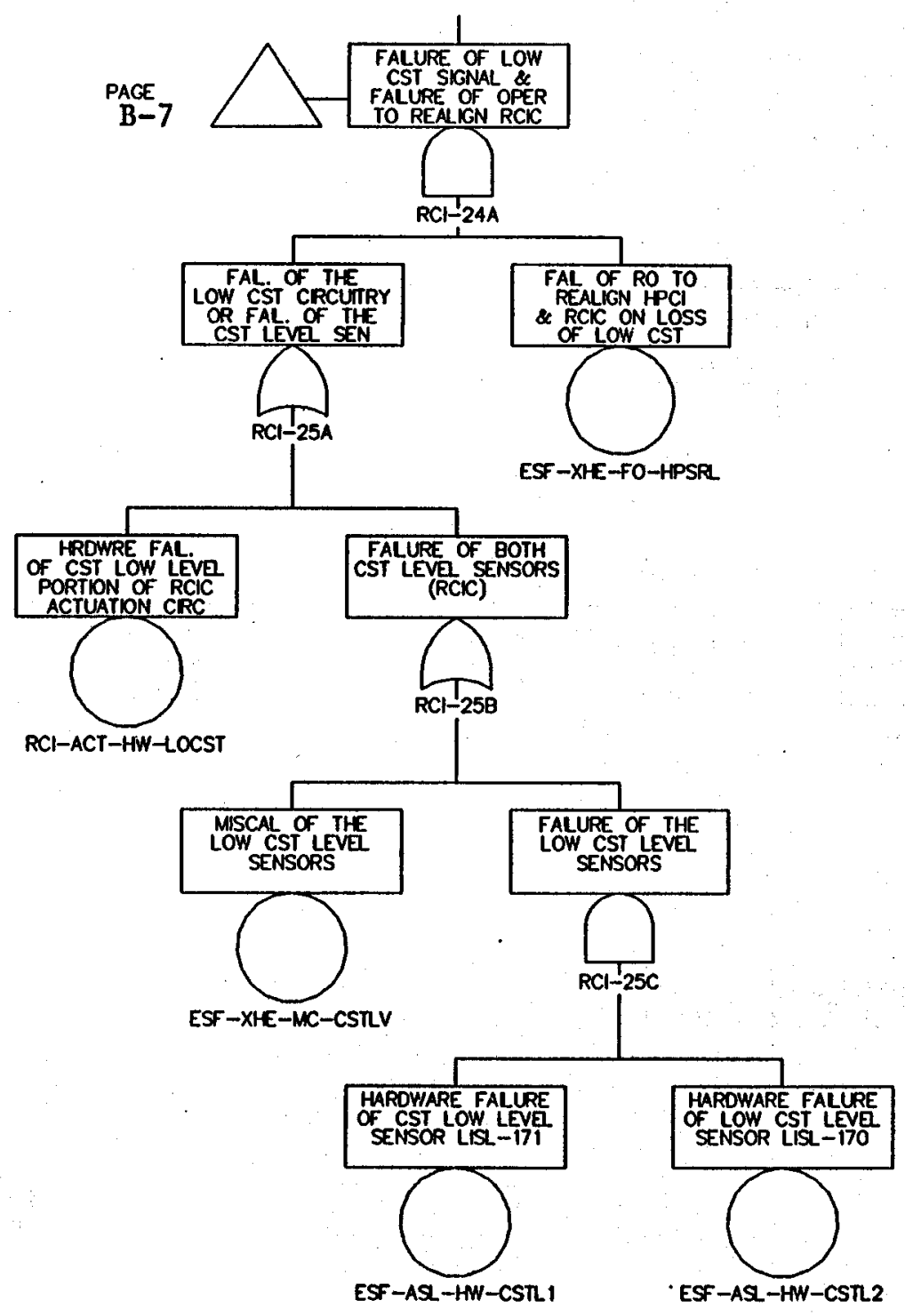

Figure B.1 RCIC system fault tree (Cont'd) 


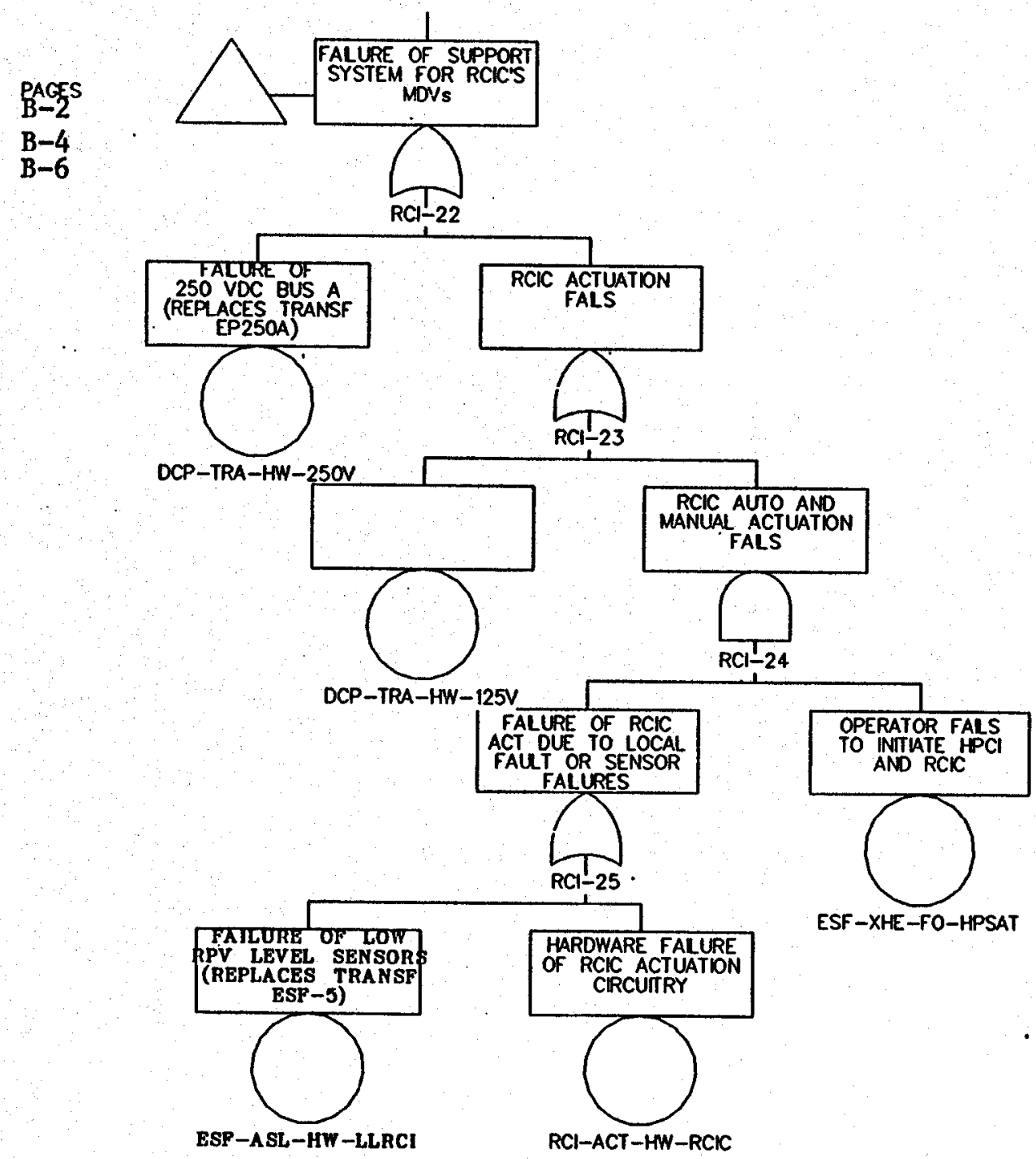

Figure B.1 RCIC system fault tree (Cont'd) 



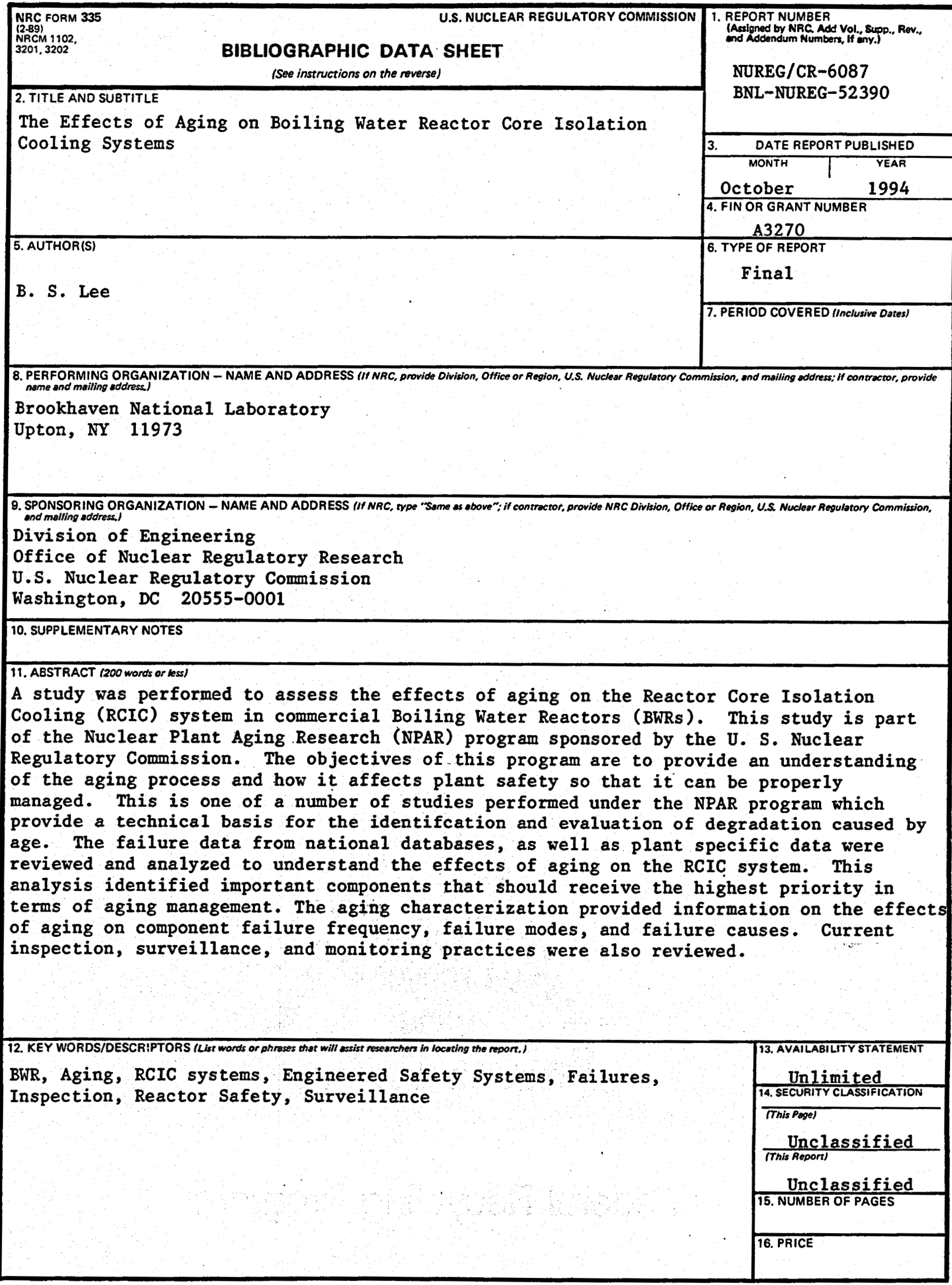




$$
\theta
$$

